\title{
Investigation into the Load Bridging Effect for Block Class Pallets as a Function of Package Size and Pallet Stiffness
}

\author{
Steven Michael Morrissette \\ partial fulfillment of the requirements for the degree of \\ Master of Science \\ In \\ Forest Products \\ Laszlo Horvath, Committee Chair \\ Dan Hindman \\ Earl Kline
}

Thesis submitted to the faculty of the Virginia Polytechnic Institute and State University in

April 26, 2019

Blacksburg, VA

Keywords: Pallets, Block Class, Load Bridging, Corrugated Boxes 
Investigation into the Load Bridging Effect for Block Class Pallets as a Function

of Package Size and Pallet Stiffness

Steven Michael Morrissette

\section{ACADEMIC ABSTRACT}

Pallets and corrugated boxes are ubiquitous in the global supply chain. However, the interactions that exist between the boxes and pallet are ignored during the pallet design process resulting in an over design of pallet performance and the waste of raw materials. The goal of this research is to understand how pallet performance is affected by headspace, box size, and base design across multiple support conditions using block class wooden pallets.

Headspace and base design had no effect on pallet deflection for the experimental weights used throughout testing. The effect of box size was significant on pallet deflection across multiple support conditions. The effect was greatest for lower stiffness pallets and low stiffness support conditions (RAW) with up to a 50\% reduction in pallet deflection observed by switching from small to large boxes on a very low stiffness pallet.

Evaluation of pressure mat data showed an increase in the redistribution of pressure away from the center of the pallet and towards the supports as box size increased. The redistribution of pressure towards the supports is known as load bridging and validates the observed reduction in pallet deflection as a function of box size. The results indicate that incorporating the effect of packages into current pallet design practices could result more effective and cheaper pallet designs. 
Investigation into the Load Bridging Effect for Block Class Pallets as a Function of Package Size and Pallet Stiffness

Steven Michael Morrissette

\section{GENERAL AUDIENCE ABSTRACT}

Transportation and storage of material goods at a national and international level is an integral part of our economy with pallets and corrugated boxes making up the majority of packaging materials. Currently, the interactions that exist between the boxes and pallet are ignored during pallet design resulting in an over design of pallet performance and a waste of raw materials. Understanding the interactions that exist in a unit load is important in optimizing pallet performance, reducing the amount of raw materials used, and ultimately reducing cost.

This research project is specifically focused on the interactions between corrugated boxes and block class wooden pallets. The effect of headspace (the gap between the products and the top of the box) and box size was investigated as a function of pallet stiffness, support condition, and bottom deck design. Both pallet deflection and the pressure distribution on the top surface of the pallet were examined to evaluate pallet performance.

It was found that headspace does not have an effect on pallet deflection unless the weight of the unit load exceeds 3,500 lbs. for small boxes and 1,750 lbs. for large boxes. Base design showed no significant effect on pallet deflection for all of the support conditions evaluated. The effect of box size had a major effect on the deflection of the pallet. Large boxes showed the greatest change especially when lower stiffness pallets were used. Increasing the box size can reduce the deflection of the pallet as much as 50\% which means that pallets supporting larger boxes could support much more weight than currently estimated.

Evaluation of pressure mat data showed that when the size of the boxes increased, more pressure is distributed towards the supports. More pressure is applied to the pallet section on the top of the supports; therefore, less pressure is available to cause pallet bending. This finding validates the observed reduction in pallet deflection as a function of box size. The obtained results help pallet designers to incorporate the interactions between the packages and the pallet into their design process which will allow them to reduce the amount material used for pallet. 


\section{ACKNOWLEDGEMENTS}

I would like to acknowledge everyone who helped make this project possible. I would first like to thank my major professor, Dr. Laszlo Horvath, for the opportunity to pursue my Master's degree here at Virginia Tech. His constant support and guidance throughout this project were paramount to my success. I also want to thank Dr. Dan Hindman and Dr. Earl Kline for their support as members of my committee. Both Dr. Hindman and Dr. Kline offered their time and knowledge in order to help me throughout my project. Thanks to the support staff who made my project possible. Thank you to Matt Hixon, David Jones, and Angela Riegel for being there whenever I needed help.

I would also like to thank all of the undergraduate students who dedicated to time to help me conduct the research for my project. Thank you to Jack Cook, Jacob Zalewski, Andre Sobert, Mark Lewandowski, David Xu, Jack Lumley, Madison Reynolds, Logan Tallman, and Johnny Fuentes. This project would not have been possible without your help and companionship.

Thank you to all of my fellow graduate students (past and present) who were there whenever I needed help, or just a friend to talk to. Thank you to Chandler Quesenberry, Alina Mejias Rojas, Nico Navarro, Dorina Bugledits, Nathan Gerber, Gloria Alvarez, and Eduardo Molina. It was a pleasure getting to know all of you and I enjoyed our conversations. A special thank you to Page Clayton. Without you, I wouldn't have had the determination to get through this project. Your help and continued support were invaluable to my success.

Thank you to the National Wooden Pallet and Container Association for funding my project. I appreciate the continued support and constant contact offered. Thanks to Kristen DeLack for being available to help with all aspects of my project/project on such short notice.

Finally, I would like to thank my family and friends. Thank you to my mom and dad for always believing in me and allowing me to find my own path in life. Thank you to all of my grandparents for supporting me and encouraging me. Thank you to my sister for being there for me whenever I needed someone to call. Thank you to Lynette Morrissette for your support and encouragement. Thank you to Kayla Matthews for always being positive and pushing me to do my best. And, thank you to my roommate, Kyle Rollins. You were always there to help get my mind on track, to help me stay focused, and to take time out to enjoy life. 


\section{TABLE OF CONTENTS}

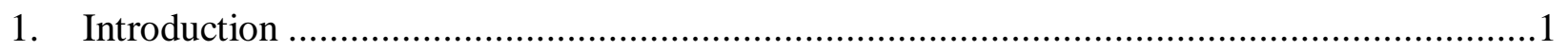

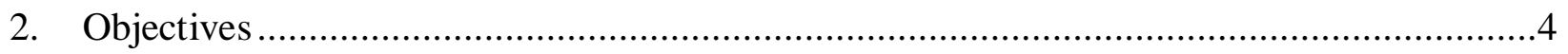

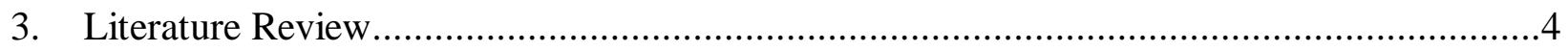

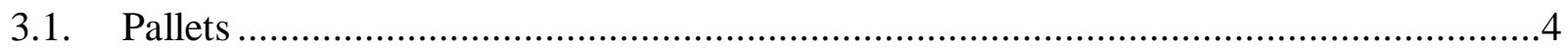

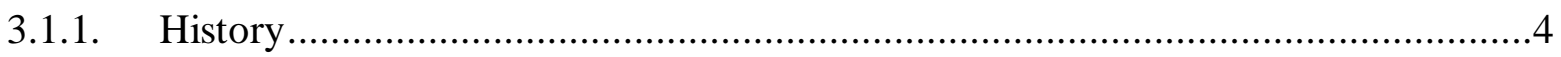

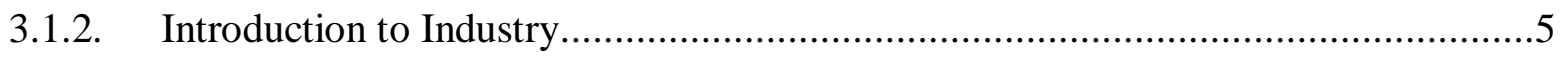

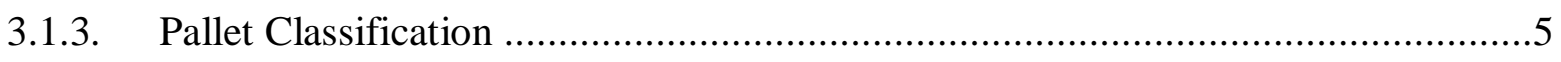

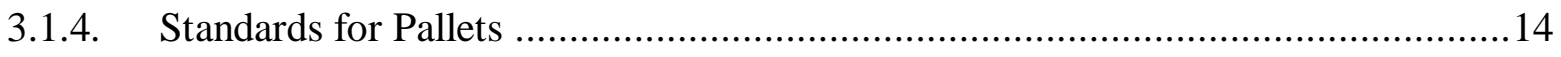

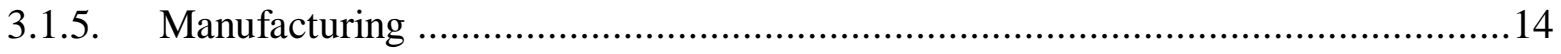

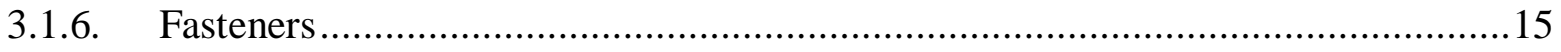

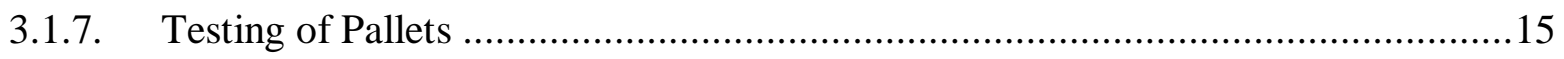

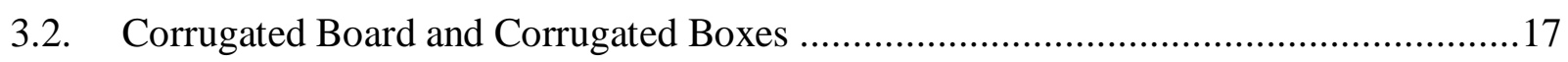

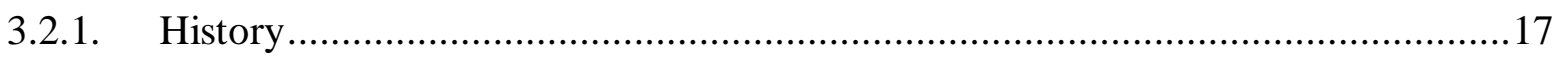

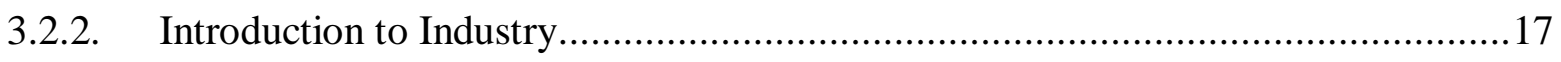

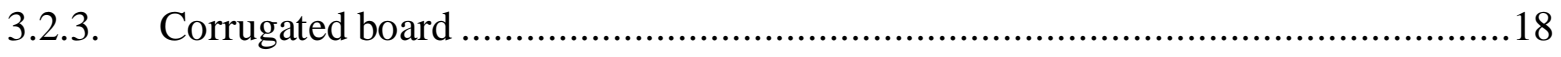

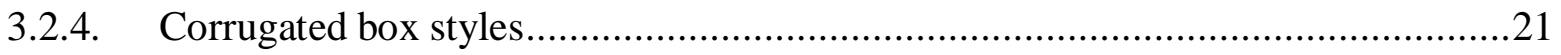

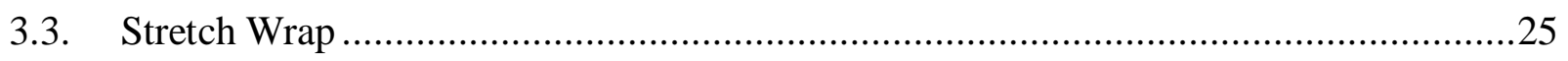

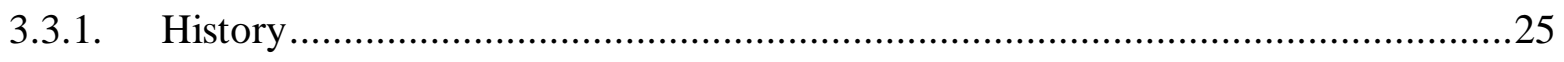

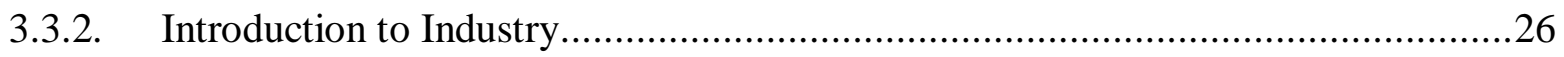

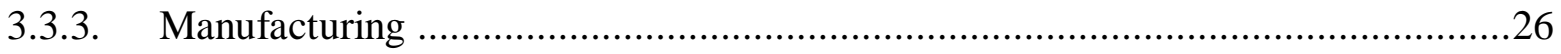

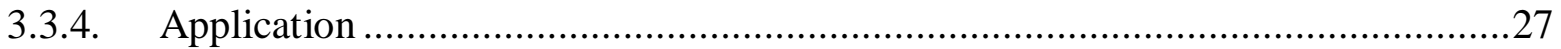

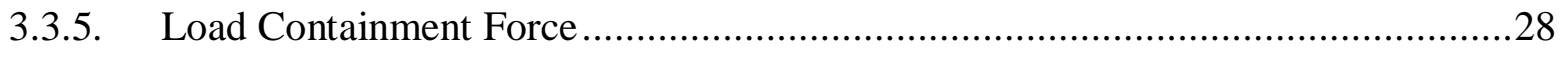

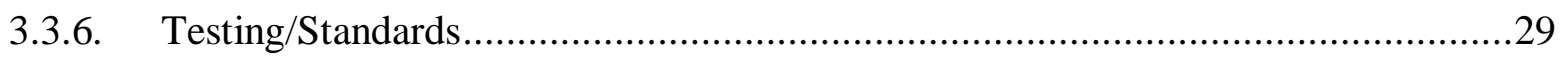

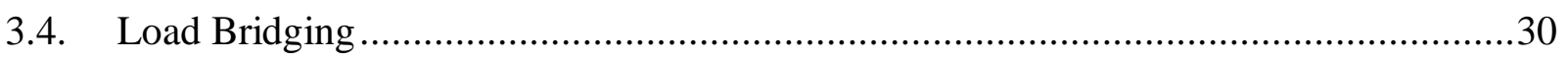

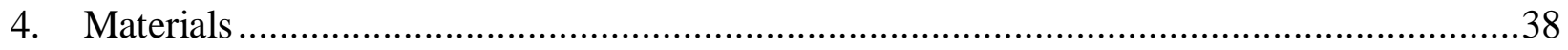

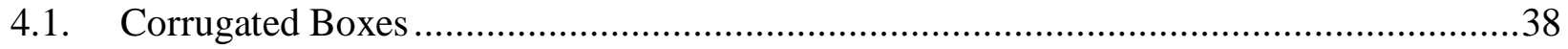

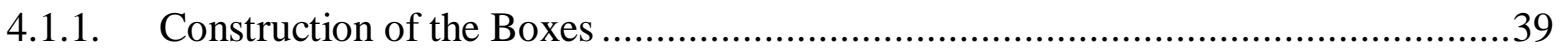

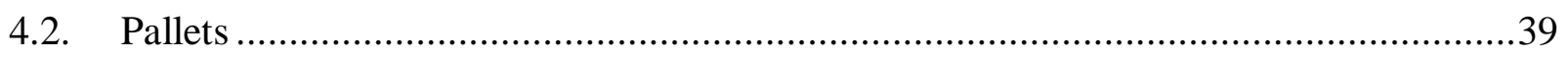

4.2.1. MOE of Pallet Components ……………....................................................

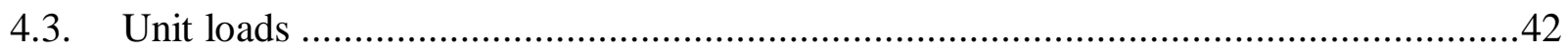




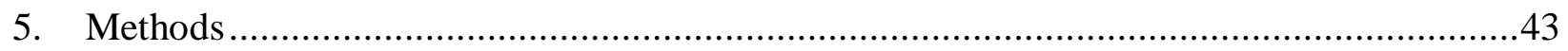

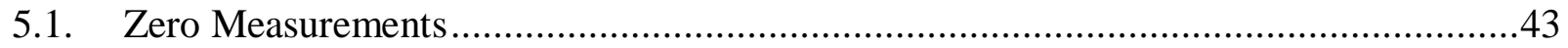

5.2. Warehouse Racking Across the Width and Length ....................................................44

5.3. Single Stacked and Double Stacked Floor Support .......................................................4

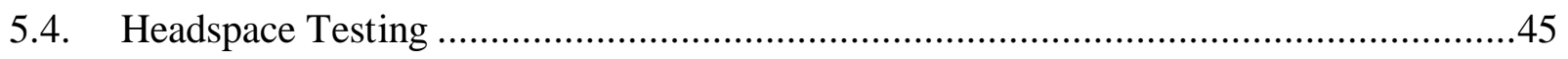

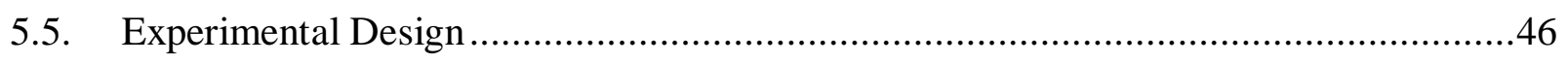

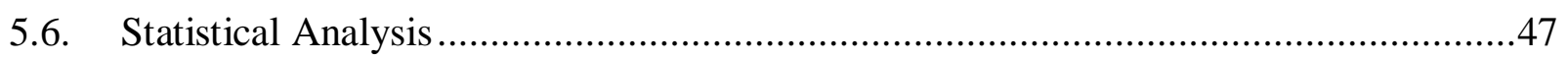

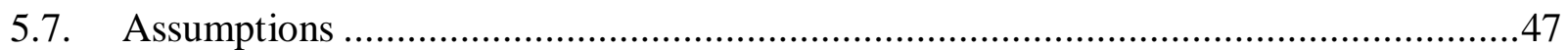

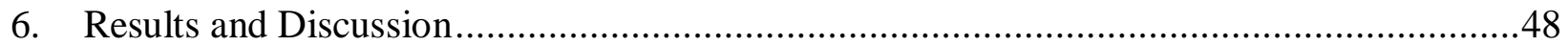

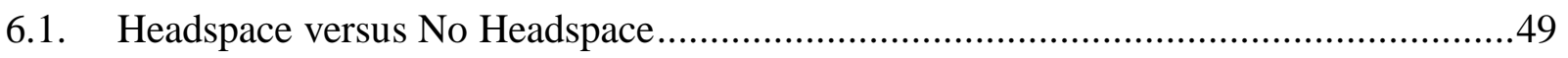

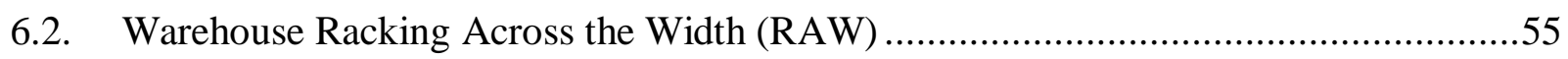

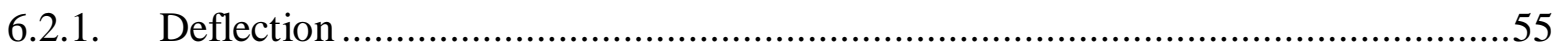

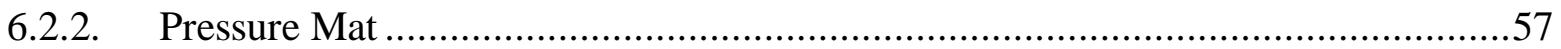

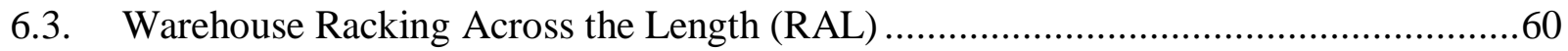

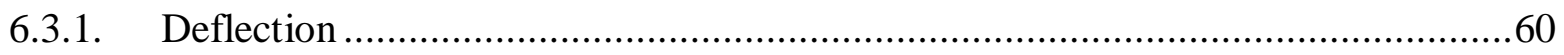

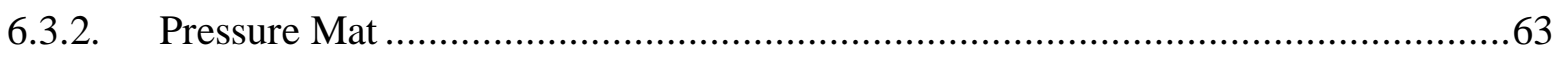

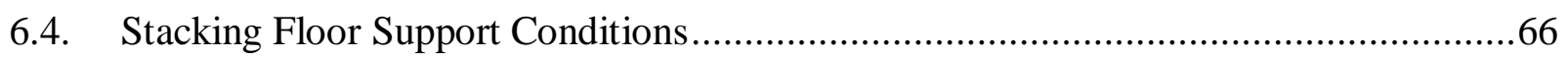

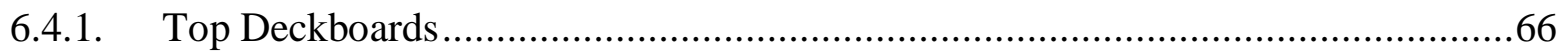

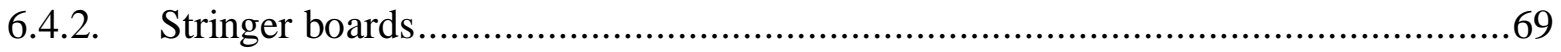

6.4.3. Double Stacking - Bottom Deckboards ...........................................................

6.5. Unidirectional Base Design versus Perimeter Base Design ........................................74

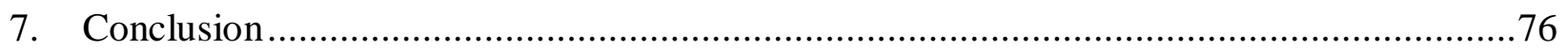

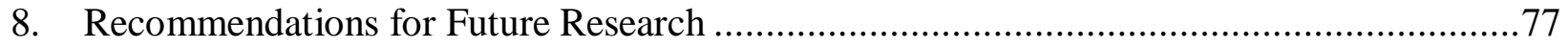

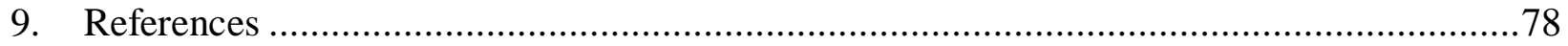

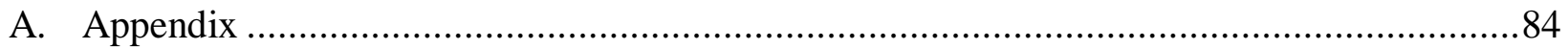

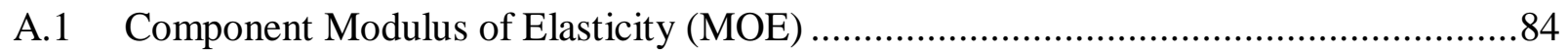

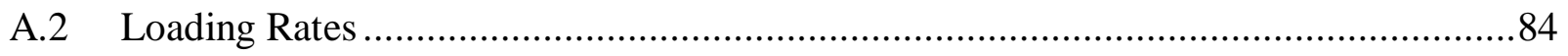

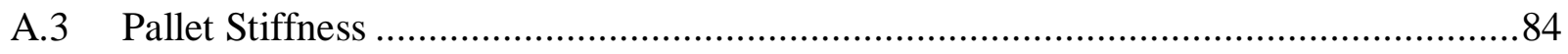

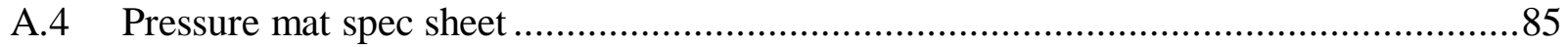

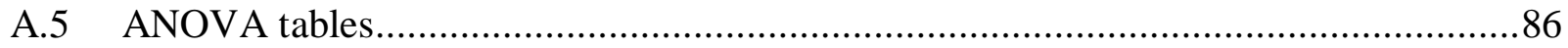

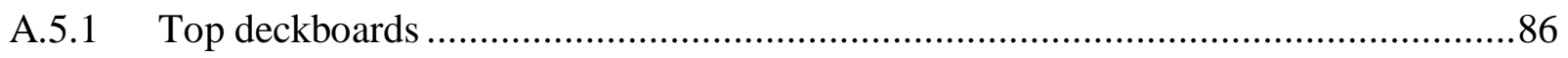

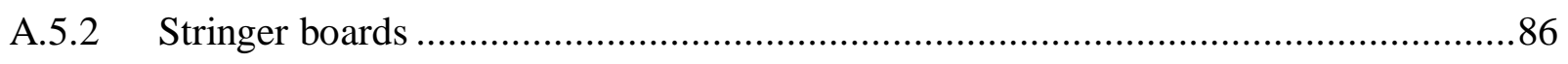




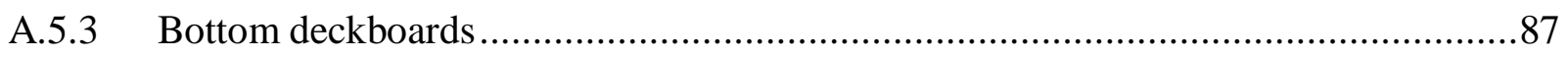

A.5.4 Base design comparison .................................................................... 88 


\section{INTRODUCTION}

Our economy is heavily dependent upon the distribution of material goods at both a national and international level. As such, companies are constantly looking for the cheapest packaging and shipping options to transport their product from manufacturing plants to the final consumer as quickly as possible, yet in a safe manner. Unit loads, consisting of a pallet, the product on the pallet, and a form of load stabilization, have become the preferred method of shipping. Up to $80 \%$ of the material goods in the United States being transported in a unitized form (LeBlanc, 2019). Both wooden pallets and corrugated boxes quickly became favorites in unitization throughout the packaging industry due to the low cost of materials, ease of customization, and speed of manufacturing.

By 2019, there are projected to be over 2.6 billion pallets in circulation globally (Freedonia Group, 2015). The materials used for pallet construction include solid wood, plastic, metal, paperbased, wood composite, or a combination of these materials. The majority of pallets are made from solid wood with $96 \%$ of companies currently using wooden pallets (McCrea, 2016). Pallets come in a variety of sizes; however, the 48 inch x 40 inch pallet, referred to as the Grocery Manufacturers Association (GMA) pallet, is the most common pallet and accounted for $35 \%$ of wooden pallet production in 2016 (Gerber, 2018).

Corrugated boxes are the packaging material most commonly used and up to $95 \%$ of products are transported this way (Fibre Box Association, 2015). Corrugated boxes consist of an arrangement of flat linerboards (liners) and wavy or fluted linerboards (mediums) glued together, cut to size, and folded into shape to get the desired performance. A variety of mechanical properties can be achieved by constructing corrugated boxes out of different quality paperboard, using different combinations of liners and mediums, and varying the spacing of the flutes (Fibre Box Association, 2015). The most common material used for corrugated boxes, with up to $80 \%$ of the

market share, is single-wall C-flute corrugated board. Single-wall C-flute corrugated board is made of two liners and one fluted medium spaced 5/32 inches apart with 39 \pm 3 flutes per foot (Twede et al., 2014).

Historically, studies have focused on understanding the mechanical properties of the components in a unit load individually in an approached called "Component Based Design" - 
(White, 2005). Considering the components of a unit load separately over-simplifies the design process as it ignores the interactions between components. Using a "Component Based Design" can result in higher material costs associated with overdesign, product damage due to inadequate design, and costly downtime associated with unit load failures. More recently, a "Systems Based Design", which attempts to analyze the performance of the unit load considering the interactions of all the components with each other and with material handling equipment, was presented by Dr. White from Virginia Tech (White, 2005).

Unit load interactions can either be analyzed by determining the effect of the pallet on the packages or by determining the effect of the packages on the pallet. Historically, most research has attempted to understand how packages, usually corrugated boxes, are affected by palletization and pallet design. Box over hang (Monaghan and Marcondes, 1992), deckboard gap (Monaghan and Marcondes, 1992, Baker, 2016), deckboard stiffness (Baker, 2016, Phanthanousy, 2017), stacking configuration (Singh et al., 2011, Meng et al., 2007), and the contents of the packages (Frank et al., 2010) have all been determined, by various researchers, to influence the strength of corrugated boxes. While these studies have furthered how palletization affects corrugated box performance, they fail to understand the effect that corrugated boxes can have on pallet performance.

Recent studies have focused on understanding which factors affect pallet performance. Pallets are currently designed and tested assuming a uniformly distributed load. However, unit loads behave more like a series of discrete concentrated loads effected by the interactions between unit load components (Fagan, 1982). The redistribution of pressure away from the center and towards the supports based on unit load interactions is called load bridging. Various researchers have identified several factors which influence the extent of load bridging.

Fagan (1982) was the first to study load bridging and determined that pallet deflection for stringer class pallets is significantly effect by both pallet stiffness and method of loading (air bag vs. boxes vs. platen). Collie (1984) furthered the knowledge of load bridging by investigating stringer class pallets in various support conditions. The stiffness of a pallet in its intended support condition was determined to affect load bridging. Pallets in the less stiff support condition of warehouse racking across the width (RAW) experienced greater load bridging when compared to pallets in the warehouse racking across the length (RAL) support condition. Researchers at 
Virginia Tech's Center for Unit Load Design also studied load bridging and found that the shape and stiffness of the package, the type of load stabilizer used, the applied containment force, stacking pattern, pallet stiffness, and unit load handling over time all influenced the amount of load bridging observed for stringer class pallets (White et al., 1999).

Yoo (2011) created a model based on beam theory in order to understand the distribution of pressure between the packages and the top surface of a stringer class pallet. The model includes factors such as deckboard stiffness, package stiffness, and the flexibility of pallet joints. Park (2015) examined the effect of box size, flute type, and stretch wrap containment force on load bridging for stinger class pallets. All of the factors investigated were determined to have a significant effect on load bridging. Molina (2017) was the first to investigate the effect of stacking pattern on load bridging for stringer class pallets. An interlocked stacking pattern only showed a significant effect for low stiffness pallets under the warehouse racking across the width (RAW) support condition. Clayton (2018) was the first to investigate how load bridging of stringer class pallets was influenced by box size and headspace across multiple support conditions using an entire unit load. Clayton (2018) proved that box size has a significant effect on load bridging for low stiffness pallets with the effect being the greatest for the low stiffness support conditions such as warehouse racking across the width (RAW).

Unit load height and the coefficient of friction between components in a unit load are also factors known to influence load bridging; although, little research has been done to understand the magnitude of each effect in a quantitative manner. While extensive research has been done in order to understand the factors which can influence load bridging, all studies to date have focused on stringer class pallets. No one has determined whether the same factors can be expected to influence load bridging for block class pallets. Understanding which factors influence load bridging for block class pallets furthers the knowledge base for the packaging industry. As a complete knowledge of load bridging is developed for both stringer class and block class pallets, unit load design can be optimized, and unit loads can be designed with the intended product in mind. Customizing unit load design for individual scenarios saves material costs while ensuring desired performance and safe transportation. 


\section{OBJECTIVES}

The main objective of this project is to investigate the effect of load bridging caused by corrugated boxes on the deflection of full four-way block class wooden pallets.

Specific objectives include

- Investigate the effect of headspace, box size, and base design on pallet deflection using support conditions which are most commonly used by industry.

- Investigate the relationship between the pressure distribution on the top surface of the pallet and the amount of deflection experienced by the pallet.

\section{LITERATURE REVIEW}

\subsection{PALLETS}

\subsubsection{History}

The movement of large quantities of material goods has been constantly studied in order to increase efficiency and ease of transportation. Throughout history, the movement of materials has been achieved through the use of wooden boxes, barrels, and crates, along with skids. Skids, which have no bottom deckboards, were the predecessors to pallets and have been used for over 2000 years (Moorey, 1994). Bottom deckboards were added to the skid in 1925 creating the pallet (LeBlanc, 2002). The main breakthrough in pallet advancement coincided with the development of the forklift. Forklift technology has its origins in the late 1880's (LeBlanc, 2002). The original lift truck was crude and has undergone several notable changes over the years. Over time, the forklift has developed a greater lift height, hydraulic controls instead of manual controls, a cantilevered design, and most importantly the addition of forks (LeBlanc, 2002). As the forklift gained better material handling abilities, the pallet became an integral part of the storage and transportation of material goods. During WWII, the need for fast transportation and storage of large quantities of material goods with minimal manual labor led to an explosion in the use of pallets and forklifts (LeBlanc, 2018). 


\subsubsection{Introduction to Industry}

In the United States, about $80 \%$ of material goods are transported using pallets (LeBlanc, 2019). The number of pallets in circulation is projected to reach 2.6 billion in 2019 (Freedonia Group, 2015). With the growing number of pallets, there was a need for organization and uniformity throughout the industry. To help with this, the American National Standards Institute created the Material Handling 1: Pallet, Slip Sheets, and Other Bases for Unit Loads (ANSI MH1:2016), a voluntary standard, to define industry terminology, recommend standardized sizes and dimensions, and establish testing and inspection procedures (MH1 Committee, 2016). According to the ANSI MH1:2016 standard, a pallet is defined as a "portable, horizontal, rigid, composite platform used as base for assembling, storing, stacking, handling, and transporting goods as unit loads" (MH1 Committee, 2016). Furthermore, the standard establishes that pallets can be described by their class, use, type, style, bottom deck, size, and design (MH1 Committee, 2016).

\subsubsection{Pallet Classification}

There are two main classifications of pallets and several additional sub-classifications. The main classification separates pallets into either stringer pallets or block pallets. This differentiation is based on the components used to manufacture the pallet. Stringer pallets are the more common of the two comprising about $76 \%$ of the market in 2016, while block pallets accounted for $21 \%$ (Gerber, 2018). Sub-classifications separate the pallets even further based on the intended use of the pallet, the accessibility of the pallet to handling equipment, and other design characteristics.

\subsubsection{Stringer Class Pallets}

Stringer pallets are the most common class of pallets used by the industry because of their faster manufacturing time which leads to lower manufacturing costs (Clarke, 2004). Stringer pallets are constructed using a combination of stringers and both top and bottom deckboards. Stringers are components made of dimensional lumber, most commonly nominal 2 x 4's (1.5 inch by $3.5 \mathrm{inch}$ ), that run the length of the pallet and are positioned on edge to separate the top and bottom deckboards. There are at least two stringers, but more commonly, three stringers in any given stringer pallet. Stringers allow connection points for all deckboards running perpendicular to the stringers. An example of a stringer pallet, with all components, labelled is shown in Figure 1. 


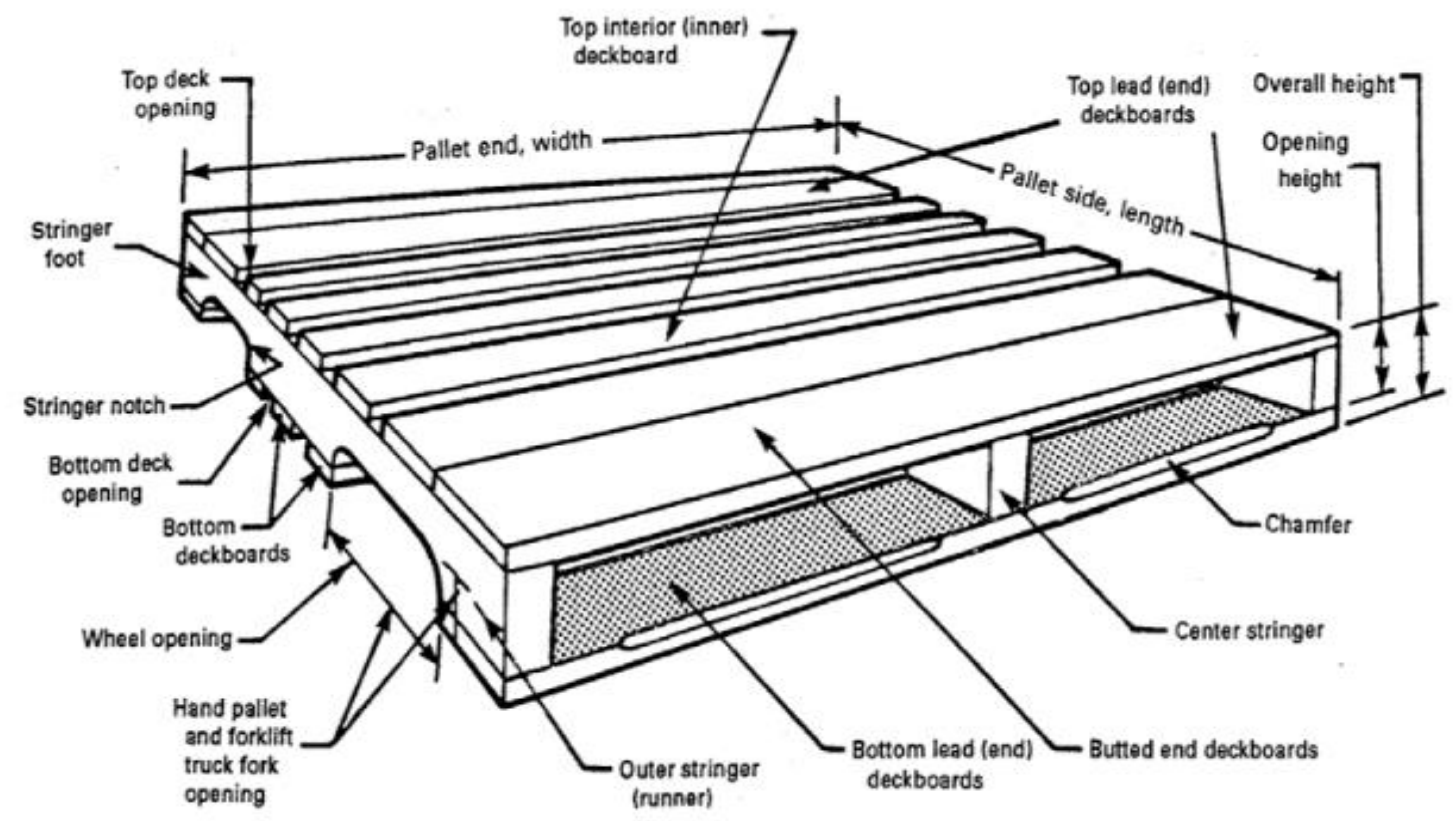

Figure 1: Stringer Class Pallet - Flush, Double-Face, Nonreversible, Partial Four-way, Unidirectional Base (MH1 Committee, 2016)

\subsubsection{Block Class Pallets}

Block pallets use a series of components, called blocks, to separate the top and bottom deckboards. Most commonly, nine blocks are used to create a block class pallet. Blocks are located at each of the four corners, center span on each of the four sides, and at the very center of the pallet for a total of nine blocks. Blocks vary in dimensions based on design and their location in the pallet; however, many blocks are designed to fully support other pallet components such as stringer boards. Stringer boards are used to connect the blocks to the top deckboards. Due to the greater number of components and a more complex manufacturing process, block pallets use more materials and are more expensive (Clarke, 2004). However, this design, using blocks instead of stringers, has the distinct advantage of allowing greater access to the pallet with pallet handling equipment. Another advantage of the block pallets is their increased strength and durability when compared to stringer pallets (Baker, 2016). Although block pallets currently only represent $21 \%$ of the market (Gerber, 2018), there is great hope for the future of block pallets. Large retail companies, such as Wal-Mart and Costco, prefer block pallets due to ease of access (FPInnovations, 2009). Also, large pallet pooling companies such as CHEP prefer block pallets due to their greater strength and durability (Baker, 2016). An example of block pallet, with all components labelled, is shown in Figure 2. 


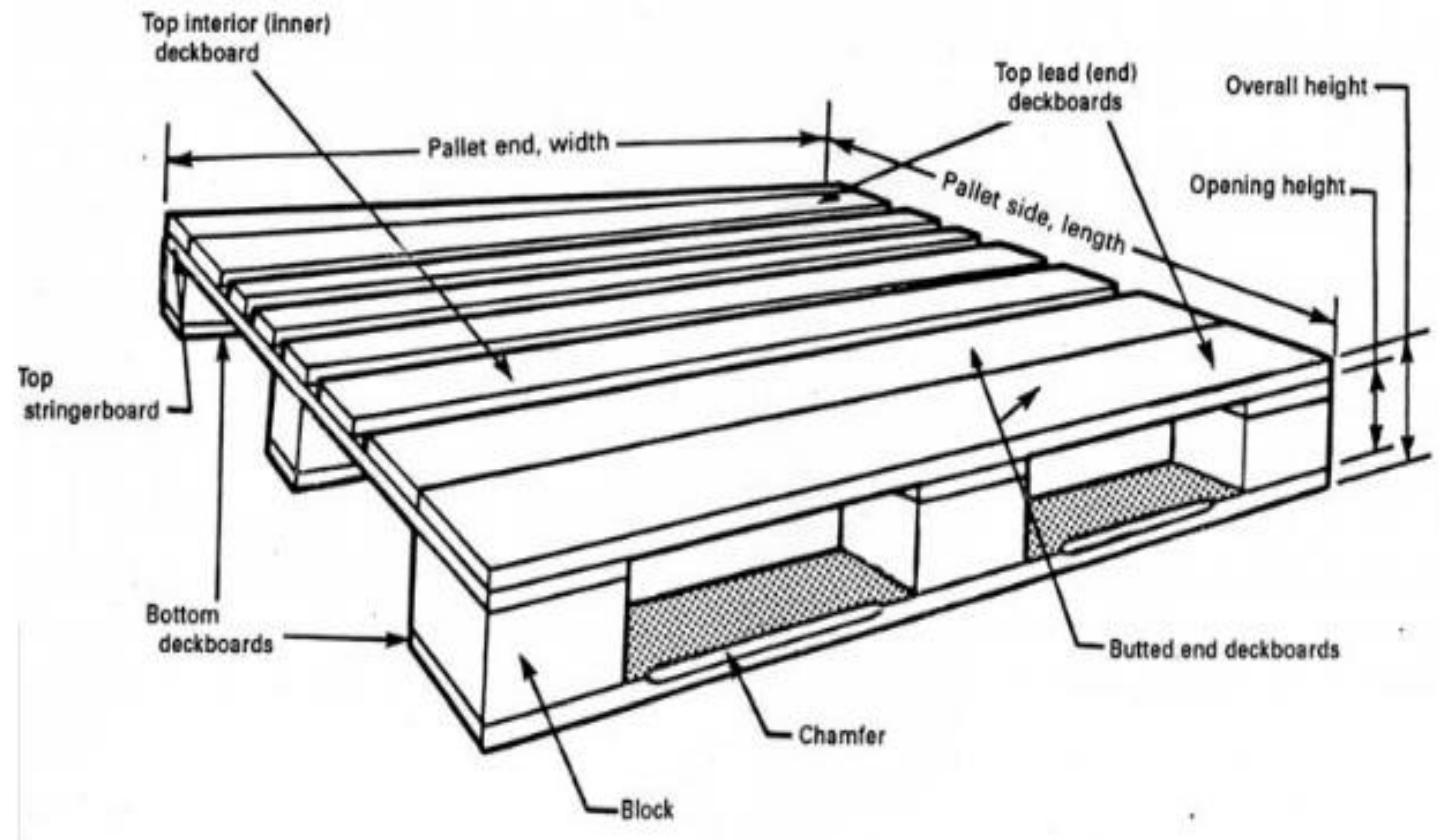

Figure 2: Block Class Pallet - Flush, Double-Face, Nonreversible, Full Four-way, Unidirectional Base (MH1 Committee, 2016)

\subsubsection{Intended Use}

Pallets which are meant to be used only one time are called single use, expendable, or oneway pallets, and they are disposed of or recycled after use. Single use pallets can be designed to a lower quality and are an inexpensive solution if you do not need the pallet returned (MH1 Committee, 2016). The alternative is a multiuse or a reusable pallet. Reusable pallets are built with durability in mind which increases the life expectancy of the pallet (MH1 Committee, 2016). While the initial cost is higher, if these pallets are used in a closed loop and/or are able to be retrieved, then the initial cost is offset through long term savings.

\subsubsection{Entry Type}

A pallet is classified as either a two-way pallet, a partial four-way pallet, or a full four-way pallet based on pallet construction. Stringer pallets can either be two-way pallets or partial fourway pallets. A two-way pallet has solid stringer boards and can only be accessed from the two ends using either a pallet jack or a forklift. A partial four-way pallet has notched stringer boards. This allows for the same access as a two-way pallet, with additional access from the sides of the pallet using a forklift. The notches aren't large enough for a pallet jack hence the name partial four-way. Block pallets are considered full four-way pallets. Block pallets can be accessed from 
all four sides using both a pallet jack and a forklift. A typical wooden pallet design of each entry type is shown in Figure 3.

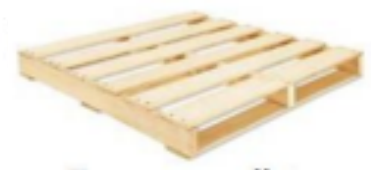

Two-way pallet

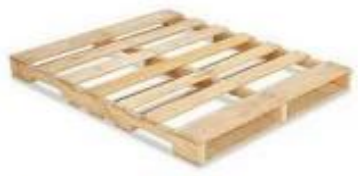

Partial four-way pallet

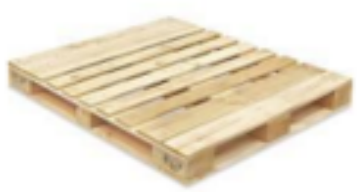

Four-way pallet

Figure 3: Example of typical two-way, partial four-way, and four-way wooden pallets (adapted from Uline, n.d.)

\subsubsection{5. $\quad$ Other Design Characteristics}

There are several design characteristics which can be used to classify pallets. One design characteristic is face construction, either single-face or double-face. Single face pallets have no bottom deckboards and are often called skids. Most pallets are double-faced pallets which have both top and bottom deckboards. Double-faced pallets can be further subdivided into reversible and nonreversible. Reversible pallets have the same top and bottom deck designs allowing the pallet to be flipped over. Nonreversible pallets differ in top and bottom deck construction and therefore have a designated top and bottom (usually fewer deckboards on the bottom).

Another design characteristic is the alignment of the top and bottom deckboards with the stringers or stringer boards. If the deckboards are evenly aligned with the stringers or stringer boards, then the pallet is called a flush pallet. If the top deckboards overhang the stringers or stringer boards then the pallet is considered a single winged pallet (MH1 Committee, 2016). If both the top and bottom deckboards overhang, then the pallet is considered a double winged pallet. Examples of flush, single-winged, and double-winged pallets are shown in Figure 4.

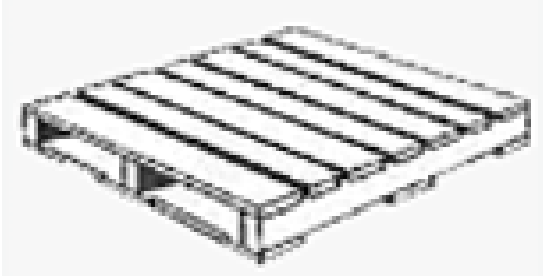

Flush Pallet

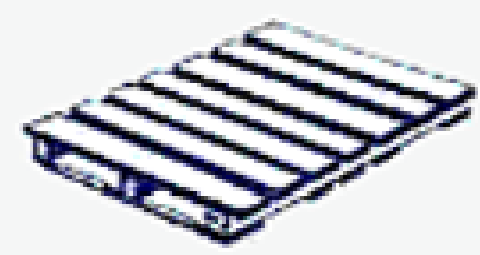

Single-Winged Pallet

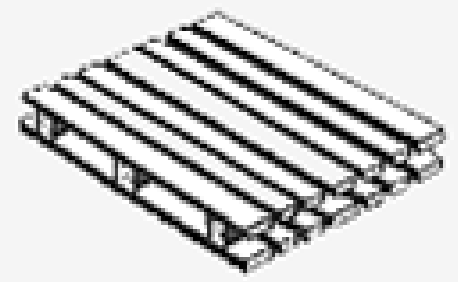

Double-Winged Pallet

Figure 4: Examples of flush, single-winged, and double-winged stringer pallets (Adaptalift Group, 2013) 
Top deck construction can also vary between pallet designs. Stringer pallets use either deckboards or a panel connected directly to the stringers to create the top deck surface. Block pallets need an extra component when using deckboards and employ the use of stringer boards to connect the top deckboards to the blocks below. When using a panel as the top deck surface, the panel can either be connected directly to the blocks or it can be connected using the same stringer board method mentioned above (Figure 2).

The bottom deck can also take on several different configurations. The unidirectional base design is one in which all bottom deck boards are oriented in the same direction. Some block pallets have a unidirectional base design and almost all stringer pallets are considered unidirectional. Block pallets can also have an overlapping base design, a perimeter base design, or a cruciform base design. An overlapping base design is when bottom stringer boards are used in conjunction with bottom deckboards to create a base that is composed of two layers. A perimeter base design is when the bottom deckboards are butted up against each other instead of overlapping. The bottom deckboards are arranged in two different directions; usually three along the length and two along the width. A cruciform base also uses a butted bottom deckboard design, but it includes an extra bottom deckboard across the center width of the pallet. Wooden pallets with a cruciform bottom deck design are most commonly created using an overlapping design; plastic pallets can have a single layer cruciform bottom deck design. An example of a cruciform bottom deck is shown in Figure 5 with all of the components labelled.

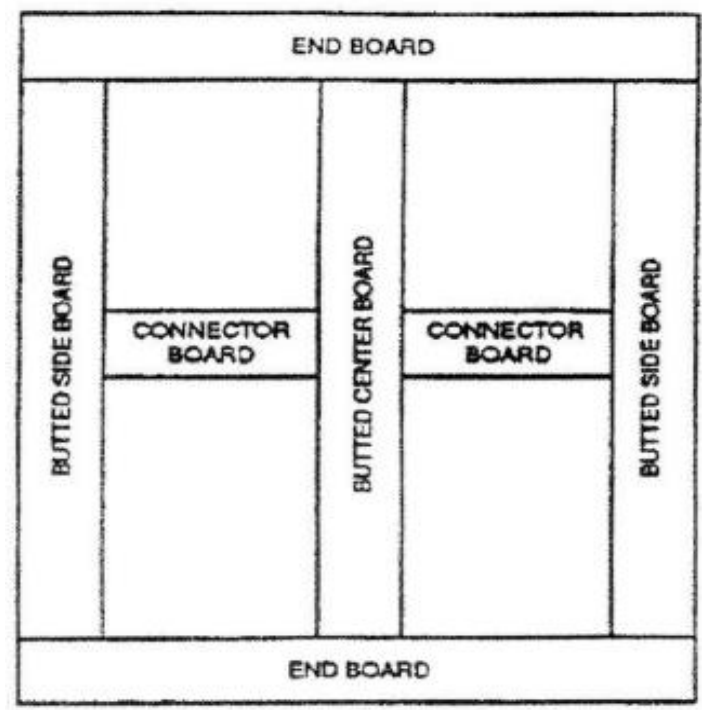

Figure 5: Component names for perimeter and cruciform bottom deck construction (MH1 Committee, 2016) 


\subsubsection{Materials Used}

There are several different materials used in pallet construction. The choice of materials depends on desired strength and stiffness properties, intended use, and all associated costs. Pallets can be solid wood, plastic, wood composite, metal or paper based. Some pallet designs even combine different materials to create the desired properties in the finished pallet.

\subsubsection{1. $\quad$ Solid Wood}

Pallets were originally constructed from solid wood. Currently $96 \%$ of companies in the United States use solid wood pallets (McCrea, 2016). Wooden pallets have experienced a $14 \%$ growth in production from 2011 to 2016 (Gerber, 2018). There were around 849 million new and repaired wood pallets constructed in the United States in 2016 (Gerber, 2018). Pallets made from solid wood can be made of softwood or hardwoods and the exact species varies between different regions. The chosen species is usually limited to just a few species which are native to the given manufacturing region (Figure 6).

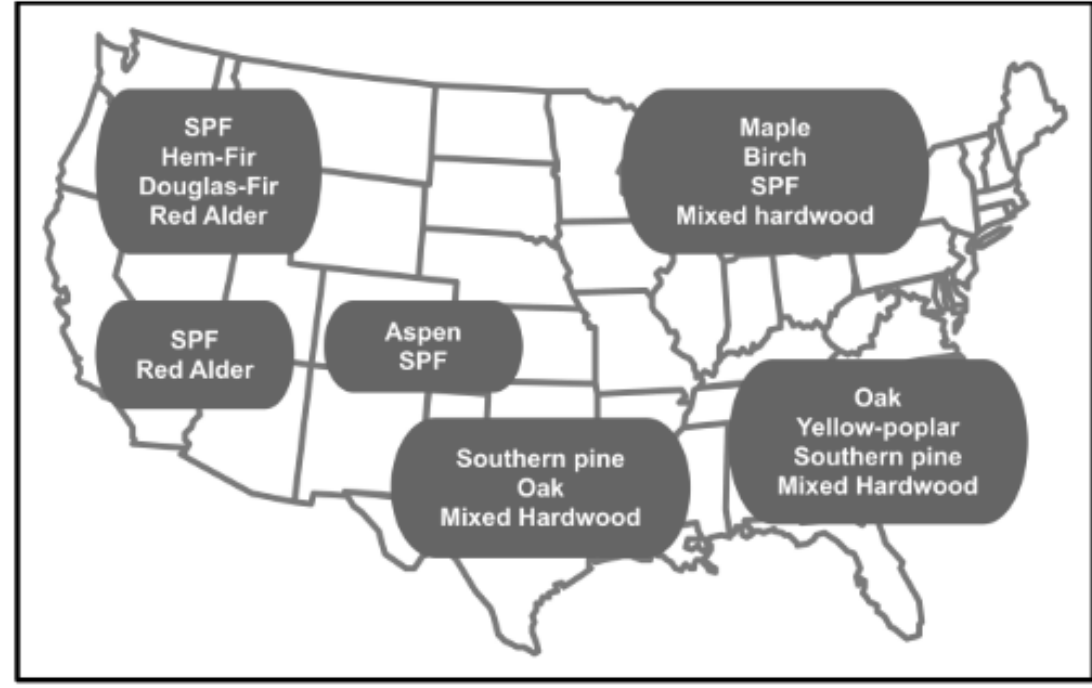

Figure 6: Species typically used for pallet production in various regions of the United States (adapted from White, 2012)

Wood is the material of choice for pallets for multiple reasons. The raw materials for pallet construction are cheap and easy to obtain. Most pallet wood is the low grade wood that is available from sawmills and which has few other uses (Bejune, 2001). Another reason wood is favored is because the manufacturing process is quick and cheap, which results in faster production rates and produces cheaper pallets. Wood pallets can also be repaired with relative ease, and recycling facilities already exist to repurpose old pallets with broken components into useable pallets for 
resale. The disadvantages of wood include the potential for fastener withdrawal and splintering, which can cause product damage or bodily injury. Wood pallets can also experience moisture issues, including mold and insects, if not heat treated and stored properly. Also, the natural variations in solid wood materials' properties (e.g. density, growth variations such as knots and wood grain) lends itself to higher variation in the performance of the pallets themselves.

\subsection{Plastic}

Plastic pallets entered the market in the 1960's (LeBlanc, 2015). Plastic is currently the second most common material for pallet manufacturing, with $37 \%$ of United States companies using plastic pallets (McCrea, 2016). High-density polyethylene (HDPE) and polypropylene (PP) are the two most common types of plastics used for pallet manufacturing. Just like wood pallets, plastic pallets also have their advantages and disadvantages. One advantage of plastic pallets is their resistance to moisture. This helps eliminate problems with insects, mold, and product damage due to desorption of the water in the wood. Plastic pallets also have no issues with fastener withdrawal since there are no fasteners used in the construction of plastic pallets. When compared to wood, plastic pallets also have higher durability. Plastic pallets lend themselves to a much wider range of design alternatives, and they tend to be lighter weight. Disadvantages of plastic pallets include lower stiffness, higher initial costs, and no ability to repair damaged pallets. Considering the advantages and disadvantages, plastic pallets are usually used in closed loop environments or situations in which sanitation is a concern.

\subsection{Wood Composite}

Wood composites are another option for pallet materials with $15 \%$ of companies using these composite pallets (McCrea, 2016). Wood composites pallets, usually molded wood, address some of the issues associated with solid wood pallets ( $\mathrm{Li}$ et al., 2018). The biggest problem addressed by wood composite pallets is the high variability in material properties associated with solid wood. Wood composites randomize wood growth variations increasing the overall homogeneity of the pallet. Wood composite pallets also have fewer issues relating to moisture than solid wood pallets. Wood composite pallets are not subject to the same pest regulations due to the high temperatures used in their manufacturing process (Li et al., 2018). However, wood composite pallets cost more than solid wood pallets, but they are usually cheaper than plastic or metal pallets. The disadvantages of wood composite pallets include costly repairs, problems associated with fastener withdrawal, and moisture problems in wet environments when compared to plastic and 
metal. Given the advantages and disadvantages, wood composite pallets are mainly used in situations where pest regulations are a concern or where increased durability or strength is needed.

\subsection{Metal}

Metal, usually aluminum or steel, is yet another material from which pallets are constructed (McCrea, 2016). Metal pallets can be manufactured in several ways, including CNC machining and robotic welding (Avex Steel Products, 2018). Only 5\% of companies currently use metal pallets due to their high initial costs (McCrea, 2016). The primary use for metal pallets is transporting and storing heavy loads. Metal pallets are extremely durable, have high strength and stiffness values, and are easy to recycle. These pallets are also free of issues relating to moisture, fasteners, and sanitation. The disadvantages include a high initial cost, heavy pallet weight, and lower surface friction (Clarke, 2004). Due to the high initial cost and the potential for long term use, metal pallets are most commonly used in closed loop environments where pallet loss is not a concern.

\subsection{Paper-based}

Paper-based pallets were first conceived of in the 1940's and the term encompasses pallets made of corrugated, honeycomb, solid fiberboard, and molded pulp (LeBlanc, 2017). While paperbased pallets are lightweight, easy to recycle, and have high adaptability, the price is similar to that of wood pallets (LeBlanc, 2017). These pallets tend have low stiffness, low durability, and a high level of moisture related issues; as such, paper-based pallets are expected to be single use pallets. One of the biggest challenges for paper-based pallets is industry perception. Currently, around $90 \%$ of the largest retail stores in the United States, including Walmart ${ }^{\circledR}$, will not accept paper-based pallets (Change The Pallet, 2015).

\subsubsection{Sizes}

To help keep the processes consistent throughout transportation, storage, and handling, there are several standard pallet sizes. These standard sizes vary by industry and country. Pallet dimensions are given in the form of length by width (MH1 Committee, 2016). The length is defined as the dimension parallel to the stringers for stringer pallets and the dimension parallel to the stringer boards for block pallets (MH1 Committee, 2016). The width of a pallet is defined as the direction of the top deck perpendicular to the length (MH1 Committee, 2016). The most common pallet sizes by region are shown in Table 1 in both millimeters and inches. The wood pallet sizes which are most commonly used in the United States are presented in 
Table 2 by industry and percentage of new wood pallet production in various years. The 48 in. $\mathrm{x} 40$ in. pallet, known as the GMA (Grocery Manufacturers Association) pallet, accounted for $35 \%$ of all wood pallets produced in the U. S. in 2016 (Gerber, 2018).

Table 1: Most common pallet sizes by region in both inches and millimeters (ISO, 2003)

\begin{tabular}{|c|c|c|}
\hline Metric size (mm) & US size (in.) & Region \\
\hline $1200 \times 1000$ & $47.24 \times 39.37$ & Europe, Asia \\
\hline $1200 \times 800$ & $47.24 \times 31.50$ & Europe \\
\hline $1219 \times 1016$ & $48.00 \times 40.00$ & North America \\
\hline $1140 \times 1140$ & $44.88 \times 44.88$ & Australia \\
\hline $1100 \times 1100$ & $43.30 \times 43.30$ & Asia \\
\hline $1067 \times 1067$ & $42.00 \times 42.00$ & North America, Europe, Asia \\
\hline
\end{tabular}

Table 2: Most popular wood pallet sizes by industry and percentage of new wood pallet production in the United States in various years (adapted from Gerber, 2018 and Clayton, 2018)

\begin{tabular}{|c|c|c|c|c|}
\hline \multirow{2}{*}{ Industry } & \multirow{2}{*}{ Dimensions } & \multicolumn{3}{|c|}{ Year } \\
\cline { 3 - 5 } & & $\mathbf{2 0 0 6}$ & $\mathbf{2 0 1 1}$ & $\mathbf{2 0 1 6}$ \\
\hline Grocery & 48 in. x 40 in. & $27 \%$ & $24 \%$ & $35 \%$ \\
\hline Military & 40 in. x 48 in. & $5 \%$ & $3 \%$ & $4 \%$ \\
\hline Drums & 48 in. x 48 in. & $4 \%$ & $4 \%$ & $7 \%$ \\
\hline Automotive & 48 in. x 45 in. & $2 \%$ & - & $5 \%$ \\
\hline Chemical, Beverage & 48 in. x 42 in. & $4 \%$ & - & $3 \%$ \\
\hline Beverage, Shingles, Packaged Paper & 48 in. x 36 in. & $2 \%$ & $2 \%$ & $1 \%$ \\
\hline Chemical & 42 in. x 42 in. & $5 \%$ & $5 \%$ & $5 \%$ \\
\hline Beverage & 37 in. x 37 in. & $2 \%$ & $2 \%$ & $<1 \%$ \\
\hline European & 800 mm x 1200 mm & - & $1 \%$ & $1 \%$ \\
\hline Various & Other & $50 \%$ & $60 \%$ & $39 \%$ \\
\hline
\end{tabular}




\subsubsection{Standards for Pallets}

There are several standards which relate directly to quality, reliability, and repeatability of pallets throughout the packaging industry. One of the largest and most comprehensive standards is the MH1 - Pallets, Slip Sheets, and Other Bases for Unit Loads (2016) produced by the Material Handling Industry and certified by the American National Standards Institute (ANSI). The ANSI MH1:2016 standard originated in 1953 (ASME, 2005) Improvements and adjustments have continually been made to this standard in order to remain current with industry trends. This standard defines industry terminology in Part 1, establishes common pallet dimensions in Part 2, and addresses the manufacturing and tolerances of pallets and their components in Part 3 and Parts 9 - 14. It also has sections relating to the use of fasteners, including tables of common fasteners and their specifications (Part 5), along with a protocol for measuring the quality of pallet nails and staples (Part 6). Part 7 of the ANSI MH1:2016 standard refers to multiple testing methods (standards) which are intended to evaluate the performance of pallets across a variety of real-world scenarios.

Another leading standard in the packaging industry is the National Wooden Pallet and Container Association (NWPCA) Uniform Standard for Wood Pallets (2014). The effort by NWPCA to establish industry wide standards started at Virginia Tech in the late 1950's with the creation of a pallet grading system (Brindley, 2006). It wasn't until the early 1990's that a uniform voluntary standard was developed (Brindley, 2006). The current NWPCA standard stemmed from Part 3: Wood Pallets of the ANSI MH1:2016 standard and is almost identical. Since NWPCA is a leading organization in the wooden pallet industry, this standard was adopted from the Material Handling Industry and was established as a voluntary industry wide standard.

\subsubsection{Manufacturing}

Both standards mentioned above address manufacturing specifications for pallets. The NWPCA standard focuses on the manufacturing of wooden pallets, while the ANSI MH1:2016 standard has additional sections which encompass the manufacturing of pallets from other materials such as plastic and plastic composites, corrugated/paper-based, metal, and molded, wood-based composites. When it comes to wood pallets, both standards establish quality control by addressing manufacturing topics such as defects arising from wood growth variations, component tolerances, and moisture content (MH1 Committee, 2016). 
Tables presented in the standards establish different defect limitations for pallet components based on whether the pallet is classified as reusable or single-use. The standards also define manufacturing tolerances for pallet components. For deckboards and stringer boards, component tolerances are expected to be $\pm 1 / 16$ inch $( \pm 1.6 \mathrm{~mm})$ of desired thickness and $+1 / 8$ inch (+3 mm) or -1/4 inch (-6 mm) of desired length (NWPCA, 2014 and MH1 Committee, 2016). For stringers and blocks, the width and height can vary by only $\pm 1 / 16$ inch $( \pm 1.6 \mathrm{~mm})$ from desired dimensions and the length must fall within the range of $+1 / 8$ inch $(+3 \mathrm{~mm})$ to $-1 / 4$ inch $(-6 \mathrm{~mm})$ of desired length (NWPCA, 2014 and MH1 Committee, 2016). Moisture content is not limited as long as component dimensions are within the expected tolerances.

\subsubsection{Fasteners}

Fasteners play a large role in the performance of a unit load. Fastener performance can affect the strength and stiffness of individual pallet joints, and ultimately, the unit load as a whole (Yoo, 2011). There are several fasteners intended for wood pallets including bolts, wood screws, and lag screws along with driven fasteners such as nails and staples which are the most common. Nails are further classified, according to the surface of the shank, into categories of plain shank, fluted, annularly threaded, helically threaded, or twisted square wire. Staples can be either round or square which refers to the shape of the wire that was used to manufacture the staples.

The NWPCA standard establishes minimum quality requirements for fasteners based on their intended use (single use vs. multiuse) and addresses issues such as fastener placement, protruding fasteners, and fastener caused splits (NWPCA, 2014). The ANSI MH1:2016 standard has this same information as the NWPCA standard, but it also includes a protocol for measuring the quality of pallet nails and staples based on work done by Stern and White in 1993 (MH1 Committee, 2016). This testing protocol establishes two quantitative values of fasteners, termed the fastener withdrawal index (FWI) and the fastener shear index (FSI), to determine their expected quality and performance (MH1 Committee, 2016).

\subsubsection{Testing of Pallets}

Understanding the mechanical properties of pallets under typical support conditions is important in creating a safe, yet cost effective, pallet design. Before the early 1980's, pallets were tested by manually loading packages on to them in order to create a unit load. In 1982, Fagan (1982) developed a testing apparatus which used an airbag to apply a uniform load. This method 
produced more reliable and repeatable results than previous testing methods through the use of a constant loading rate and uniform load distribution. Since then, several testing standards have been created with the ultimate goal of estimating pallet durability and load capacity. Durability tests are conducted to determine the average life expectancy of any given pallet design. Durability tests can include incline impact tests, vibration tests, and corner or end drop tests. Load capacity tests are conducted to determine the safe load capacity of a pallet across various support and loading conditions. The support conditions typically seen in industry include storage in pallet rack system [warehouse racking across the width (RAW) and warehouse racking across the length (RAL)], floor stacking (including top and bottom deckboard), fork tine support (in both directions where applicable), and conveyor support.

The two most commonly used standards for testing general use pallets are ASTM D1185 Standard Test Methods for Pallet and Related Structures Employed in Materials Handling and Shipping (2017a) and ISO 8611 - Pallets for material handling - Flat Pallets (2011a). ISO 8611 is the newer of the of the two standards and is recognized internationally, while ASTM D1185 is mostly used in the United States. The loading method differs slightly for each of the two standards. While both standards try to simulate uniform load distribution, ASTM D1185 achieves this through the use of an airbag and ISO 8611 uses a rigid plate on top of two rigid beams for increased repeatability between laboratories. Since the load capacity of a pallet depends on the type of load the pallet is experiencing, the two standards generate slightly different results; hence, each standard applies a different safety factor to their results. Due to the fact that a uniform load creates conservative loading conditions, these standards produce a conservatively low, safe load capacity pallets which tend to be overdesigned. When pallets only carry a specific package type, such as corrugated boxes, their load capacity can be significantly greater than either standard would predict. Therefore, ISO 8611 allows the use of a specific load type to generate a so-called Maximum Working Load value. The maximum working load capacity of the pallet incorporates the effect of packages, but it only applies when the pallet carries the exact same packages that were used for the test (ISO, 2011b).

In the past, the only way to understand the mechanical properties of pallets was to conduct physical tests. More recently, however, software has emerged to help with evaluating the performance of pallets through predictive mathematical models which include various design 
features. These design features include pallet materials, component dimensions, fastener specifications, and the expected loading conditions among others. The two most popular pallet software programs are Pallet Design System (PDS), that was based on research conducted at Virginia Tech and currently commercialized by NWPCA, and Best Load, created by White and Company. Both programs use mathematical models to predict the strength and stiffness properties of any given pallet design, which allows users to find an optimal balance between cost and performance.

\subsection{CORRUGATED BOARD AND CORRUGATED BOXES}

\subsubsection{History}

The first documented use of corrugated paper was a patent issued in 1856 for use as a cushion or liner in the sweatband on hats (Twede et al., 2014). It was not until 1871 that a patent was issued to Albert Jones for the use of corrugated paper as a packaging material (Twede, 2007). In 1874, faces (liners) were added to corrugated paper by Oliver Long in order to prevent stretching (Twede et al., 2014). The first double-faced (single wall) corrugated box was produced in 1894 by Thompson and Norris for use by Wells Fargo (Twede et al., 2014). Over the last hundred years, advances have been made in the manufacturing process allowing for greater output rates and increased manufacturing accuracy. Advances have also been made in developing standard grades of corrugated board and standard testing methods (Fibre Box Association, 2015). Today, a wide variety of corrugated products are available with known strength properties.

\subsubsection{Introduction to Industry}

Corrugated boxes are the items most commonly shipped on a unit load (Fibre Box Association, 2015). Up to $95 \%$ of consumer goods are packaged and transported in this manner (Fibre Box Association, 2015). The corrugated fiberboard industry was valued at $\$ 26.1$ billion in 2011 (Twede et al., 2014). That represents $63 \%$ of the value, and $78 \%$ of the tonnage, of the paper packaging industry as a whole (Twede et al., 2014). Corrugated boxes are manufactured from corrugated fiberboard which is constructed using a pattern of flat containerboards, called liners, glued together in combination with wavy containerboards, called corrugated mediums. Using different numbers of liners and mediums, along with different flute heights and spacing (height of corrugated peak and distance between corrugated peaks), allows corrugated board to be extremely versatile, and it finds many different uses throughout the packaging industry. There are also several 
different styles of corrugated boxes that can be constructed. As the industry has evolved, testing standards have been developed to ensure the performance of corrugated board and corrugated boxes during intended use.

\subsubsection{Corrugated board}

Corrugated board is a panel product composed of inner layers, which are wavy or corrugated, and outer layers, which are flat. Inner layers are referred to as the mediums or the walls, and outer layers are referred to as the liners, linerboards, or faces (Twede et al., 2014). Linerboards are most commonly made of Kraft linerboard, which is composed of softwood fibers pulped using the Kraft process (sulfate pulping) (Koning, 1995). The corrugated medium is either made from hardwood fibers using the neutral sulfite semi chemical (NSSC) pulping process, or made from recycled corrugated board (Twede et al., 2014). Due to the manufacturing differences between linerboard and the corrugated medium, linerboards are considered two-ply while the medium is a single ply fiberboard (Soroka, 2009).

Different numbers of liners and mediums are glued together to create a variety of corrugated boards, each with their own desired properties and intended purposes. One linerboard glued to one medium is termed single-faced corrugated board. Single-faced corrugated is sold in rolls, and it is mainly used to wrap products not manufacture boxes (Twede et al., 2014). Doublefaced corrugated board is made by gluing two linerboards to a single corrugated medium, and it is more commonly referred to as single wall corrugated board. Single wall corrugated is the most common type used throughout the industry (Soroka, 2009). Double and triple wall corrugated boards are manufactured by gluing additional linerboards and mediums to a single wall corrugated board in order to create a thicker and more rigid product. Due to superior strength properties, double wall and triple wall corrugated board is mainly used for heavy duty applications (Twede et al., 2014). The different types of corrugated board are shown in Figure 7. 
(a)

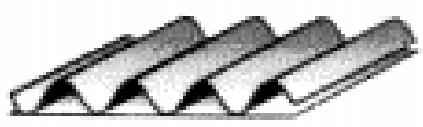

(b)

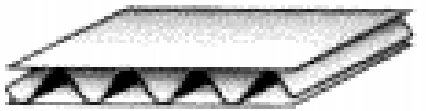

(c)

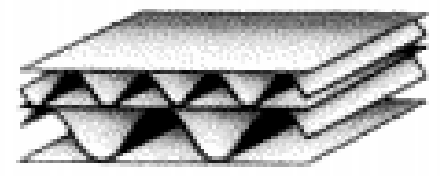

(d)

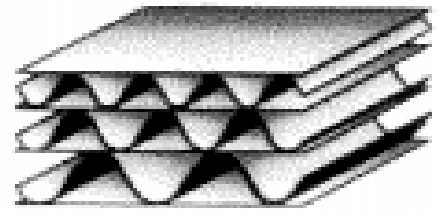

Figure 7: Examples of different types of corrugated board: a) single face b) double face or single wall c) double wall d) triple wall (adapted from Kirwan, 2005)

\subsubsection{Flute Types}

The term flute refers to the arch like structure formed from bending the medium into its corrugated shape (Fibre Box Handbook, 2015). The fluting of corrugated fiberboard has been grouped according to fluting specifications such as number of flutes per foot (or meter), flute height in inches or millimeters (sometimes referred to as thickness), and take up factor. Take up factor is defined as a ratio of the length of the medium to the length of the linerboards (Soroka, 2009). The various sizes of corrugated board are given alphabetical designations to differentiate them based on their specifications. It is important to note that the alphabetical designations are ordered chronologically rather than by size (Twede et al., 2014). The most common flute sizes along with their specifications are presented below in Figure 8 and Table 3. C-flute is the most common size of corrugated board used by the industry with around $80 \%$ of corrugated boxes in the United States being constructed of C-flute corrugated board (Twede et al., 2014). Although corrugated board is sold based on fluting characteristics, these characteristics can vary widely between manufacturers depending on manufacturing equipment. 


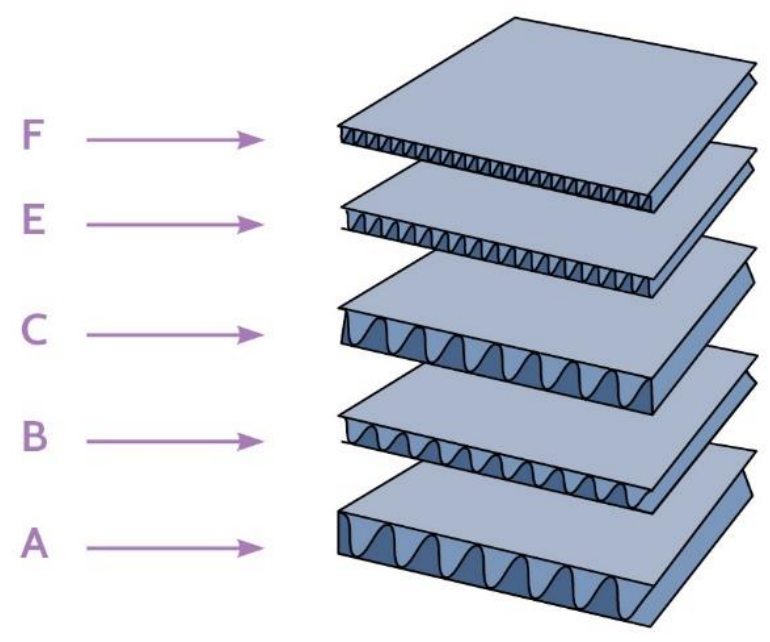

Figure 8: Most common flute types used by industry (Fibre Box Handbook, 2015)

Table 3: List of the most common flute types along with their specifications including flutes per meter, flutes per foot, flute thickness in millimeters (inches), and take up factor (adapted from

Twede et al., 2014)

\begin{tabular}{|c|c|c|c|c|}
\hline Flute Type & Flutes per meter & Flutes per foot & $\begin{array}{c}\text { Flute thickness } \\
\text { mm. (in.) }\end{array}$ & $\begin{array}{c}\text { Take-up } \\
\text { Factor }\end{array}$ \\
\hline A & $108 \pm 10$ & $33 \pm 3$ & $4.8(3 / 16)$ & 1.54 \\
\hline C & $128 \pm 10$ & $39 \pm 3$ & $4.0(5 / 32)$ & 1.45 \\
\hline B & $154 \pm 10$ & $47 \pm 3$ & $3.0(1 / 8)$ & 1.35 \\
\hline E & $295 \pm 13$ & $90 \pm 4$ & $1.6(1 / 16)$ & 1.25 \\
\hline
\end{tabular}

\subsubsection{Board Grades}

The linerboards and mediums that compose corrugated board can vary in strength and stiffness properties based on weight and thickness (Soroka, 2009). To help with standardization throughout the industry, grades were created based on grammage or basis weight, both of which represent the weight of fiber in a given area. Grammage is reported in units of grams per square meter $\left(\mathrm{g} / \mathrm{m}^{2}\right)$ while basis weight is reported in pounds per 1,000 square feet $\left(\mathrm{lb} / 1,000 \mathrm{ft}^{2}\right.$ ) (Soroka, 2009). These grades were determined based on meeting established requirements of the Mullen burst test (see Mechanical Properties/Standards) (Soroka, 2009). Due to differences in their manufacturing processes, linerboards and mediums have different standardized grades. The most common grades used to identify linerboards and mediums are shown in

Table 4. 
Table 4: Common basis weight in pounds per 1,000 square feet (lb/1,000 ft2) and grammage in grams per square meter (g/m2) for both linerboards and mediums (Twede et al., 2014)

\begin{tabular}{|c|c|c|c|}
\hline \multicolumn{4}{|c|}{ Common Basis Weight or Grammage } \\
\hline \multicolumn{2}{|c|}{ Linerboard } & \multicolumn{2}{|c|}{ Medium } \\
\hline $\begin{array}{c}\text { U. S. Customary } \\
\left(\text { llb./1000ft }^{2}\right)\end{array}$ & $\begin{array}{c}\text { Metric } \\
\text { System } \\
\left(\mathrm{g} / \mathrm{m}^{2}\right)\end{array}$ & $\begin{array}{c}\text { U. S. Customary } \\
\left(\text { lb./1000ft }{ }^{2}\right)\end{array}$ & $\begin{array}{c}\text { Metric } \\
\text { System } \\
\left(\mathrm{g} / \mathrm{m}^{2}\right)\end{array}$ \\
\hline 26 & 125 & 26 & 125 \\
\hline 33 & 150 & 28 & 140 \\
\hline 38 & 175 & 30 & 150 \\
\hline 42 & 200 & 36 & 175 \\
\hline 47 & 225 & 40 & 200 \\
\hline 69 & 339 & 42 & 200 \\
\hline
\end{tabular}

Note: Relation between the common basis weights is not equivalent to the mathematical conversion of the units

Corrugated board can be manufactured using any combination of the different grades of both the linerboard(s) and medium(s). To describe corrugated board, the grammage, or basis weight, of the individual components are listed from the outside to the inside (Soroka, 2009). A corrugated board listed as 159/125B/140 would consist of an outside linerboard with a grammage of $159 \mathrm{~g} / \mathrm{m}^{2}$, a B-fluted medium with a grammage of $125 \mathrm{~g} / \mathrm{m}^{2}$, and an inside linerboard with a grammage of $140 \mathrm{~g} / \mathrm{m}^{2}$.

\subsubsection{Corrugated box styles}

Box styles are specified by the use of a descriptive name, an acronym, and an international code number (Twede et al., 2014). The international code numbers were created by a joint effort between the European Federation of Corrugated Board Manufacturers (FEFCO) and the European Solid Fiberboard Organization (ESBO). They worked together in order to help create uniformity throughout the industry and across different languages (FEFCO-ESBO, 2007). This was later adopted by the International Corrugated Case Association and the United Nations (Fibre Box Association, 2015). 
The international code is four digits long and is used to denote the standard shape and design of any given box. The first two digits represent different box styles based on form, and the second two digits represent a specific design based on characteristics such as shape, number of flaps, and amount of flap overlap. The different forms of boxes include slotted boxes, telescope boxes, folders, rigid boxes (bliss boxes), ready glued boxes (self-erecting boxes), and interior forms, among others (Fibre Box Association, 2015).

Slotted boxes are manufactured from a single piece of corrugated with a manufacturers joint (which is a glued joint that helps form a square shaped box) along with top and bottom flaps. Telescope boxes are created using a multi-piece design in which a top and/or bottom fit into each other or over the box body. Folders are also constructed from a single piece of corrugated; however, this type, is folded around the product, with the intention of fully supporting the bottom of the box (Fibre Box Association, 2015). Rigid boxes use a three-piece design including two side panels held together as the body is wrapped around them. Ready glued boxes are manufactured in such a manner that the box can be constructed without the use of adhesive or equipment (Twede et al., 2014). Interior forms can be used to strengthen the box, separate products, or reduce product movement, and they can take on a variety of shapes.

The Regular Slotted Container (RSC), is one of the most common designs for slotted boxes, and it is designated by the international code number 0201 (Fibre Box Association, 2015). On an RSC, all of the flaps are the same length and each are exactly half of the container's width. This allows the flaps along the length of the box to meet in the center when folded, creating an economic design with minimal waste (Twede et al., 2014). All box designs can be manufactured to have any desired dimensions, although ISO 3394 - Packaging - Complete, Filled Transport Packages and Unit Loads - Dimensions of Rigid Rectangular Packages (2012) was created to help standardize box dimensions based on standard pallet dimensions.

\subsubsection{Mechanical Properties/Standards}

Historically, grammage, or basis weight, was used as an indication of the expected performance of a given fiberboard and therefore of corrugated board. However, there has been an increase in the amount of recycled fiber used to manufacture both linerboards and mediums, and these recycled fibers reduce the strength properties for a given grammage or basis weight (Twede et al., 2014). To address this variation in strength properties, other tests, such as the Mullen burst 
test and the edge crush test (ECT), are used to assess mechanical properties of the board itself. These tests are able to specify the strength properties of the corrugated board as a whole.

A set of rules for corrugated box construction was created which includes specifications for the weight of the box including its contents, the dimensions of the box, and the combined weight of the facings. These rules were used to separate corrugated board into different categories based on minimum requirements for both the Mullen burst test and the edge crush test (ECT). The different categories are shown in the Table 5 below. It is important to note, that although the burst strength and ECT values are established for a given box size and weight, these values are not directly comparable (Baker, 2016).

Table 5: Minimum strength requirements for single wall corrugated fiberboard boxes based on either Mullen burst test rating and minimum combined facing weight (Part A) or edge crush test (ECT) rating (Part $B)$ for varying levels of maximum box and content

\begin{tabular}{|c|c|c|c|c|}
\hline \multicolumn{5}{|c}{ Single Wall Corrugated Fiberboard Boxes } \\
\hline \multirow{3}{*}{$\begin{array}{c}\text { Max Weight, } \\
\text { Box and } \\
\text { Contents (lbs.) }\end{array}$} & $\begin{array}{c}\text { Max. Outside } \\
\text { Dimension (length } \\
\text { + width + depth) }\end{array}$ & $\begin{array}{c}\text { Min. Burst } \\
\text { Test } \\
\text { (lb./sq. in.) }\end{array}$ & $\begin{array}{c}\text { Min. Combined } \\
\text { Weight of } \\
\text { Facings }\end{array}$ & $\begin{array}{c}\text { Min. Edge Crust } \\
\text { Test (ECT) } \\
\text { (lb./in. width) }\end{array}$ \\
\hline 20 & 40 & 125 & 52 & 23 \\
\hline 35 & 50 & 150 & 66 & 26 \\
\hline 50 & 60 & 175 & 75 & 29 \\
\hline 65 & 75 & 200 & 84 & 32 \\
\hline 80 & 85 & 250 & 111 & 40 \\
\hline 95 & 95 & 275 & 138 & 44 \\
\hline 120 & 105 & 350 & 180 & 55 \\
\hline
\end{tabular}

*Mullen (Part A) and ECT values (Part B) are presented side-by-side, but there is no correlation between the values.

The oldest test for evaluating the strength of corrugated board is the Mullen burst test, which measures the amount of pressure (usually in pounds per square inch) that is required to puncture or rupture the corrugated board (Twede et al., 2014). Several standardized tests have been established in order to measure the burst strength including TAPPI T 810: Bursting Strength of Corrugated and Solid Fiberboard (2017a) and ISO 2759: Board - Determination of Bursting Strength (2014). The Mullen burst test can be used to measure the burst strength of the corrugated board as a whole or of the linerboards individually. Burst strength has been shown to be additive. 
This means that the individual burst strength of each linerboard in a given corrugated board can be combined to estimate the burst strength of the corrugated board as a whole (Twede et al., 2014). The results of a Mullen burst test are a good indication of expected containment strength, as the test reproduces the forces typically experienced during the material handling process including drops and impacts (Allaway, 2005).

The edge crust test (ECT) became popular in the 1990's as a way of specifying the compression strength of corrugated board, since it is directly related to stacking strength (Twede et al., 2014). The ECT is evaluated using one of several standards including TAPPI T 811: Edgewise Compressive Strength of Corrugated Fiberboard (Short Column Test) (2017b) and ISO 13821: Corrugated Fiberboard - Determination of Edgewise Crush Resistance - Waxed Edge Method (2013). The edge crush test consists of compressing a piece of corrugated board, with the flutes parallel to the direction of loading, until failure. The ECT value is the ratio of the force at failure over the length of the sample and is reported in pounds-force/inch (kilonewtons/meter). To help with the introduction of a new rating system, ECT values were determined for each of the different categories of corrugated board that were already established by the Mullen burst test (Twede et al., 2014).

To help with correlating the strength of the corrugated board to overall box performance, the McKee formula was created. This equation is used to estimate box compression strength (BCT) for regular slotted containers (RSC) based on the corrugated boards' thickness, the size of the perimeter of the box, and the edge crush test (ECT) values (Twede et al., 2014). There are also several standardized testing methods for determining the BCT of a given box design including TAPPI T 804: Compression Test of Fiberboard Shipping Containers (2012), ASTM D642: Stand Test Method for Determining the Compression Resistance of Shipping Containers, Components, and Unit Loads (2015), and ISO 12048 Packaging - Complete, Fill Transport Packages Compression and Stacking Tests Using a Compression Tester (1994). The different standards allow for testing under multiple loading conditions (fixed platen vs. floating platen) and with different box contents (filled vs. empty).

\subsubsection{Manufacturers certificate}

A Box Manufacturer's Certificate (BMC) is a stamp printed on the corrugated box to specify the minimum performance standards met by that box (Koning, 1995). The BMC is also a 
guarantee that the box complies with the minimum requirements set forth by the given transportation industry [National Motor Freight Classification (NMFC) for truck transport and Uniform Freight Classification (UFC) for rail transport] (Fibre Box Association, 2015). All BMCs include the name and location (city and state) of the box manufacturer along with the box's gross weight and size limits. This stamp also includes either the edge crust test (ECT) rating or the burst test rating and the combined facing weight. An example of a BMC for both ECT rating and burst test rating are shown in Figure 9. Boxes intended for use as small parcels will often use BMCs designating the burst rating, while boxes intended for palletization prefer BMCs indicating the ECT value. The manufacturer's stamps indicate the stresses the boxes are able to withstand given their intended use (Twede et al., 2014).
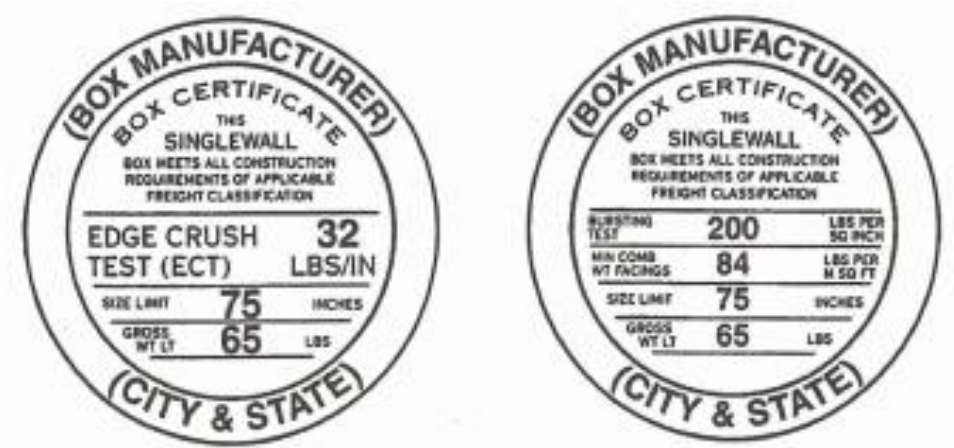

Figure 9: Left: Box Manufacturer's Certificate displaying the edge crush test (ECT) rating Right: Box Manufacturer's Certificate displaying burst testing rating and combined weight of facings (Soroka, 2009)

\subsection{STRETCH WRAP}

\subsubsection{History}

Originally, products were secured to a pallet using either rope or metal strapping, both of which can damage products through pressure points (Bisha, 2012). In the early 1970's, the use of stretch wrap for unit load containment was proposed by the Lancaster brothers from Lantech (Wathen, 2016). Stretch wrap was initially made from polyvinyl chloride (PVC) and low density polyethylene (LDPE), both of which had drawbacks. PVC was originally preferred by the industry because of its greater ability to stretch, but PVC quickly gave way to LDPE as technological advances increased the elastic properties of LDPE (Bisha, 2012). In the late 1970's, linear lowdensity polyethylene (LLDPE) was invented, and it quickly became the choice material for manufacturing stretch wrap as a result of its improved elasticity and durability (Dowler, 2015). The next breakthrough in stretch wrap technology was the addition of extra layers composed of 
different chemicals in order to optimize the stretch wrap's mechanical properties (Bisha, 2012). The number of layers was increased to three in the 1980's, five in the 1990's, and up to nine layers by the 2000's (Dowler, 2015). Today, a multilayer stretch film manufactured from linear lowdensity polyethylene (LLDPE) is most commonly used by the industry due to its high puncture resistance and enhanced elastic properties compared to other available polymers (Bisha, 2012).

\subsubsection{Introduction to Industry}

It is important to consider the stability of a unit load as it moves through the supply chain. A stable unit load is less likely to shift during transportation; therefore, it can reduce product damage and repackaging costs while increasing employee safety (Bisha, 2008). There are several methods employed by the packaging industry to keep the contents of unit loads stable throughout the supply chain, including stretch wrap, pallet sheets, strapping, break away adhesives, stretch tape, shrink wrap, stretch hooding, and the use of interlocked stacking patterns. Stretch wrap, considered an elastic packaging film, is the most common method of load stabilization (Rogers, 2011). More than $65 \%$ of unit loads utilize stretch wrap during transportation (Wainer, 2002). In addition to load stabilization, stretch wrap helps reduce exposure to moisture, dust, and UV rays. It also acts as a physical barrier to reduce tampering with products (Hazel 4D, n.d.). It can reduce overall costs associated with product handling, labor, and transportation (Wainer, 2002).

\subsubsection{Manufacturing}

Stretch wrap can be manufactured using two different methods: cast film or blown film. These two films utilize different manufacturing procedures which result in distinct properties for each. Both types of films have advantages and disadvantages associated with their mechanical properties and as such, each film type has its intended markets (Bisha, 2012).

Cast film is manufactured by extruding molten resin through a slotted die, creating a thin sheet of film (Degroot et al., 1994). This thin sheet is then pressed against chilled rollers and cooled rapidly to re-solidify the resin (Degroot et al., 1994). Due to this manufacturing method, cast films tend to have higher clarity, better quality control, and the ability to manufacture more film types through the use of additional layers (Bisha, 2012). Cast films are uni-axially oriented (meaning its desirable properties exist in one direction) and are used in the machine direction to take advantage of these properties. Since cast films have less resistance to tears and punctures than blown films, cast films remain the primary choice for the packaging industry (Bisha, 2008). 
The alternative to cast film is blown film, which is also manufactured by extruding molten resin through a die. Instead of a slotted die, the resin is forced through a circular die in the shape of a bubble. Air is blown from underneath in order to inflate the bubble. As the bubble extends vertically, it is cooled and flattened then cut to desired dimensions and wrapped onto a roll. Blown films have a greater load retention, better load coverage (Singh et al., 2014), and a higher puncture resistance when compared to cast films due to their elastic properties (Bisha, 2008). The manufacturing process for blown film creates a bi-axially oriented product which has the desired properties in both the machine and cross-machine directions. Disadvantages include higher opacity and a higher noise level during application (Bisha, 2008).

Stretch wrap can be sold in a variety of dimensions which include film thickness (gauge), length, roll width, roll diameter, and weight. One of the most important properties of stretch wrap is the thickness, or gauge, of the material which is measured in microns. The manufacturing method, along with the gauge, and its chemical composition, directly affects the performance and mechanical properties of the stretch wrap. Other properties, such as tensile strength, cling (ability to adhere to itself or another surface), tear resistance, puncture resistance, and elasticity are rarely mentioned on stretch wrap product specifications as these properties are highly variable and require laboratory testing for verification.

\subsubsection{Application}

Stretch wrap is applied to unit loads using one of three methods based on the level of automation required: manual, semi-automatic, or fully automatic (Bisha, 2012). The manual stretch wrapping method requires no automation, and instead, the unit load is wrapped by hand. While this method requires no equipment, stretch wrapping by hand is a labor-intensive process prone to inaccuracy and uneven containment (Park, 2015). Semi-automated application is when the unit loads are manually loaded onto stretch wrappers, and once in place, the machine applies the stretch wrap. Fully automated stretch wrappers are able to load and stretch wrap the unit loads without physical labor, usually through the use of conveyors and electronic sensors. Both semiautomated and fully automated stretch wrappers can be either turn table machines or rotary tower machines (Collins, n.d.). Turn table machines rotate the unit load while applying stretch wrap from a film carriage. The film carriage moves vertically along a fixed mast in order to wrap the entire unit load. Conversely, rotary tower machines apply stretch wrap to a stationary unit load through 
the use of a mechanical arm that travels around the unit load. Since the unit load remains stationary during this stretch wrapping process, rotary tower machines are mainly used for heavy or unstable unit loads (Rogers, 2011).

Regardless of the method used, there are several key variables to consider when applying stretch wrap. These variables include prestretching the film, wrapping speed (either turntable speed or rotary tower arm speed), and wrapping pattern. Wrapping pattern includes number of wraps to be applied, location of the first wrap, and amount of overlap between wraps. Most of these variables would be difficult to control consistently during manual stretch wrapping methods. However, semi-automated and fully automated machines are able to control all of these variables through the use of sensors and photoelectric eyes (Rogers, 2011).

\subsubsection{Load Containment Force}

Load containment force refers to the amount force applied by the stretch wrap while securing the unit load. Elastic recovery, the tendency of stretch wrap to return to its initial state after being stretched, is directly related to load containment forces; hence, films with a higher elastic recovery will exhibit a greater containment force (Bisha, 2012). Load containment force can be manipulated by changing to a film with different mechanical properties or by controlling the variables associated with stretch wrap application. Temperature also plays a role in containment force due to the change in polymer rigidity as temperatures fluctuate (Brown, 1999).

Bisha (2012) looked at the relationship between stretch wrap prestretch and observed containment force. Unit loads were wrapped using varying levels of prestretch. An initial load containment force was recorded at three different locations (top, middle, and bottom of unit load). The wrapped unit loads were then put through the ISTA 3E (2018) testing sequence. Additional containment force measurements were recorded during and after testing. Bisha (2012) concluded there was no relationship between the amount of prestretch and the observed containment force. This was true for containment force measurements throughout the duration of Bisha's experiment. Since prestretch had no effect on containment force, it was recommended to use the highest level of prestretch possible in order to reduce the total amount of stretch wrap film used (Bisha, 2012).

Singh (2014) further explored this relationship between the tensile properties of stretch wrap and the measured containment force. The standard definition of containment force was 
separated into two distinct quantities of film stiffness and containment force. Film stiffness was measured on a face of the unit load while containment force was measured at the corners of the unit load. Both definitions include the measurement of the force at a given location. Although a thorough analysis of the tensile properties of stretch wrap was conducted, a linear model predicting the containment force based on tensile properties was considered impractical. Singh (2014) concluded that other factors, not controlled during the experiment, may play a role in understanding the relationship between stretch wrap properties and containment force. These factors may include the various stretch wrapper application settings.

\subsubsection{Testing/Standards}

ASTM D4649-03 Standard Guide for Selection and Use of Stretch Wrap Films (2016b) was created as a method for measuring and comparing the load containment force of a unit load. Two methods of measuring containment force are presented in this standard. One is referred to as the pull-plate method, and the other is referred to as the wrap-scale-in method. For the pull-plate method, a six-inch diameter plate is inserted behind the stretch wrap so that the center of the plate is 10 inches from the top and 18 inches from the side of the unit load. A ruler is placed next to the pull-plate, and it is used to measure the distance of the plate relative to the unit load. A fish scale is used to pull the plate away from the unit load, and the load containment force is defined as the amount of force (in pounds or Newtons) required to pull the stretch film a distance of four inches away from the unit load. The wrap-scale-in method uses a strain gauge, commonly a bathroom scale, to measure the containment force. The scale is held in place by the stretch wrap with the center of the scale located 10 inches from the top and 18 inches from the side of the unit load. The load containment force for this method is defined as the force displayed on the strain gauge after sitting undisturbed for five minutes.

Currently, there is no way to calculate the final containment force based on factors such as film properties or stretch wrap application variables. Using ASTM D4649-03 to measure containment force has its drawbacks. The quantification of load containment force can only be found through experimental testing, which is a trial and error approach. Also, containment forces are known to be higher at the corners of unit load than at the sides (Bisha, 2012). Since ASTM D4649-03 only measures containment forces on the sides of the unit load, the potential for an underestimation of maximum containment force exists. There is also inherent variability in the test 
procedures and even greater variability between the two methods. While this standard has its drawbacks, it is useful for making comparisons between different stretch wrapping solutions based on relative performance.

ASTM D4649-03 (2016b) references additional standards to verify the physical and mechanical properties of a given stretch wrap. These include breaking factor, cling, elastic recovery, stress retention, tensile strength, and yield (coverage) among others. There is also a section referencing standards pertaining to the performance of the stretch wrap in a unitized form. These include testing the abrasion resistance, determining the effects of vibration and horizontal impact, and evaluating the performance of unitized loads during handling. In addition to the tests referenced by ASTM D4649-03 (2016b), there are several standards established to evaluate the load stability of a unit load as it moves throughout the supply chain. The two most commonly used standards are ASTM D4169-16 Standard Practice for Performance Testing of Shipping Containers and Systems (2016a) and ISTA 3E Similar Packaged-Products in Unitized Loads for Truckload Shipment (2017). Both of these standards also reference other standardized tests available which can also be used to evaluate unit load performance.

Other attempts to quantify the effectiveness of stretch wrap include efforts by Lantech (2019) and Highlight Industries (2018). Lantech (2019) created a handheld measurement tool, called the CFT-6, as a different method of quantifying containment force. A containment force value is obtained through the use of the CFT- 6 by determining the force required to pull the stretch wrap a given distance away from the unit load. The CFT-6 allows the user to quantify the containment force through the use of a single measurement tool. Highlight Industries also created a portable measurement system which uses load cells to measure the containment force at up to three different locations (Park, 2015). The stretch wrap is applied directly over the load cells which then transmit real-time measurements to a computer.

\subsection{LOAD BRIDGING}

There are two different ways to analyze unit load interactions; determining the effect of the pallet on the packages or determining the effect of the packages on the pallet. Historically, research has focused on understanding how palletization and pallet design affects the packages (usually corrugated boxes) in the unit load. Several factors have been identified that influence the strength of corrugated boxes. These include the effect of box overhang (Monaghan and Marcondes, 1992), 
deckboard gap (Monaghan and Marcondes, 1992 and Baker, 2016), deckboard stiffness (Baker, 2016, Phanthanousy, 2017), stacking configuration (Singh et al., 2011 and Meng et al. 2007), and the contents of the packages (Frank et al., 2010). While these studies have all been influential in the advancement of our understanding of corrugated boxes, the affects that the corrugated boxes can have on the performance of the pallet, and therefore the unit load as a whole, have largely been ignored.

Recently, studies have focused on understanding how packages affect the performance of the pallet. Currently, design and testing methods for the more commonly used pallets assume a uniformly distributed load. However, the unit load rarely acts like a uniform load. Instead, a given load usually consists of a series of discrete concentrated loads, and the interactions between the packages forming the load (Fagan, 1982). This combination of discrete loading and physical interactions between packages results in a phenomenon referred to as load bridging. Load bridging causes the pressure distribution on top of the pallet to shift away from the center of the pallet and towards the supports which can result in a reduction of unit load deflection (Figure 10). The amount of load bridging is controlled by several factors that have all been studied by various researchers over the years.

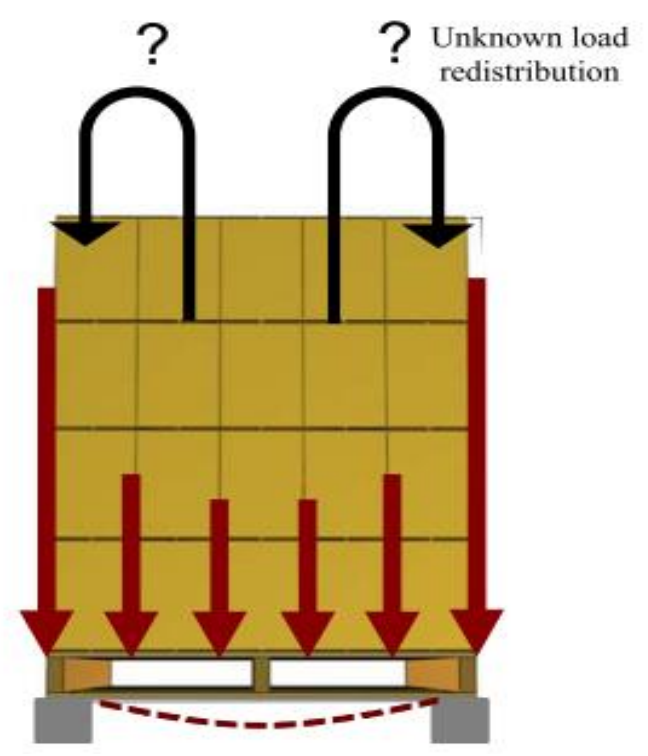

Figure 10: Example of the redistribution of the load away from the center of the pallet in a warehouse racking support condition for a stringer class pallet; a phenomenon known as load bridging (Molina, 2018)

The first person to study the idea of load bridging was Fagan (1982). He investigated the effect of various loading scenarios on four different stringer class pallets, each with a different 
stiffness. All tests were conducted in warehouse racking support conditions including warehouse racking across the width (RAW) and warehouse racking across the length (RAL). The loading scenarios used were selected to represent varying levels of load bridging. An airbag was used to simulate a uniform load with no load bridging. Boxes arranged in two different stacking patterns were used to create the low load bridging and medium load bridging scenarios. Two line loads were used to simulate a platen-type load with extreme load bridging. Fagan (1982) concluded that there is a significant difference in pallet deflection based on the method of loading (airbag vs. boxes vs. platen) and pallet stiffness. Fagan also determined that pallet stiffness determines the extent of the load bridging effect.

Collie (1984) further investigated the phenomenon of load bridging through several experiments. First, the stacking pattern and number of unit loads in the stack were examined for the three different stiffness stringer class pallets to determine their effect on load bridging. Six different stacking patterns, using either boxes or bags as the load, were tested and compared to the uniformly distributed load of an airbag as a control. Two of the stacking patterns were stacked both two and three unit loads high to determine the effect of the number of unit loads in a stack on load bridging. It was determined that for stringer class pallets in a stacking support condition, pallet stiffness, stacking pattern, and load type (bags vs. boxes), have no effect on the load distribution. The number of pallets in the stack was identified to be a significant factor in load distribution and adjustment factors were created to account for this effect.

The second of Collie's (1984) experiments looked at identifying various factors involved in load bridging for both warehouse racking across the width (RAW) and warehouse racking across the length (RAL) support conditions. Once again, three different stringer class pallets were used, each with a different stiffness. Five different loading types were chosen to represent varying levels of load bridging. An airbag was chosen to simulate no load bridging, bags were used to simulate low load bridging, two different arrangements of stacked boxes were used to simulate medium load bridging, and large rigid boxes were used to simulate extreme load bridging. Pallet deflection was measured as a determination of the effect of load bridging. Collie (1984) verified Fagan's (1982) results and concluded that load bridging displays a greater effect for low stiffness pallets and the effect disappears as the stiffness of the pallet increases. 
Collie (1984) also discovered that the support condition does affect load bridging for stringer class pallets. Pallets racked across the width experienced greater load bridging than those racked across the length due to the lower stiffness of a stringer class pallet when it's racked across the width. Collie (1984) was the first to address the fact that the number of boxes on a pallet directly affects the load bridging. Collie showed mathematically that as the number of boxes across the supports increase, the load is distributed across a greater number of discrete points, which apply more load across the pallet causing greater deflection. Conversely, as the number of boxes across the supports decrease, there are fewer discrete points which causes a higher percentage of the load to be shifted to the supports. Collie's (1984) analog models demonstrating the effect of box size on the extent of load bridging are shown in Figure 11. 


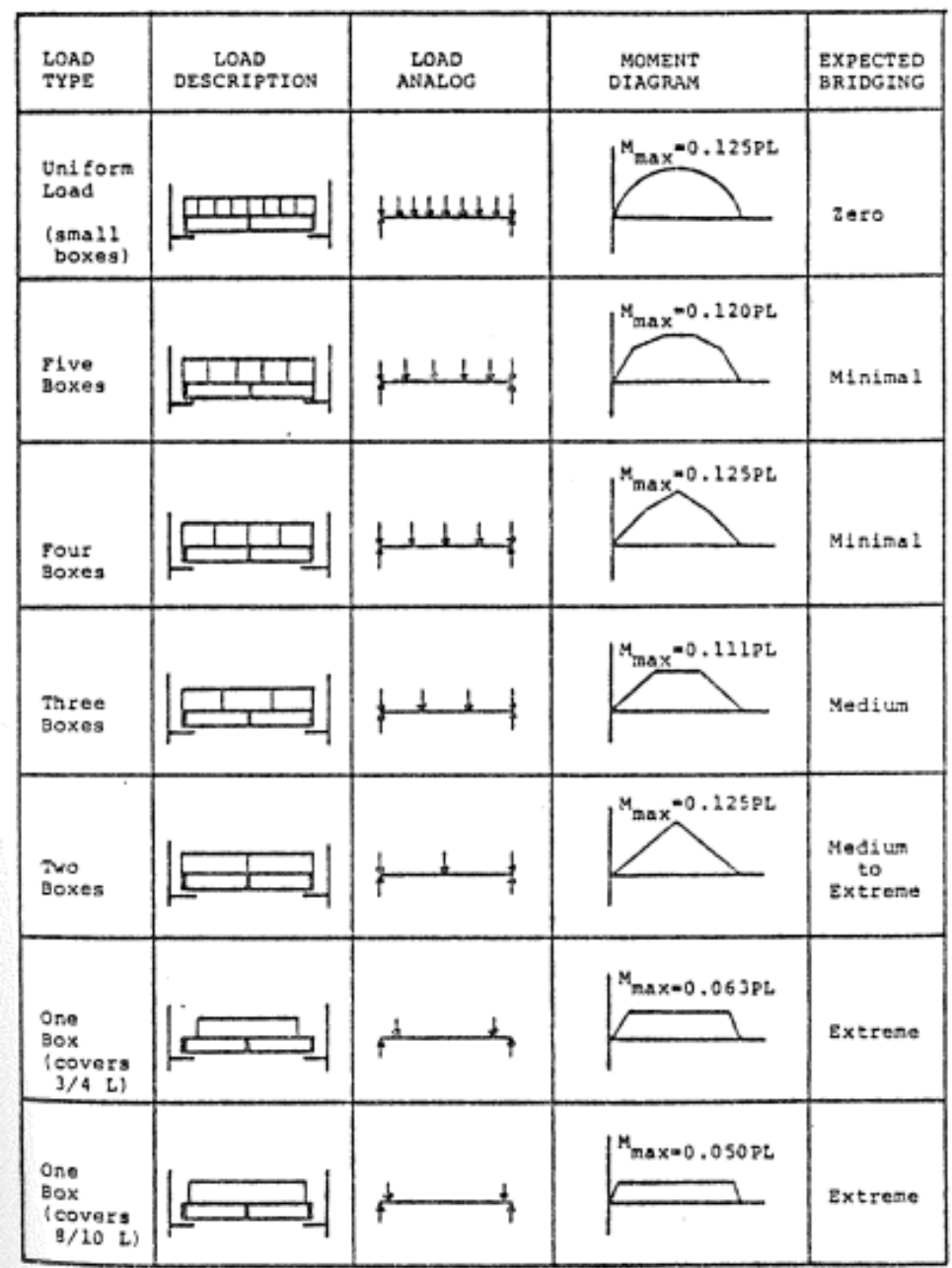

Note: $\mathrm{P}=\mathrm{wL} ; \mathrm{w}=$ load per unit length, $\mathrm{L}=$ span

Figure 11: Mathematical and analog models showing the effect of box size on the extent of load bridging (Collie, 1984)

Dr. White (Professor Emeritus of Wood Science and Forest Products at Virginia Tech) conducted research at Virginia Tech's Center for Unit Load Design in order to further understand the load bridging phenomenon. White (1999) tested a series of different loading configurations and various load stabilizers. He used plywood to simulate four pallets, each with a different stiffness, to determine the effect on load bridging in racked support conditions (White et al., 1999). The loads were selected to emulate different levels of load bridging. The loads used in this study included an airbag as a control (no load bridging), cinderblocks, sacks, cases, 5 gallon pails, and 55 gallon drums. The effect of load stabilizers was examined for all loading conditions except cinderblocks and included stretch tape, an interlocked stacking pattern, pallet sheets, stretch wrap, adhesive, and strapping. This study identified several factors which influence the extent of load 
bridging including the shape and stiffness of the packages, the type of load stabilizer used and its applied containment force, the stacking pattern, pallet stiffness, and unit load handling overtime. Although several factors were identified, many variables such as the containment force of the load stabilizers and the stiffness of the packages, were not controlled in any quantitative manner.

Yoo (2011) furthered the understanding of load bridging by creating a model using beam theory on an elastic foundation. Yoo (2011) looked at the stress distribution between the boxes and simulated pallet deckboards. Two different deckboard thicknesses, each with its own stiffness, were used to create simulated pallet segments, and three different loads were used (boxes of bottles, boxes of flour, and empty boxes) to represent variations in the packaging stiffness. Yoo (2011) concluded that stresses are non-uniformly distributed across pallets with stresses being higher near the supports and decreasing towards the middle of the spans. This same trend identified by Collie (1984) and Fagan (1982), of load bridging decreasing with pallet stiffness was also observed by Yoo (2011). It was also determined that packaging stiffness had an effect on the pressure distribution between boxes and pallets, although it has a minor role compared to pallet stiffness.

Park (2015) looked at the effect of box size and flute type on load bridging. Three different stiffness pallet segments and three different size boxes were used for testing. For the small boxes, the effect of flute type was investigated by comparing E-flute, B-flute, and BC-flute corrugated boxes. Park (2015) concluded that both box size and flute type had a significant effect on deflection and ultimately on load bridging. As box size increased, load bridging increased; hence, it reduced the unit load deflection. There was a $70 \%$ reduction in unit load deflection observed for all pallet stiffnesses, and up to a $76 \%$ reduction for low stiffness pallets was shown by switching from the uniform loading of an airbag to the discrete loading of large boxes. There was no significant difference in the deflection experienced by using B-flute versus BC-flute corrugated; however, switching to E-flute corrugated resulted in a reduction of unit load deflection between 19\%-23\% depending on pallet stiffness.

Park (2015) also investigated the effect of stretch wrap containment force on load bridging during warehouse racking support conditions. The experiment consisted of two different thicknesses of plywood to simulate different pallet stiffnesses, three levels of containment force $(0$ lbs., 30 lbs., and 60 lbs.), and three different package sizes. A pressure mat was used to determine 
the stress distribution. Deflection measurements were recorded and compared to those obtained from uniform loading with an airbag. Stretch wrap containment force had a significant effect on unit load deflection for small and medium boxes, but it had much less of an effect for large boxes due to the large amount of load bridging already occurring. Up to an $81 \%$ reduction in unit load deflection was observed by increasing the containment force from $0 \mathrm{lbs}$. to $60 \mathrm{lbs}$. for small boxes. This was also verified with the pressure mat, which showed a redistribution of pressure away from the center and towards the edges as containment force increased.

Phanthanousy (2017) conducted an experiment to understand how load bridging was affected by the contents of the packages. Three different box sizes (small, medium, and large) were examined along with three pallet segments, each with a different stiffness. The packages were filled with either OSB boxes, manufactured to the inside box dimensions, an OSB board with chamfered edges and a metal weight in the center, or wood pellets to represent a rigid, semi-rigid, or flexible package, respectively. The weight of each box size varied in order to keep the unit load weight consistent throughout testing. Phanthanousy (2017) established that package rigidity has no effect on load bridging across multiple box sizes and pallet stiffnesses. It was also determined that box size plays an important role in how the unit load is able to bridge the gap and different box sizes achieve load bridging through different mechanical means.

Molina (2017) studied the effect of stacking patterns on load bridging for stringer class pallets. The experiment consisted of a low, medium, and high stiffness pallet each tested with five different stacking patterns and across varying support conditions. The five stacking patterns included column stacking and two different stacking patterns each with a medium and high level of interlocking. The support conditions included floor stacking, warehouse racking across the width (RAW), warehouse racking across the length (RAL), and racked across the width fork tine support. Molina (2017) concluded that using any of the interlocked stacking patterns reduces unit load deflection especially when compared to column stacking support conditions where the pallet deflection was large enough to exhibit the effect. A pictorial example of how stacking pattern can affect unit load deflection is shown in Figure 12. The interlocked stacking pattern only presented a difference in deflection for low stiffness pallets under the RAW support condition. A load to stiffness ratio was created. It was identified that for high stiffness pallets with a low applied load, 
the effect of load bridging disappears. It is impractical to consider this effect when designing a unit load.
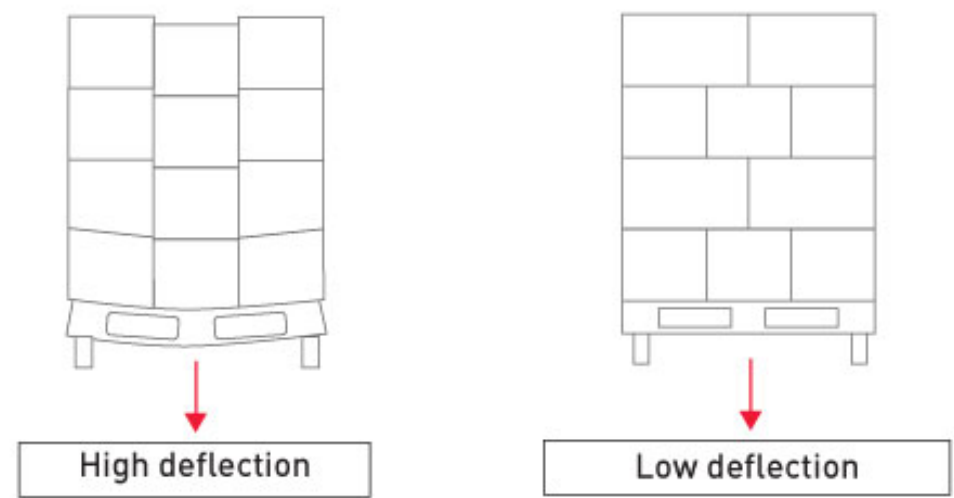

Figure 12: Example of effect of interlock stacking on pallet deflection (adapted from CABKA Group, 2019)

Clayton (2018) was the first to examine the effect of box size and headspace for stringer class pallets across multiple common support conditions using an actual unit load. For this experiment, three different pallet stiffness levels, two box headspace levels $(25.4 \mathrm{~mm}$ and $0 \mathrm{~mm})$, and three different box sizes were used (small, medium, and large). Clayton (2018) concluded that box size plays a significant role in the degree of load bridging for pallets racked across the width, with deflection decreasing as box size increases. For pallets racked across the length, the effect of box size on load bridging was only present for low and medium stiffness pallets. Under fork tine support conditions (both racked across the width fork tine and racked across the length fork tine) no load bridging was observed due to the very small deflection under this support condition. This data was used to create a finite element model used in the pallet design software PDS. Measurement methods were adopted from Clayton (2018), and they included methods of measuring pallet deflection and the pressure distribution across the top surface of the pallet.

Other factors known to affect load bridging include unit load height and the coefficient of friction between the components in a unit load; although, little research has been done to understand these factors in a quantitative manner. Park (2015) began to investigate the effect of unit load height on load bridging, in a preliminary study, he conducted as part of his dissertation. Park (2015) used a single box size as he constructed unit loads ranging from one to five layers in 
height. Plywood was used to simulate a pallet but only one thickness of plywood was used to represent a single pallet stiffness. The simulated pallet had 240 pounds evenly distributed between the given layers. It was determined that, as the unit load height increased, deflection decreased, and up to a $75 \%$ reduction in deflection can be observed by switching from one layer to five layers.

Although the concept of load bridging has been investigated by researching several different factors that were expected to influence pallet deflection, all research so far has focused around stringer class pallets. No research has been conducted to understand which factors affect load bridging for block class pallets. Investigating the load bridging phenomenon for block class pallets will give the packaging industry a more complete understanding of the factors to consider in unit load design. Once load bridging is fully understood, pallets can be designed for specific scenarios encountered throughout distribution. Ultimately, material costs can be reduced while maintaining desired performance ratings.

\section{Materials}

\subsection{Corrugated BoXes}

Regular slotted container (RSC) style corrugated boxes were used for this study. All boxes were production grade boxes manufactured by Packaging Corporation of America (PCA) in Roanoke, Virginia. The boxes were shipped flat with the industry standard manufacturers joint and constructed using C-Flute, single wall corrugated board with a nominal 44 lbs./inch Edge Crush Test (ECT) strength rating. Four sizes of boxes were manufactured. The inside dimensions and the type of corrugated board used for each box size is shown in Table 6.

Table 6: The specifications of the corrugated boxes used for the study.

\begin{tabular}{|c|c|c|c|c|c|}
\hline \multirow[b]{2}{*}{ Box Size } & \multicolumn{3}{|c|}{ Inside Dimensions (in.) } & \multirow{2}{*}{$\begin{array}{c}\text { Corrugated } \\
\text { Board }\end{array}$} & \multirow{2}{*}{$\begin{array}{c}\text { Filled Box } \\
\text { Weight } \\
\text { (lbs.) }\end{array}$} \\
\hline & Length & Width & Height & & \\
\hline Small & $119 / 16$ & $99 / 16$ & $111 / 4$ & C - flute & 21.3 \\
\hline Medium & $159 / 16$ & $1211 / 16$ & $11 \frac{1 / 4}{4}$ & C - flute & 38.3 \\
\hline Large & $119 / 16$ & $199 / 16$ & $11 \frac{1 / 4}{4}$ & $\mathrm{C}-$ flute & 44.4 \\
\hline
\end{tabular}




\subsubsection{Construction of the Boxes}

The box was first inserted into the $90^{\circ}$ corner jig to help with alignment and ensure squareness. The bottom flaps were secured using hot melt glue (3M $3762 \mathrm{TC)}$ by applying three parallel lines of glue on each small flap under each large flap. An example of the gluing pattern used on the bottom of the boxes is shown in Figure 13. A plywood board (PureBond 3/4 inch Maple Plywood) was placed on the bottom of the corrugated box while the remaining space was filled using wooden boards with nominal $2 \times 4,4 \times 4,2$ × 2 dimensions, random thicknesses of plywood, and corrugated inserts all cut to leave 0.75 inches of headspace. For the corrugated box designs without any headspace, two sheets of B/C-flute and two sheets of E-flute corrugated board inserts were used to fill the gaps. Standard 1.88 inch packaging tape from Staples was used to close the top flaps. The boxes were filled and then weighed using a floor scale (Arlyn Scales: model number MKE-5). The box weights ranged from 19.6 lbs. -23.2 lbs., 37 lbs. - 39.4 lbs., and 42 lbs. -46.8 lbs. for small, medium and large boxes respectively. Boxes were organized in such a way as to ensure that each column had the same weight and applied an even and symmetric load across the pallet.

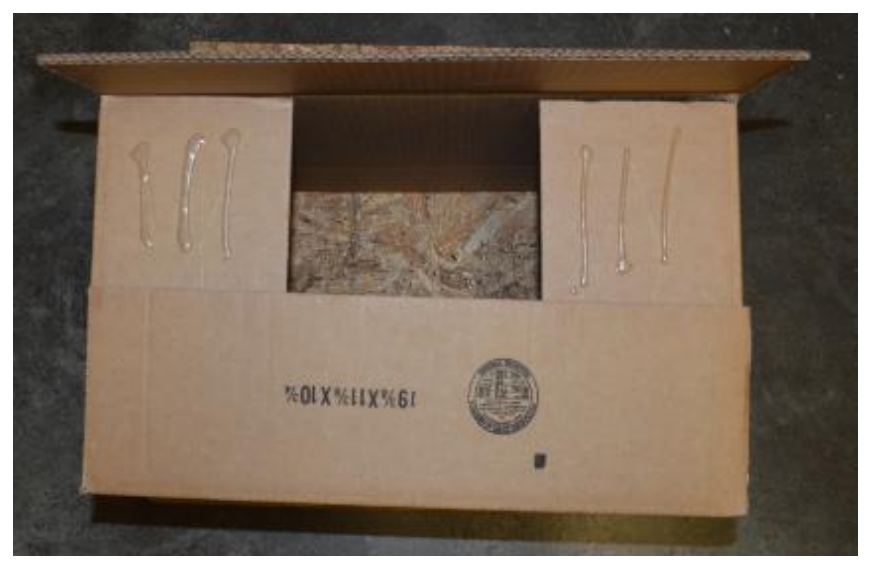

Figure 13: Gluing pattern for bottom of boxes

\subsection{Pallets}

Five unique full four-way, block class, non-reversible, 48 inch x 40 inch pallet designs were tested. One pallet was constructed of $1 / 2$ inch polycarbonate boards (Makrolon® General Purpose by Covestro) and four of the pallets were constructed of plywood boards (Baltic Birch, Grade B) with between 7-13 plies depending on component thickness. All boards were held together by a variety of \#6 and \#8 screws, depending on the component thickness and location of 
connection. Screws in line with blocks varied from 3.5 inches to 4 inches in length, while all other screws varied from 0.75 inches to 1.25 inches long. Adhesive was also used to secure pallet components together and to avoid any loosening of the connections. The adhesive used for the polycarbonate pallet was Weld On 16 manufactured by SciGrip Smarter Adhesive Solutions, as it was recommended for polycarbonate materials. The adhesive used for wooden pallets was Titebond III Ultimate Wood Glue.

The top deck boards for each pallet consisted of two lead deck boards (one on each end) along with five interior deck boards. The lead deck boards were 5.5 inches wide and the interior deck boards were 4 inches wide. All top deck boards were 40 inches long. Three stringer boards were used for each pallet design. The stringer boards were 4 inches wide and 48 inches long. All blocks were made by laminating sheets of 0.625 -inch plywood together and sanding in order to reach 3.5 inches in height. All blocks had a width of 4 inches in order to fully support the stringer boards. The length of the blocks along the width sides of the pallet ( 6 blocks total: 4 corners and 2 side blocks along the width) was 5.5 inches to fully support the 5.5 inch wide lead deckboards while the remaining blocks ( 3 blocks total: 2 side blocks along the length and the center block) were 4 inches long.

Four pallet designs were constructed with a perimeter base using five 4-inch-wide bottom deck boards. The fifth pallet design was constructed with a unidirectional base using three 4 inches wide parallel bottom deck boards. An example of both the perimeter base design and the unidirectional base design used for testing are shown in Figure 14. The top deckboard, stringer board, and bottom deckboard thicknesses were manipulated to create different pallet stiffnesses. The pallet stiffness, component thicknesses, pallet base designs, and the materials used to construct the pallet for each of the five designs tested are presented in Table 7. 


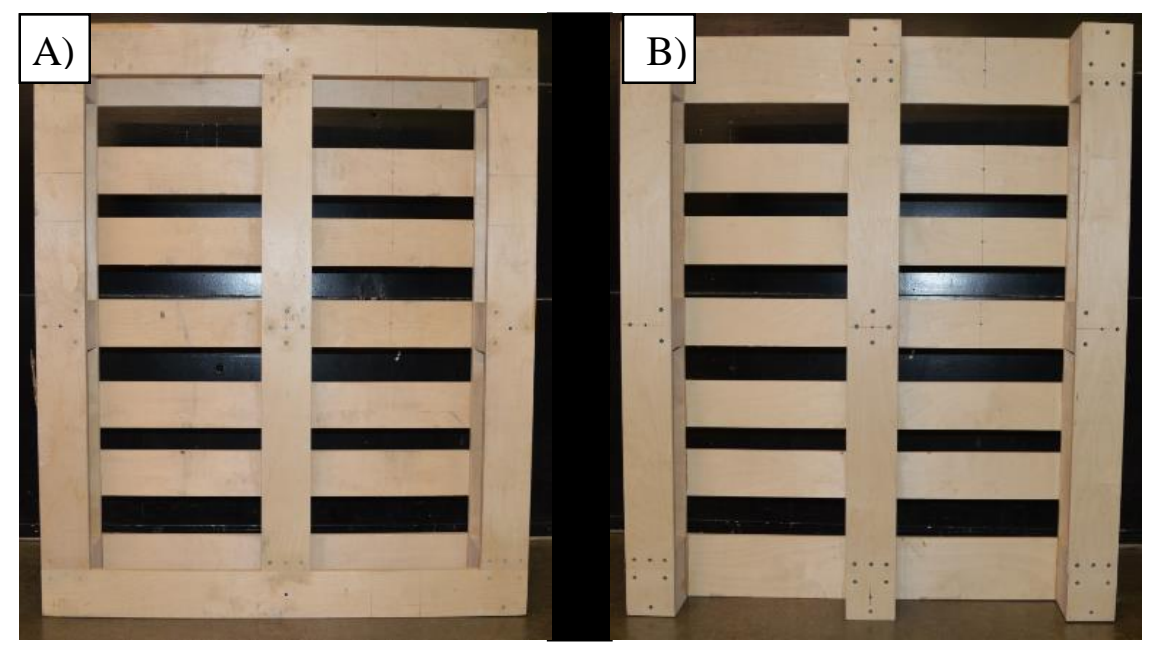

Figure 14: A) Perimeter Base Design B) Unidirectional Base Design

Table 7: Pallet designs by stiffness, component thickness, base design, and pallet material

\begin{tabular}{|c|c|c|c|c|}
\hline $\begin{array}{c}\text { Pallet } \\
\text { Stiffness }\end{array}$ & $\begin{array}{c}\text { Top Deck board } \\
\text { Thickness (in.) }\end{array}$ & $\begin{array}{c}\text { Other Boards } \\
\text { Thickness (in.) }\end{array}$ & Base Design & Pallet Material \\
\hline Very Low & 0.5 & 0.5 & Perimeter & Polycarbonate \\
\hline Low & 0.375 & 0.5 & Perimeter & Plywood \\
\hline Medium & 0.5 & 0.5 & Perimeter & Plywood \\
\hline Medium & 0.5 & 0.5 & Unidirectional & Plywood \\
\hline High & 0.625 & 0.625 & Perimeter & Plywood \\
\hline
\end{tabular}

\subsubsection{MOE of Pallet Components}

Before pallet assembly, the modulus of elasticity (MOE) for each pallet component was determined by using ASTM D3043-17: Standard Test Methods for Structural Panels in Flexure (2017b) (data in appendix A.1). A universal testing machine (MTS model number 244.31) with a 5,000lb load cell (model number 661.20E-01) was used to measure the load displacement curve. The boards were supported by two roller bearing supports spaced 44 inches apart for stringer boards and 36 inches apart for all other boards. The deflection was measured mid-span along the neutral axis using a linear variable differential transducer (LVDT) (Range of 2 inches and sensitivity of 0.0001 inches) secured to a wooden yoke. The yoke was supported on two wood screws positioned directly over the roller bearing supports ( 2 inches from either end). The load rate varied as the component thickness changed, and it was calculated using ASTM D3043-17 (2017b) (see appendix A.2). The load rate was calculated in order to reach the maximum load in a comparable time regardless of component thickness or length. The pallet components were sorted 
based on their measured MOE and each pallet was assembled to make sure that the performance of the pallet was symmetrical to its axes.

To measure the stiffness of the assembled pallet, the guidelines of ASTM D1185-98a (2017a) were followed during testing. The pallets were tested before and after data collection (data in appendix A.3), in a Tinius Olsen compression tester equipped with four 10,000 lb. load cells. Metal beams were used to simulate the investigated support conditions and a flexible airbag was used to apply the load. The pallets were loaded with $700 \mathrm{lbs}$. in 2 minutes. The deflection of the pallets was measured using string potentiometers (Model: P510-5-S10-N0S-30K) with a range of 5 inches and a sensitivity of $\pm 0.30 \%$.

\subsection{UNIT LOADS}

To build a unit load, the pallet was placed on the floor and a rubber mat was placed on top in the front right corner of the pallet. The rubber mat was used to help reduce any small errors or screw holes created during pallet construction from becoming pressure points on the pressure mat. Next, a pressure mat inside a plastic sleeve was aligned with the front right corner of the pallet (on top of the rubber mat). The pressure mat was used to determine the pressure distribution between various pallet and box interactions. The pressure mat used for this experiment was model number 7202 manufactured by Tekscan ${ }^{\mathrm{TM}}$ (specs in appendix A.4). The pressure mat was composed of sensels measuring 0.14 inches by 0.14 inches and arranged into 99 rows and 88 columns. The plastic for the sleeve was 0.0275-inch-thick polyethylene terephthalate (PET). I-Scan software (Tekscan ${ }^{\mathrm{TM}}$ ) was used to process the results. An external power supply was used to reduce extraneous noise in the pressure mat readings. The handle of the pressure mat was also grounded to reduce the noise experienced by the system. The pressure measurements were conducted using a sensitivity setting of S34.

The layout of the unit loads varied with the box sizes: small boxes ( 4 x 4 array), medium boxes ( 3 x 3 array), large boxes ( 4 x 2 array). All unit loads were constructed three layers tall. Small, medium, and large unit loads weighed around 1,013 lbs., 1,030 lbs., and 1,067 lbs. respectively. The amount of under-hang around the perimeter of the pallet ranged from 0 inches to 0.5 inches. The amount of under-hang was adjusted, so it was evenly distributed across the front, back, left, and right. 
The unit load was then stretch wrapped to reduce any movement of the boxes while transporting the unit load from one support condition to the next. The stretch film used was purchased from U-line and was model number S-1524. The thickness of the film was 80 gauge, and the film width was 20 inches. It was made from linear low-density polyethylene (LLDPE). The stretch wrapper used was the Highlight Synergy 4. The containment force of the applied stretch wrap was $12 \mathrm{lbs}$ measured using a Highlight Film Force Pull Kit (PTC-919) based on the guidelines of ASTM D4649-03: Standard Guide for Selection and Use of Stretch Wrap Films (2016b). The film was pre-stretched $200 \%$ before application and three top and three bottom layers were applied with a $40 \%$ overlap in the middle. The film force multiplier was set at $125 \%$ which resulted in a final film force of $43.5 \%$. The carriage speed was set at $15 \%$ while the turntable speed was 6rpm. The stretch wrap did not overlap the pallet as this would have interfered with the pressure mat and sleeve. However, a stretch film overlap was applied on the top of the unit load ranging between 0.75 inches and 1.25 inches depending on box alignment.

\section{METHODS}

The test sequence included moving a wrapped unit load through a cycle of four support conditions including warehouse racking across the width (RAW), warehouse racking across the length (RAL), single stacked floor storage, and double stacked floor storage. Deflection measurements and pressure mat readings were taken for each support condition. After the cycle, the unit load was taken apart and rebuilt using the same corrugated boxes. The cycle was repeated a total of three times.

\subsection{ZERO MEASUREMENTS}

Before and after each of the three cycles, zero measurements were taken for all support conditions. For the RAW and RAL support conditions, an empty pallet was placed on the appropriate support platform, and a $50 \mathrm{lb}$. weight was placed on each of the four corners of the pallet to reduce any bow or warp. For the floor stacking support condition, a pallet was placed on a level surface without any weights. To take the bottom deck board zero measurements for the top pallet in a double stacked condition, a unit load was first built and then a pallet was placed on top of the unit load. For all support conditions, deflection measurements were then taken at the appropriate locations and recorded as the zero measurements. 


\subsection{WAREHOUSE RACKING ACROSS THE WIDTH AND LENGTH}

The warehouse racking across the width and length support condition were set up according to ASTM D1185 (2017a). Two solid steel bars which measured 2 inches x 2 inches x 60 inches were spaced to simulate a warehouse racking support condition. A picture of the warehouse racking across the width support condition is shown in Error! Reference source not found.A. The inside to inside span of the bars was 36 inches for the RAW support condition (stringer boards parallel to supports) and 44 inches for the RAL support condition (stringer boards perpendicular to the supports). In both cases, the edges of the pallet were flush and square with the supports. A measurement jig, including a digital dial gauge (Mitutoyo C1050CEXB), was inserted under the pallet for both support conditions, and deflection measurements were taken at the appropriate locations. The locations of the deflection measurements for RAW (red and purple) and RAL (blue and purple) support conditions are shown in Figure 15B. After the deflection measurements were recorded, a pressure mat reading for that support condition was taken.
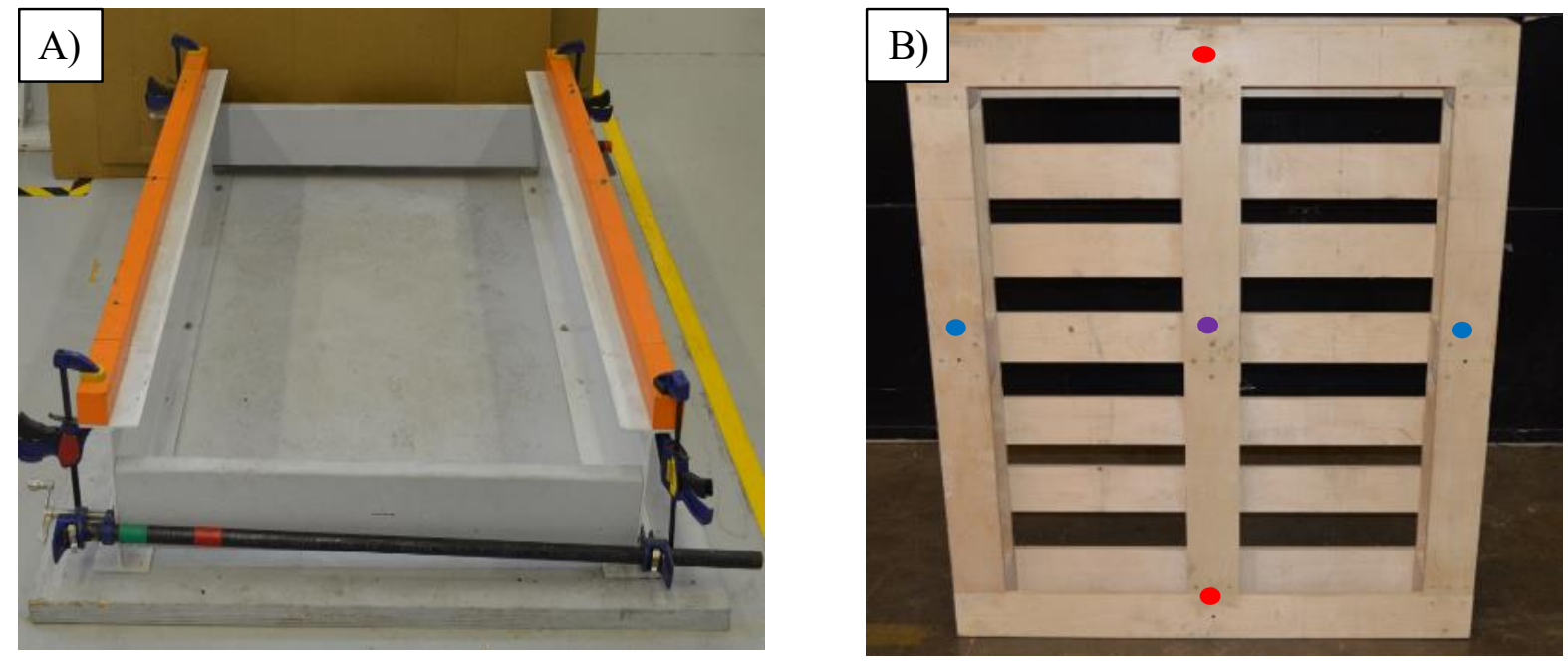

Figure 15: A) Example of warehouse racked across the width (RAW) support condition used during testing B) Measurement locations for warehouse racking across the width (red and purple) and warehouse racking across the length (blue and purple)

\subsection{SINGLE STACKED AND DOUBLE STACKED FLOOR SUPPORT}

For single stacked floor support, the unit load was placed on the floor. The deflection of the top deckboards were measured at six locations using a custom jig equipped with an analog dial gauge (Mitutoyo 2416S). The locations of these six deflection measurements taken in the front 
right of the pallet are shown in Figure 16A; four top deck board deflections (red) and two stringer board deflections (blue). After these were recorded, a pressure mat reading was taken.

For double stack floor support condition, a rubber mat and the TekScan 7202 pressure mat was placed to the front right corner on top of the bottom unit load. A unit load was constructed of the same size boxes and placed on the top of the pressure mat. Once the second, identical unit load was correctly aligned on top of the first unit load, deflection measurements were taken. This includes the same six deflection measurements taken for single stacked floor support condition along with an additional three bottom deck board measurements on the pallet in the second unit load as shown in Figure 16B. Then, two pressure mat readings are captured; one from the bottom unit load and one from the top unit load.

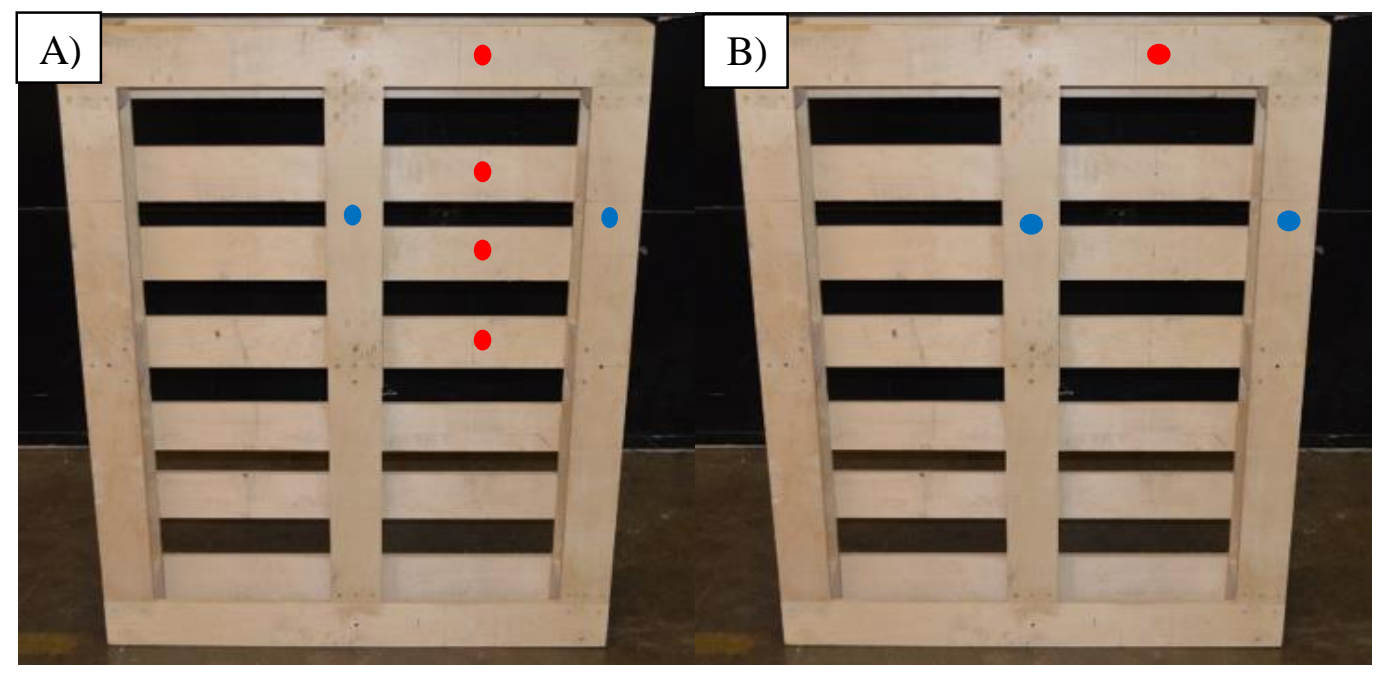

Figure 16: A) Top deckboard measurement locations for single stacked and double stacked support condition B) Bottom deckboard measurement locations for top pallet in a double stacked support condition

\subsection{HEADSPACE TESTING}

Additional testing was conducted using individual boxes in order to evaluate the effect of headspace. Boxes were constructed and filled in a manner consistent with unit load testing. Before testing, boxes were conditioned for a minimum of 72 hours at $23^{\circ} \mathrm{C}$ and $50 \%$ relative humidity in accordance with TAPPI T 402: Standard Condition and Testing Atmospheres for Paper, Board, Pulp Handsheets, and Related Products (2013). Five replicates for each combination of box size and headspace condition were conducted in a conditioned environment using a Lansmont Compression Tester (model Squeezer) using a 5,000 lbs. load cell. The loading rate was 0.5 inches 
per minute. Boxes were loaded until failure or greater than $1000 \mathrm{lbs}$ was reached. Loaddeformation curves along with pressure mat images were recorded for analysis.

\subsection{EXPERIMENTAL DESIGN}

Table 8: Experimental design for each of the four support conditions

\begin{tabular}{|c|c|c|c|}
\hline Pallet Design & Box Size & Headspace & Replicates \\
\hline \multirow{4}{*}{$\begin{array}{l}\text { Very Low Stiffness - } \\
\text { Perimeter Base }\end{array}$} & Small & \multirow{3}{*}{$\begin{array}{c}0.75^{\prime \prime} \\
\text { Headspace }\end{array}$} & 3 \\
\hline & Medium & & 3 \\
\hline & Large & & 3 \\
\hline & Medium & No Headspace & 3 \\
\hline \multirow{4}{*}{$\begin{array}{l}\text { Low Stiffness - } \\
\text { Perimeter Base }\end{array}$} & Small & \multirow{3}{*}{$\begin{array}{c}0.75^{\prime \prime} \\
\text { Headspace }\end{array}$} & 3 \\
\hline & Medium & & 3 \\
\hline & Large & & 3 \\
\hline & Medium & No Headspace & 3 \\
\hline \multirow{4}{*}{$\begin{array}{l}\text { Medium Stiffness - } \\
\text { Perimeter Base }\end{array}$} & Small & \multirow{3}{*}{$\begin{array}{c}0.75 " \\
\text { Headspace }\end{array}$} & 3 \\
\hline & Medium & & 3 \\
\hline & Large & & 3 \\
\hline & Medium & No Headspace & 3 \\
\hline \multirow{3}{*}{$\begin{array}{l}\text { High Stiffness - } \\
\text { Perimeter Base }\end{array}$} & Small & \multirow{2}{*}{$\begin{array}{c}0.75^{\prime \prime} \\
\text { Headspace }\end{array}$} & 3 \\
\hline & Medium & & 3 \\
\hline & Medium & No Headspace & 3 \\
\hline \multirow{3}{*}{$\begin{array}{l}\text { Medium Stiffness - } \\
\text { Unidirectional Base }\end{array}$} & Small & \multirow{2}{*}{$\begin{array}{c}0.75^{\prime \prime} \\
\text { Headspace }\end{array}$} & 3 \\
\hline & Medium & & 3 \\
\hline & Medium & No Headspace & 3 \\
\hline
\end{tabular}

This experimental design included four different support conditions, five different pallet stiffnesses, two headspace treatments, and three box sizes (Table 8). Only the medium boxes were tested using the no headspace condition while all other box sizes were tested using 0.75 inches of headspace. Three replicate tests were conducted for each treatment level. During the repetitions, the same boxes were restacked to simulate variations due to box positioning. The order of support conditions remained the same and was repeated in a pattern called a cycle. The cycle for this research included testing the support conditions in the following order: warehouse racking across the width (RAW), warehouse racking across the length (RAL), single stack, and double stack. 


\subsection{STATISTICAL ANALYSIS}

Statistics were analyzed with the aid of the statistical analysis software, JMP. Several different Type III analysis of variance (ANOVA) models were created in an effort to analyze all aspects of the data collected. All models were checked to make sure the assumptions of homoscedasticity and normality were met. First, models were created to examine if the presence of 0.75 inches of headspace compared to no headspace had any effect on pallet deflection for medium boxes given different combinations of support conditions and measurement locations. Next, Type III ANOVA models were created to examine the effect of pallet stiffness, box size, and the interaction between the two for boxes with headspace across all combinations of support conditions and measurement locations. Finally, ANOVA models were created to determine if there was any effect from base design on pallet deflection. For all models, a post-hoc multiple comparison was made using Tukey's Honest Significant Difference test at alpha level 0.05 to determine individual differences among box sizes for any given pallet stiffness.

\subsection{ASSUMPTIONS}

5.7.1. The levels of friction present between different layers, between the sides of boxes in a given layer, and between the bottom layer of boxes and the pressure mat sleeve are considered to be consistent across all box sizes due to the consistent nature of the corrugated board used to manufacture the boxes

5.7.2. Different pallet stiffnesses were achieved by changing the thickness of various components including the top deckboards, the stringer boards, and the bottom deckboards

5.7.3. The screw fasteners used for pallet construction are less likely to experience withdrawal (compared to nails); therefore, with the addition of an adhesive, will be better suited for maintaining pallet stiffness throughout the duration of the experiment.

5.7.4. The number of layers was fixed at 3 because most unit loads are not taller than 50 inches to allow double stacking in a trailer

5.7.5. The level of containment force was fixed at $12 \mathrm{lbs}$. which represents the lowest amount of containment force that still results in a stable unit load. 
5.7.6. The unit load weight was chosen in order to be able to safely evaluate large boxes given a double stacked support condition based on the box strength estimate calculated using the McKee equation and with a safety factor of 3.

5.7.7. The filler material in the corrugated boxes was assumed to be rigid. The plywood board on the bottom of the boxes was added to restrict vertical movement of the boards and thus prevent shearing forces from occurring within the box.

5.7.8. The corrugated boards that were used to fill the headspace for the no headspace scenario were assumed to stay rigid under the applied loading conditions.

5.7.9. There was no effect on observed deflection caused by taking measurements for the various support conditions in the same order every time (in a cycle).

\section{RESULTS AND DISCUSSION}

For both warehouse racking across the width (RAW) and warehouse racking across the length (RAL), the center measurement location consistently experienced greater deflection than either of the end measurement locations. Previous studies have also concluded that the center of the pallet experiences the greatest deflection in warehouse racking support conditions (Fagan 1982, Park 2015). Since the load carrying capacity of a pallet is determined by the maximum deflection, analysis of warehouse racking support conditions in this paper will focus only on center deflections. For the single and double stacked floor support conditions, several different comparisons were made. The top deckboard deflection measurements were analyzed separately from the stringer board deflection measurements. In both cases, the worst deflection was reported and considered for analysis. In addition to the top deckboard and the stringer board deflection measurements, bottom deckboard deflection measurements were analyzed across the width and across the length for the top pallet in all double stacked floor support conditions.

Initially, the effect of headspace for medium boxes was investigated for each combination of support locations and measurement locations. This was done by conducting an analysis of variance (ANOVA) test on medium boxes for each group to be analyzed. Additional testing was conducted using small and large boxes in order to understand differences in the effect of headspace for the various support conditions exhibited during initial analysis. Next, each combination of support condition and measurement location was examined through additional ANOVA models in 
order to determine the effect of pallet stiffness, box size, and the interaction between the two on pallet deflection. Finally, a comparison between two medium stiffness pallets (one with a perimeter base and one with a unidirectional base), was examined in all applicable support conditions. No comparisons of the base designs were made for the warehouse racked across the width (RAW) since the unidirectional base design was never tested in this support condition.

\subsection{HEADSPACE VERSUS NO HEADSPACE}

The effect of 0.75 inches of headspace versus no headspace on pallet deflection for medium boxes sized was investigated using an analysis of variance (ANOVA) test for each combination of support condition and measurement location investigated. The results of the ANOVA effects tests for the headspace main effect and the interaction between pallet stiffness and headspace are shown in Table 9. The effect of headspace on deflection for pallets under the two racking support conditions (RAW or RAL) was not significant. This was also true for the bending of top deckboards and stringer boards of pallets in a single stacked condition and the length side of the bottom deckboards of the top pallet during the double stacked condition. However, the effect of headspace was determined to be statistically significant for other pallet components investigated in the double stacked floor support condition. This includes top deckboards and stringer boards for the bottom pallet and the width side bottom deckboard of the top pallet. 
Table 9: Analysis of variance (ANOVA) based on maximum pallet deflection across multiple support conditions.

\begin{tabular}{|c|c|c|c|}
\hline \multirow{2}{*}{$\begin{array}{c}\text { Support } \\
\text { Condition }\end{array}$} & Components & Headspace & $\begin{array}{c}\text { Pallet Stiffness } \\
* \text { Headspace }\end{array}$ \\
\cline { 2 - 4 } & - & 0.3109 & 0.8878 \\
\hline $\begin{array}{c}\text { Racked Across the } \\
\text { Width (RAW) }\end{array}$ & - & 0.3987 & 0.6689 \\
\hline $\begin{array}{c}\text { Racked Across the } \\
\text { Length (RAL) }\end{array}$ & - & 0.1218 & $0.0037^{*}$ \\
\hline Single Stacked & Top deckboards & 0.9163 & 0.2725 \\
\cline { 2 - 4 } & Stringer boards & $0.0000^{*}$ & $0.0198^{*}$ \\
\cline { 2 - 4 } & $\begin{array}{c}\text { Top deckboards } \\
\text { Stringer boards }\end{array}$ & $0.0031^{*}$ & 0.1282 \\
\cline { 2 - 4 } & $\begin{array}{c}\text { Second Pallet - Width } \\
\text { Bottom Deckboards }\end{array}$ & $0.0144 *$ & 0.0916 \\
\cline { 2 - 4 } & $\begin{array}{c}\text { Second Pallet - Length } \\
\text { Bottom Deckboards }\end{array}$ & 0.37268 & 0.43825 \\
\hline
\end{tabular}

Note: p-values less than 0.05 indicate a statistically significant main or interaction effect and were marked with*.

The interaction of pallet stiffness and the headspace condition was shown to be statistically significant for top deckboards in both single stacked and double stacked scenarios. The Tukey HSD comparisons of headspace for worst top deckboard deflections are given for each pallet stiffness in Table 10. For pallets in the single stacked scenario, only the high stiffness pallet showed a difference between headspace and no headspace. For pallets in the double stacked scenario a statistical difference was observed for both the very low stiffness pallet and the high stiffness pallet. 
Table 10: Worst single stacked and double stacked top deckboard deflection measurements for 0.75 inches of headspace and no headspace along with a p-value to represent probability of being statistically different

\begin{tabular}{|c|c|c|c|c|c|c|}
\hline \multirow[b]{2}{*}{ Pallet Stiffness } & \multicolumn{3}{|c|}{ Single Stacked } & \multicolumn{3}{|c|}{ Double Stacked } \\
\hline & $\begin{array}{c}\text { Headspace } \\
\text { (in.) }\end{array}$ & $\begin{array}{c}\text { No Headspace } \\
\text { (in.) }\end{array}$ & P-value & $\begin{array}{c}\text { Headspace } \\
\text { (in.) }\end{array}$ & $\begin{array}{c}\text { No Headspace } \\
\text { (in.) }\end{array}$ & P-value \\
\hline Very Low & 0.046 & 0.056 & 0.8537 & 0.087 & 0.068 & $0.0095^{*}$ \\
\hline Low & 0.031 & 0.020 & 0.8749 & 0.042 & 0.031 & 0.2802 \\
\hline $\begin{array}{l}\text { Medium- } \\
\text { Perimeter }\end{array}$ & 0.018 & 0.012 & 0.8537 & 0.031 & 0.021 & 0.4392 \\
\hline High & 0.030 & 0.008 & $0.0285^{*}$ & 0.035 & 0.014 & $0.0017^{*}$ \\
\hline $\begin{array}{c}\text { Medium- } \\
\text { Unidirectional }\end{array}$ & 0.026 & 0.037 & 0.7802 & 0.038 & 0.037 & 1.0000 \\
\hline
\end{tabular}

Note: p-values less than 0.05 indicate a statistically significant difference between headspace and no headspace for a given support condition and pallet stiffness and were marked with *.

In order to further understand the differences between the behavior of the boxes with 0.75 inches of headspace and no headspace in single and double stacked scenarios, additional testing was conducted. Pressure mat images for small and large boxes with and without headspace under single stacked and double stacked loads are displayed in Figure 17 and Figure 18. The images were captured at a load corresponding to that experienced for a single unit load ( $42 \mathrm{lbs}$. for small and $\sim 89$ lbs. for large boxes) and a double stacked unit load ( 87 lbs. for small and 183 lbs. for large boxes). Visually comparing the images, no obvious effect of headspace is apparent at the experimental weights used for unit load construction. However, a difference between the double stacked images of large boxes with and without headspace starts to display some signs of increased pressure distribution through the length side walls. 

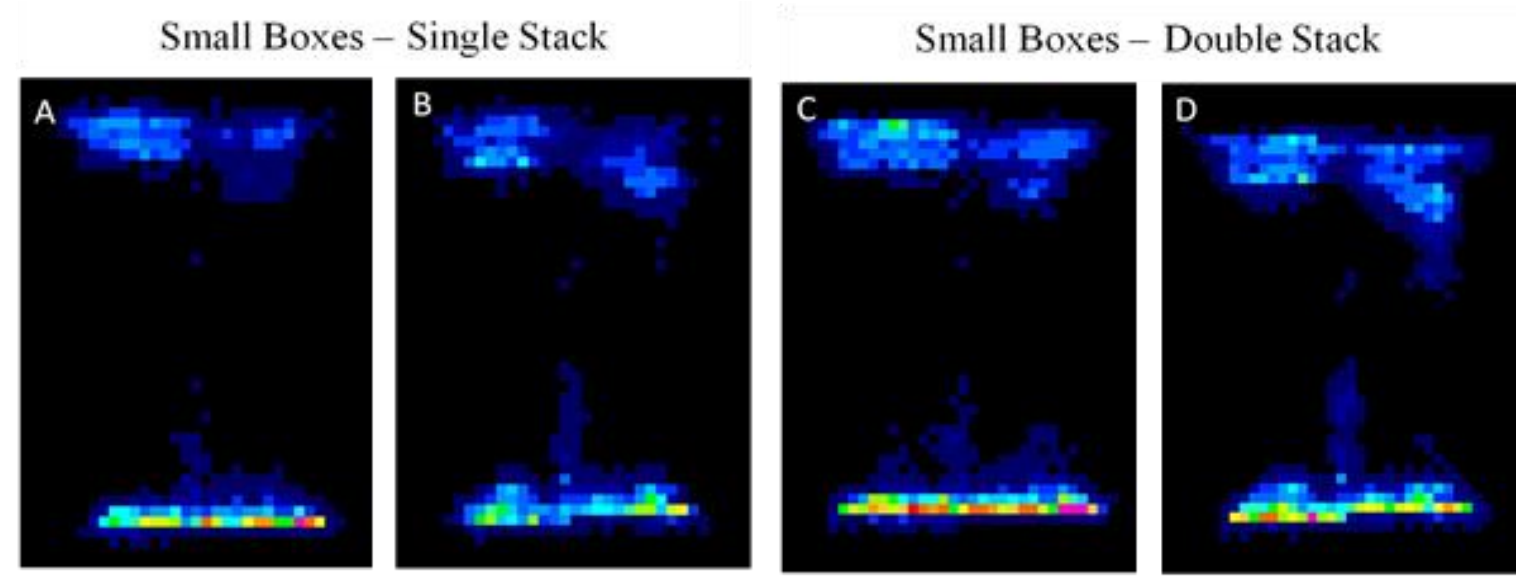

Figure 17:Small box pressure mat data comparison for A) Single stacked boxes with headspace B) Single stacked boxes without headspace C) Double stacked boxes with headspace D) Double stacked boxes without headspace
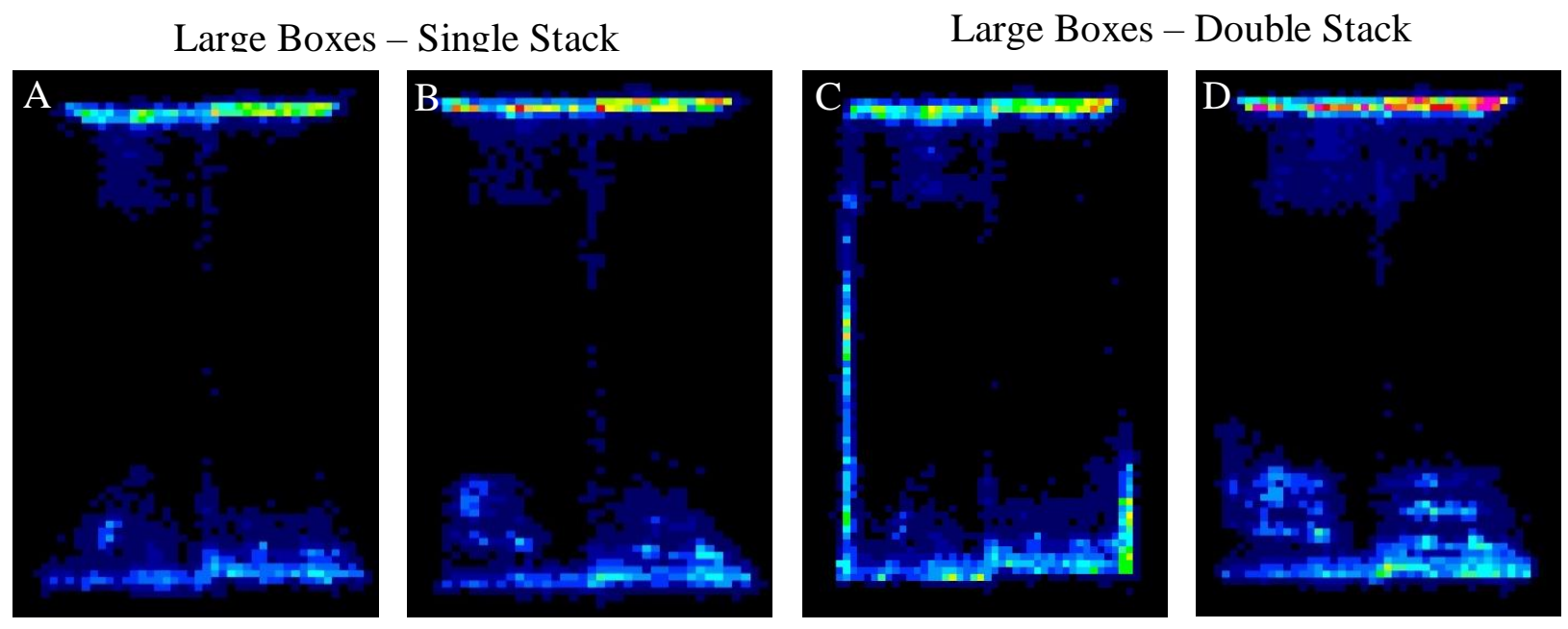

Figure 18: Large box pressure mat data comparison for A) Single stacked boxes with headspace B) Single stacked boxes without headspace C) Double stacked boxes with headspace D) Double stacked boxes without headspace

The average load-deformation curves for small and large boxes with and without headspace are shown in Figure 19 and Figure 20. The load deformation curve of the boxes with and without headspace start to divert after $200 \mathrm{lbs}$. for small boxes and after $175 \mathrm{lbs}$. for large boxes. Since the compression load on the boxes during the investigated single stack and double stack conditions were well below the point when the load-deformation curves started do deviate from each other, no difference in box performance should be expected. 


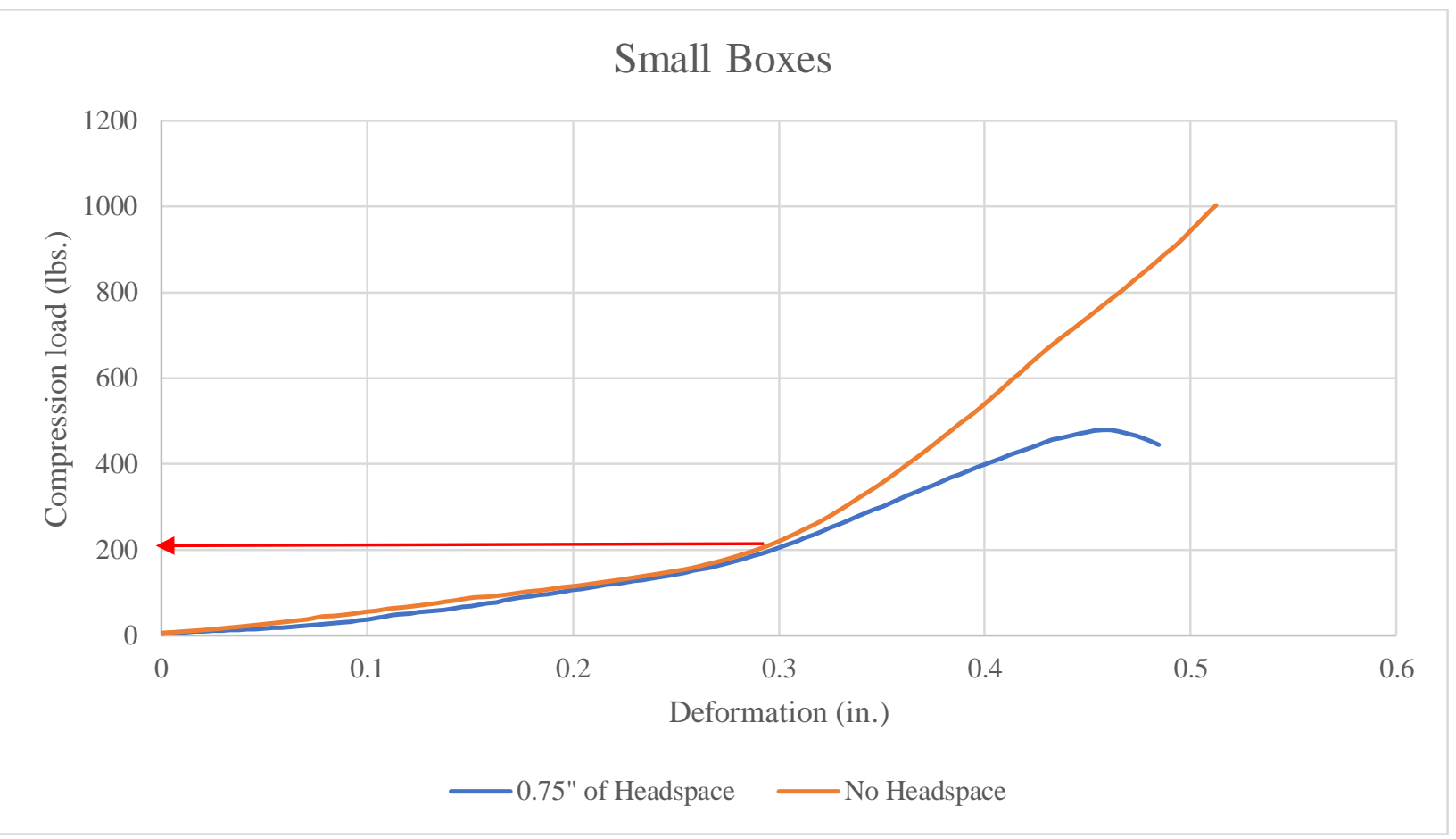

Figure 19: Load-deformation curve for small boxes with 0.75 inches of headspace and without headspace.

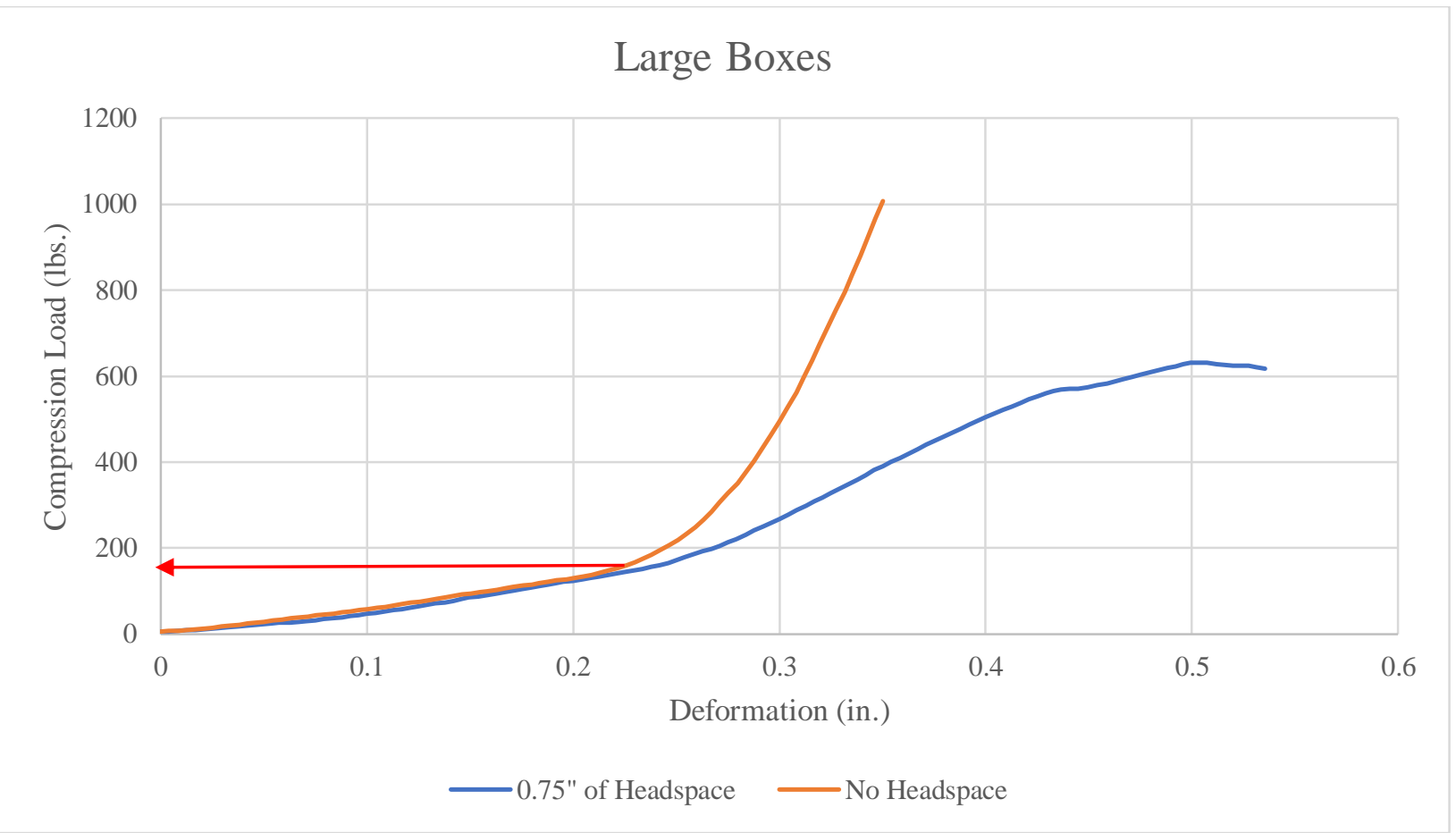

Figure 20: Load-deformation curves for large boxes with 0.75 inches of headspace and without headspace 
In order to observe a difference between small boxes with and without headspace, over 200 lbs. of force must be experienced by each of the sixteen bottom boxes in a single unit load. Including the weight of the bottom layer of boxes, this equates to a unit load payload of over 3,500 lbs. Since general use pallets are typically designed to carry a maximum working load of 2,800 lbs. (Cleveland Consulting Associates, 1990), the effect of headspace for small boxes on the pressure distribution and the deflection of a pallet during warehouse racking conditions and single stacked conditions is not significant. However, as the number of unit loads in a stack increases, the combined weight must be considered when determining if headspace will have an effect.

The pressure distribution using large boxes during warehouse racking conditions and single stacking conditions is not affected by the presence of headspace for unit load weights below 1,750lbs. For this experiment, unit load weights did not exceed 1,100 lbs. and consequently no effect from headspace was observed for pallets in warehouse racking conditions or single stacked conditions. Meanwhile, the double stacked scenario applied almost 2,200 lbs. of pressure to the bottom pallet and thus began to present a difference between large boxes with 0.75 inches of headspace compared to large boxes with no headspace. This means that the effect of headspace might be significant at the common load levels used on general use pallets, therefore, more investigation is needed.

In general, it appears that the effect of headspace is a function of box size. This effect can be attributed to the difference in box geometry between small and large boxes. The minor flaps on a small box measured $47 / 8$ inches each while the minor flaps on a large box measure $57 / 8$ inches each. This means that the minor flaps of a small box support $84 \%$ of the major flaps while the minor flaps of a large box only support $60 \%$ of the major flaps. An image representing this concept is shown in Figure 21. This difference results in the major flaps of a large box being supported by a longer span when compared to the major flaps of a small box. The longer span of the major flaps created by the box geometry of a large box is able to bend more than the shorter span of the major flaps in a small box; therefore, they exhibit a difference between headspace and no headspace at a lower weight. However, additional research should be done in order to understand this phenomenon further. 


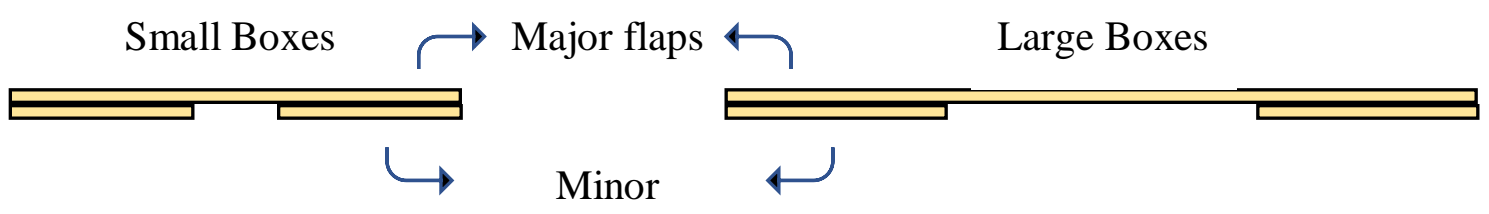

Figure 21: Support provided to major flaps by minor flaps for small and large boxes

\subsection{WAREHOUSE RACKING ACROSS THE WIDTH (RAW)}

\subsubsection{Deflection}

An analysis of variance (ANOVA) test was carried out to determine the effects of box size, pallet stiffness, and the interaction between them for pallets in the warehouse racking across the width (RAW) support condition. The ANOVA table is shown in Table 11 and the results of the effects tests are shown in Table 12. Both pallet stiffness and box size were determined to have statistically significant effects on the deflection of pallets in the RAW support condition. The interaction between pallet stiffness and box size was also concluded to be statistically significant. This means that the effect of box size on pallet deflection is dependent on pallet stiffness. An interaction plot is shown in Figure 22. It appears that as pallet stiffness increases, there is less of a difference in deflection between the various box sizes; This implies that load bridging has a greater effect on lower stiffness pallets.

Table 11: Analysis of variance (ANOVA) table for warehouse racking across the width model

\begin{tabular}{|c|c|c|c|c|}
\hline Source & DF & Sum of Squares & Mean Square & F Ratio \\
\hline Model & 10 & 0.27866666 & 0.027867 & 151.2873 \\
\hline Error & 22 & 0.00405233 & 0.000184 & Prob $>$ F \\
\hline C. Total & 32 & 0.28271900 & & $<.0001^{*}$ \\
\hline
\end{tabular}

Table 12: Analysis of variance (ANOVA) effects tests for warehouse racking across the width model

\begin{tabular}{|c|c|c|c|c|c|}
\hline Source & Nparm & DF & Sum of Squares & F Ratio & Prob > F \\
\hline Pallet Stiffness & 3 & 2 & 0.13906030 & 377.4772 & $<.0001 *$ \\
\hline Box Size & 2 & 1 & 0.00571959 & 31.0515 & $<.0001 *$ \\
\hline Pallet:Box Size & 6 & 5 & 0.02274098 & 24.6920 & $<.0001 *$ \\
\hline
\end{tabular}




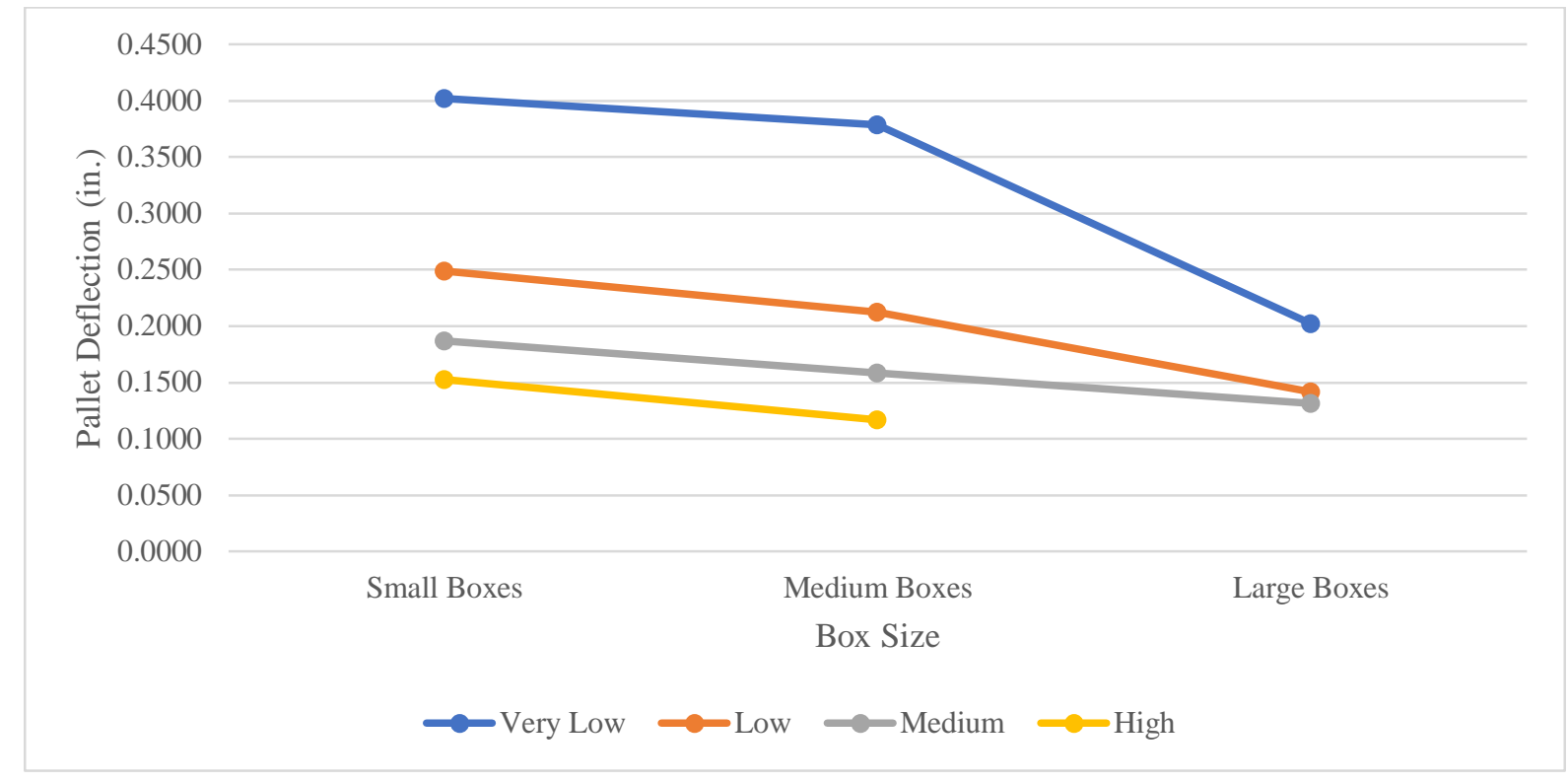

Figure 22: The effect of pallet stiffness on the pallet deflection as a function of box size for the warehouse racking across the width support condition.

Average center deflection for pallets in the warehouse racking across the width (RAW) support condition are shown in Table 13 and represented graphically in Figure 23. It was determined that deflection was significantly affected by a change from small boxes to large boxes, regardless of pallet stiffness. The largest reduction in deflection was $50 \%$, and it was achieved by changing from small boxes to large boxes on the very low stiffness pallet. This is consistent with previous research which has shown that the effect of load bridging is most pronounced for lower stiffness pallets (Fagan 1982, Collie 1984, Yoo 2011, Park 2015).

Table 13: Average pallet center deflection and the percent difference in reference to the small boxes during the warehouse racking across the width support condition using boxes with headspace.

\begin{tabular}{|c|c|c|c|c|c|c|c|c|c|c|c|c|}
\hline \multirow{2}{*}{$\begin{array}{c}\text { Box } \\
\text { Size }\end{array}$} & \multicolumn{10}{|c|}{ Pallet Deflection (in.) } \\
\cline { 2 - 12 } & \multicolumn{2}{|c|}{ Very Low } & \multicolumn{3}{c|}{ Low } & \multicolumn{2}{c|}{ Medium } & \multicolumn{3}{c|}{ High } \\
\hline Small & $\begin{array}{c}0.4018 \\
(0.0161)\end{array}$ & A & & $\begin{array}{c}0.2490 \\
(0.0038)\end{array}$ & A & & $\begin{array}{c}0.1866 \\
(0.0169)\end{array}$ & A & & $\begin{array}{c}0.1529 \\
(0.0106)\end{array}$ & A & \\
\hline Medium & $\begin{array}{c}0.3790 \\
(0.0264)\end{array}$ & A & $-6 \%$ & $\begin{array}{c}0.2126 \\
(0.0155)\end{array}$ & A & $-15 \%$ & $\begin{array}{c}0.1581 \\
(0.0095)\end{array}$ & A/B & $-15 \%$ & $\begin{array}{c}0.1171 \\
(0.0085)\end{array}$ & A & $-23 \%$ \\
\hline Large & $\begin{array}{c}0.2021 \\
(0.0023)\end{array}$ & B & $-50 \%$ & $\begin{array}{c}0.1413 \\
(0.0141)\end{array}$ & B & $-43 \%$ & $\begin{array}{c}0.1314 \\
(0.0070)\end{array}$ & B & $-30 \%$ & & \\
\hline
\end{tabular}

Note: The values in parentheses are standard deviations. The letters were determined by running a Tukey HSD with an alpha level of 0.05. Different letters for a given pallet stiffness represent statistically significant differences in expected pallet deflection 


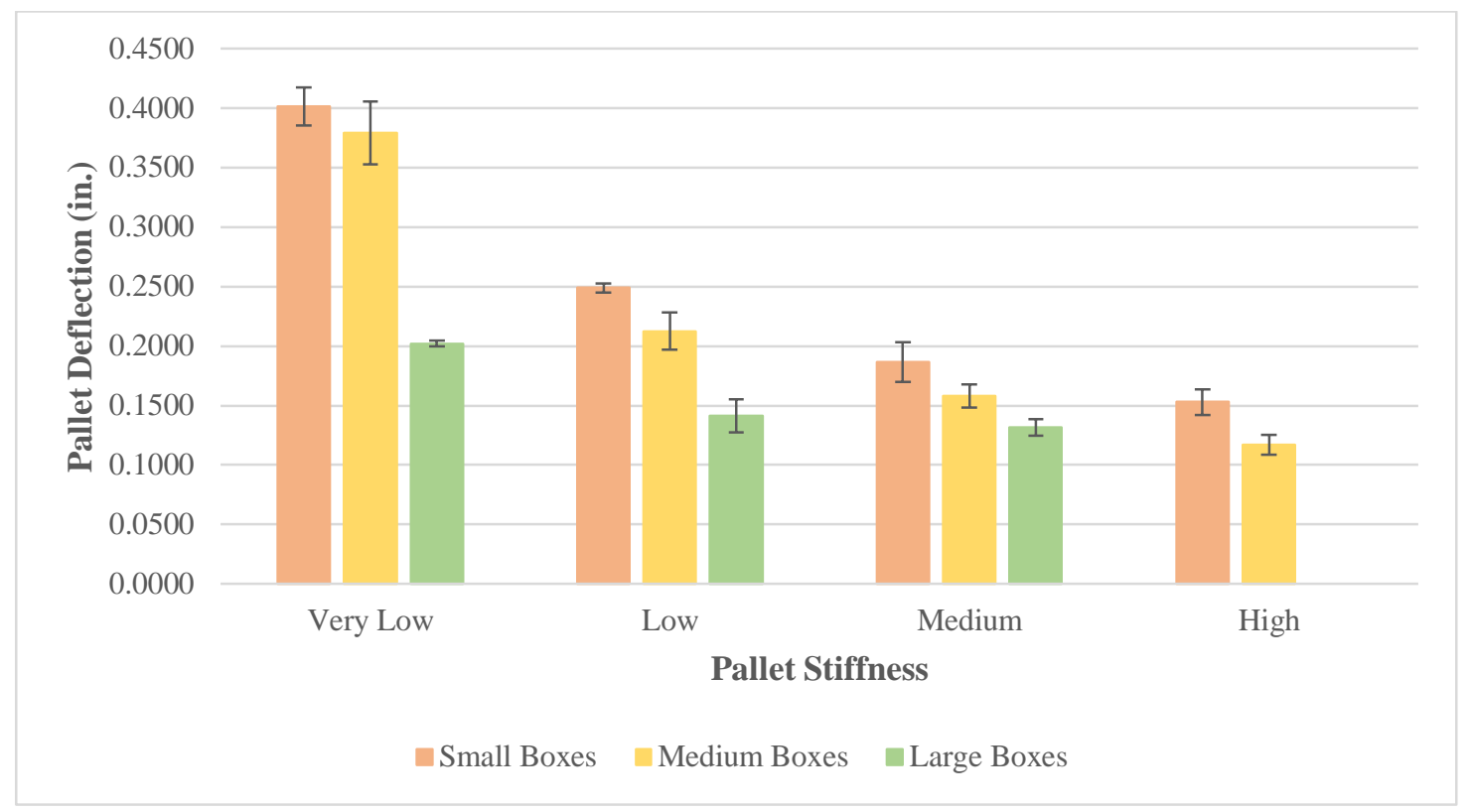

Figure 23:Average pallet center deflection during the warehouse racking across the width support condition using boxes with 0.75 in. headspace. The whiskers represent standard deviation.

\subsubsection{Pressure Mat}

In order to understand how the pressure distribution displayed in a two-dimensional array interacted with a pallet in the warehouse racking across the width (RAW) support condition, further analysis was conducted. The steps of analyzing the pressure mat data are shown in Figure 24. First, the pressure mat image of a half pallet was mirrored to create a whole pallet. Then, the two-dimensional array of sensels was summed across the rows parallel to the supports to create a one-dimensional array which could be graphed according to distance across the pallet (in inches). Finally, point loads were assumed to occur at the edges of each box. The principle of tributary area was used to assign half of a given box's pressure to each box edge. An example of the method used to assign tributary area to each point load for small boxes is shown in Figure 24 along with the point loads for medium and large boxes. 


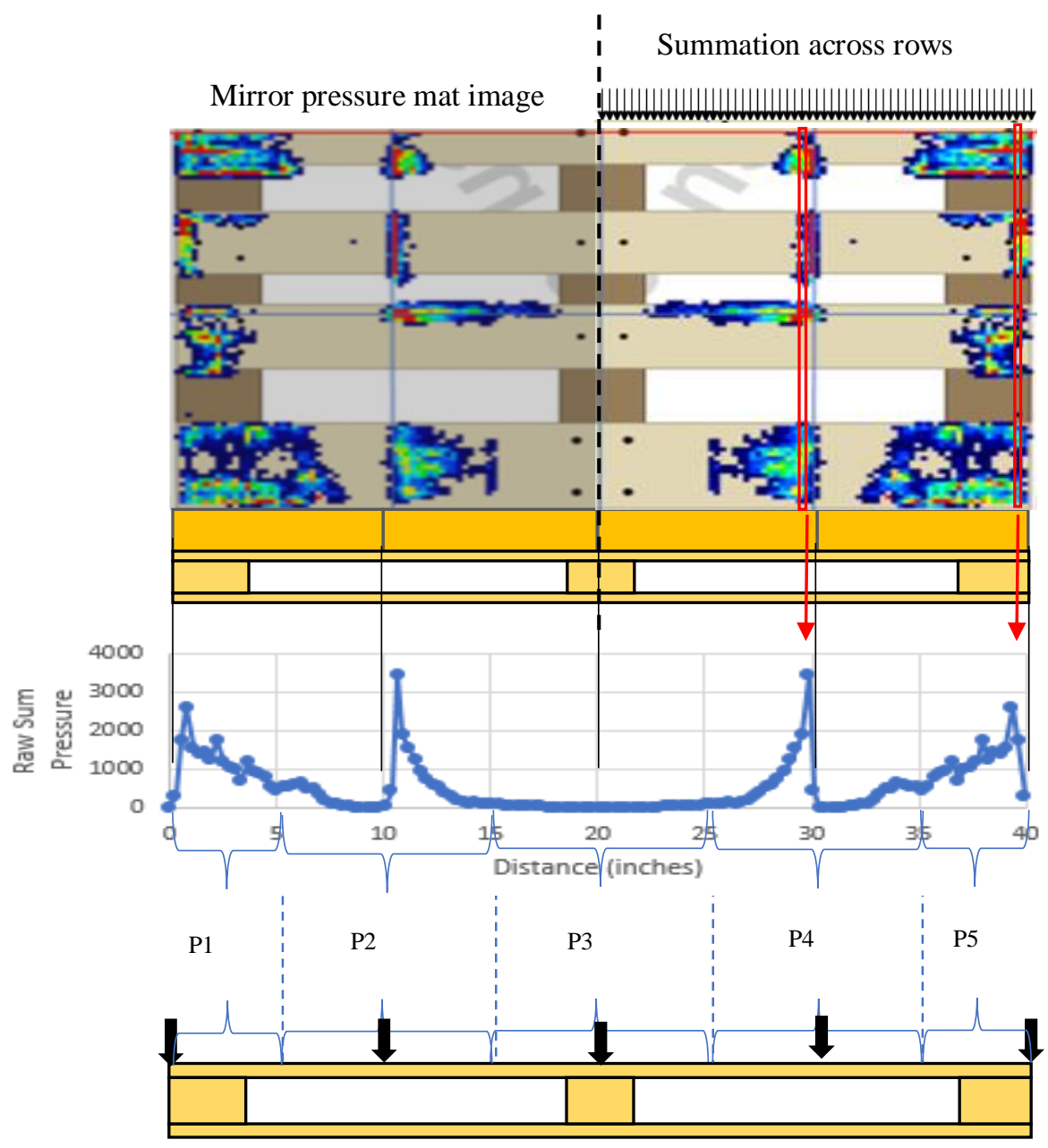

Small Box Point Loads

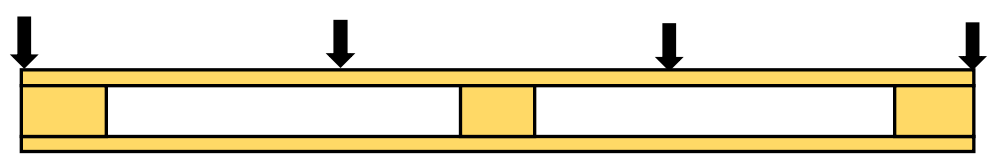

Medium Box Point Loads

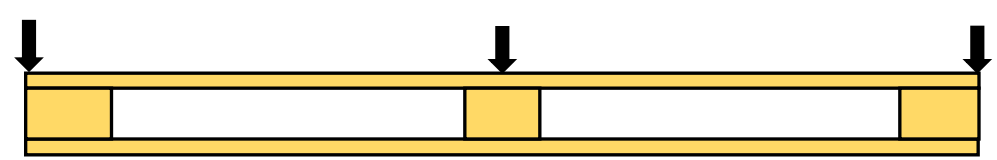

Large Box Point Loads

Figure 24: Visual representation of steps used for warehouse racking across the width (RAW) pressure mat analysis

The results of the pressure distributions based on the tributary areas assigned to each point load are shown in Table 14. The amount of pressure over the supports is represented graphically in Figure 25. When looking at the change in box size given a specific pallet stiffness, it is clear 
that as box size increases, a higher percentage of pressure is distributed away from the center of the pallet and towards the supports. This effect is greatest on low stiffness pallets where a change from small boxes to large boxes resulted in a change from $54.48 \%$ of the pressure to $91.3 \%$ of the pressure being directly over the supports. All pressure that is directly over the supports does not affect pallet deflection. The redistribution of more pressure towards the supports due to increased box size, supports the reduction in pallet deflection as a function of increasing box size measured during the experiment. It is also evident that an increase in pallet stiffness, given a specific box size, causes a reduction in the amount of force transferred to the supports.

Table 14: Pressure distribution for pallets supported in the warehouse racking across the width (RAW) based on tributary area assigned to point loads for small, medium, and large boxes across all levels of pallet stiffness

\begin{tabular}{|c|c|c|c|c|c|c|}
\hline \multicolumn{7}{|c|}{ Pressure distribution based on tributary area represented in percentages } \\
\hline $\begin{array}{c}\text { Pallet } \\
\text { Stiffness } \\
\end{array}$ & Box Size & $\mathbf{P 1}$ & $\mathbf{P 2}$ & P3 & $\mathbf{P 4}$ & P5 \\
\hline \multirow{3}{*}{ Very Low } & Small & $\begin{array}{c}27.24 \% \\
(0.6 \%)\end{array}$ & $\begin{array}{c}22.32 \% \\
(0.5 \%)\end{array}$ & $\begin{array}{l}0.88 \% \\
(0.2 \%)\end{array}$ & $\begin{array}{c}22.32 \% \\
(0.5 \%)\end{array}$ & $\begin{array}{r}27.24 \% \\
(0.6 \%) \\
\end{array}$ \\
\hline & Medium & $\begin{array}{l}37.87 \% \\
(1.7 \%)\end{array}$ & $\begin{array}{l}12.13 \% \\
(1.7 \%)\end{array}$ & & $\begin{array}{c}12.13 \% \\
(1.7 \%)\end{array}$ & $\begin{array}{r}37.87 \% \\
(1.7 \%)\end{array}$ \\
\hline & Large & $\begin{array}{c}45.65 \% \\
(0.7 \%)\end{array}$ & & $\begin{array}{l}8.70 \% \\
(0.7 \%)\end{array}$ & & $\begin{array}{r}45.65 \% \\
(0.7 \%)\end{array}$ \\
\hline \multirow{3}{*}{ Low } & Small & $\begin{array}{c}25.51 \% \\
(0.4 \%)\end{array}$ & $\begin{array}{c}22.10 \% \\
(0.6 \%)\end{array}$ & $\begin{array}{l}4.78 \% \\
(0.1 \%)\end{array}$ & $\begin{array}{c}22.10 \% \\
(0.6 \%)\end{array}$ & $\begin{array}{r}25.51 \% \\
(0.4 \%) \\
\end{array}$ \\
\hline & Medium & $\begin{array}{l}36.05 \% \\
(2.0 \%)\end{array}$ & $\begin{array}{l}13.95 \% \\
(2.0 \%)\end{array}$ & & $\begin{array}{c}13.95 \% \\
(2.0 \%)\end{array}$ & $\begin{array}{l}36.05 \% \\
(2.0 \%)\end{array}$ \\
\hline & Large & $\begin{array}{c}41.67 \% \\
(0.2 \%)\end{array}$ & & $\begin{array}{c}16.66 \% \\
(0.2 \%)\end{array}$ & & $\begin{array}{r}41.67 \% \\
(0.2 \%)\end{array}$ \\
\hline \multirow{3}{*}{ Medium } & Small & $\begin{array}{c}21.80 \% \\
(0.5 \%)\end{array}$ & $\begin{array}{c}24.09 \% \\
(0.7 \%)\end{array}$ & $\begin{array}{l}8.22 \% \\
(0.7 \%)\end{array}$ & $\begin{array}{c}24.09 \% \\
(0.7 \%)\end{array}$ & $\begin{array}{r}21.80 \% \\
(0.5 \%)\end{array}$ \\
\hline & Medium & $\begin{array}{l}32.25 \% \\
(1.7 \%)\end{array}$ & $\begin{array}{c}17.75 \% \\
(1.7 \%)\end{array}$ & & $\begin{array}{c}17.75 \% \\
(1.7 \%)\end{array}$ & $\begin{array}{r}32.25 \% \\
(1.7 \%)\end{array}$ \\
\hline & Large & $\begin{array}{c}39.35 \% \\
(1.1 \%)\end{array}$ & & $\begin{array}{l}21.3 \% \\
(1.1 \%) \\
\end{array}$ & & $\begin{array}{l}39.35 \% \\
(1.1 \%) \\
\end{array}$ \\
\hline \multirow{2}{*}{ High } & Small & $\begin{array}{c}21.43 \% \\
(1.0 \%) \\
\end{array}$ & $\begin{array}{c}24.22 \% \\
(0.4 \%) \\
\end{array}$ & $\begin{array}{l}8.70 \% \\
(1.4 \%) \\
\end{array}$ & $\begin{array}{c}24.22 \% \\
(0.4 \%) \\
\end{array}$ & $\begin{array}{l}21.43 \% \\
(1.0 \%) \\
\end{array}$ \\
\hline & Medium & $\begin{array}{c}31.45 \% \\
(1.5 \%)\end{array}$ & $\begin{array}{c}18.55 \% \\
(1.5 \%)\end{array}$ & & $\begin{array}{c}18.55 \% \\
(1.5 \%)\end{array}$ & $\begin{array}{l}31.45 \% \\
(1.5 \%)\end{array}$ \\
\hline
\end{tabular}

Note: The values in parentheses are standard deviations. 


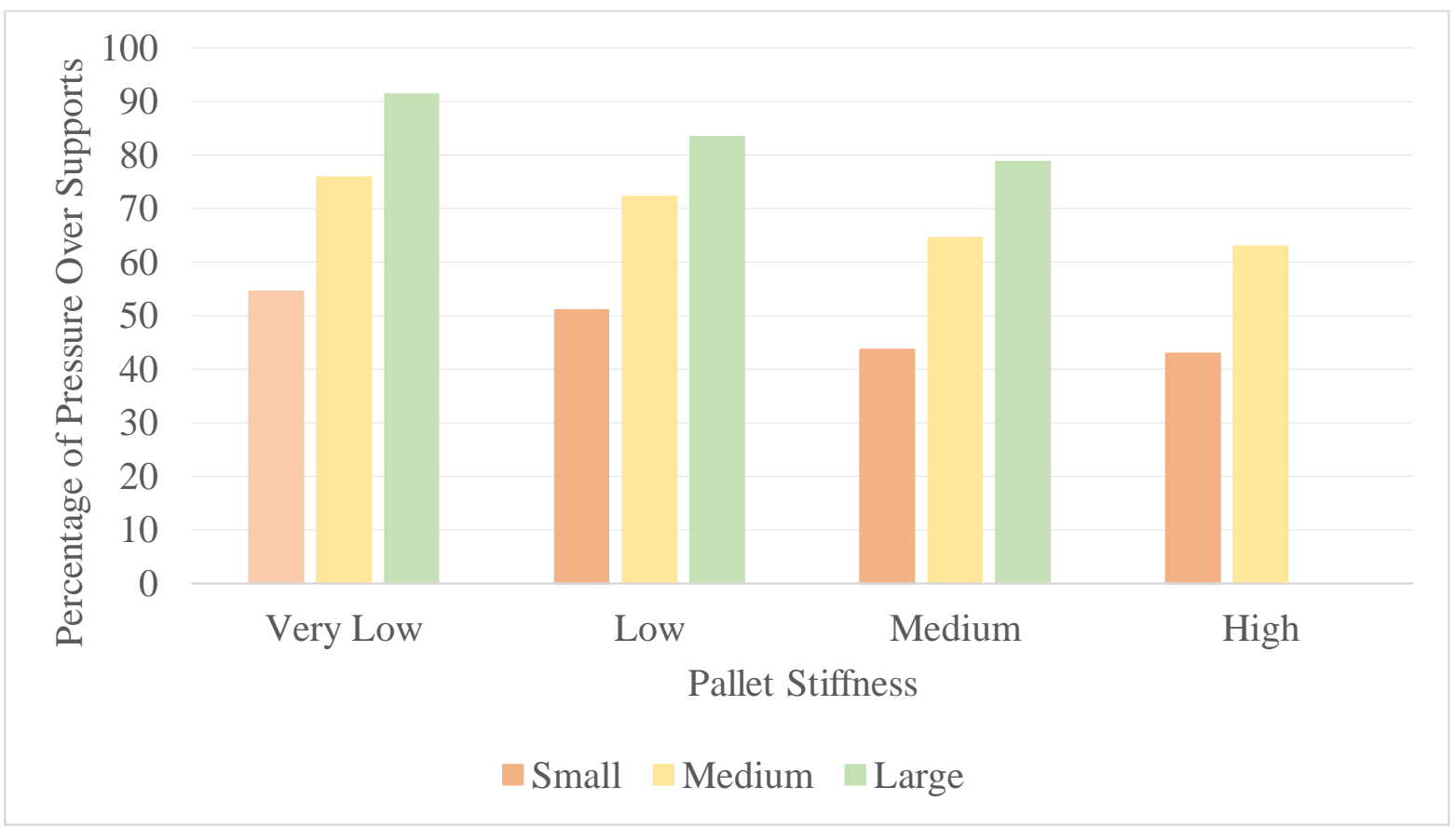

Figure 25: Percentage of pressure directly over supports for pallets supported in the warehouse racking across the width $(R A W)$ support condition for small, medium, and large boxes across all levels of pallet stiffness

\subsection{WAREHOUSE RACKING ACROSS THE LENGTH (RAL)}

\subsubsection{Deflection}

The results for the warehouse racking across the length (RAL) analysis of variance (ANOVA) model are shown in Table 15, and the results of the effects tests are shown in Table 16. For pallets in the RAL support condition, box size did not show any statistically significant effect. This can be attributed to the number of boxes along the length of the pallet for each box size. As the box size changed from small to medium to large, the number of boxes along the length of the pallet changed from four to three to four. Due to the fact that the transitions in box sizes were not represented by a linear change in the number of boxes along the length of the unit load, the effect of box size on pallet deflection for pallets in the RAL support condition was of no statistical significance. The effect of pallet stiffness was found to be significant. Load bridging decreased as pallet stiffness increased. Pallet stiffness has also been shown to have a significant effect on pallet deflection by the previous researchers (Fagan 1982, Collie 1984, Yoo 2011, Park 2015, Phanthanousy 2017, Molina 2017, Clayton 2018). The interaction between pallet stiffness and box size was also concluded to be statistically significant. This means that the effect of box size on observed pallet deflection is dependent on the stiffness of the pallet. Although, for RAW, a clear 
reduction in the effect of box size was observed as a pallet stiffness increased, for RAL, the effect was more random in nature. An interaction plot of pallet stiffness and box size is shown in Figure 26.

Table 15: Analysis of variance (ANOVA) table for warehouse racking across the length model

\begin{tabular}{|c|c|c|c|c|}
\hline Source & DF & Sum of Squares & Mean Square & F Ratio \\
\hline Model & 10 & 0.48965466 & 0.048965 & 313.4246 \\
\hline Error & 22 & 0.00343700 & 0.000156 & Prob > F \\
\hline C. Total & 32 & 0.49309166 & & $<.0001 *$ \\
\hline
\end{tabular}

Table 16: Analysis of variance (ANOVA) effects tests for warehouse racking across the length model

\begin{tabular}{|c|c|c|c|c|c|}
\hline Source & Nparm & DF & Sum of Squares & F Ratio & Prob > F \\
\hline Pallet & 3 & 2 & 0.39012236 & 1248.573 & $<.0001^{*}$ \\
\hline Box Size & 2 & 1 & 0.00023563 & 1.5082 & 0.2324 \\
\hline Pallet*Box Size & 6 & 5 & 0.00304523 & 3.8985 & $0.0111^{*}$ \\
\hline
\end{tabular}

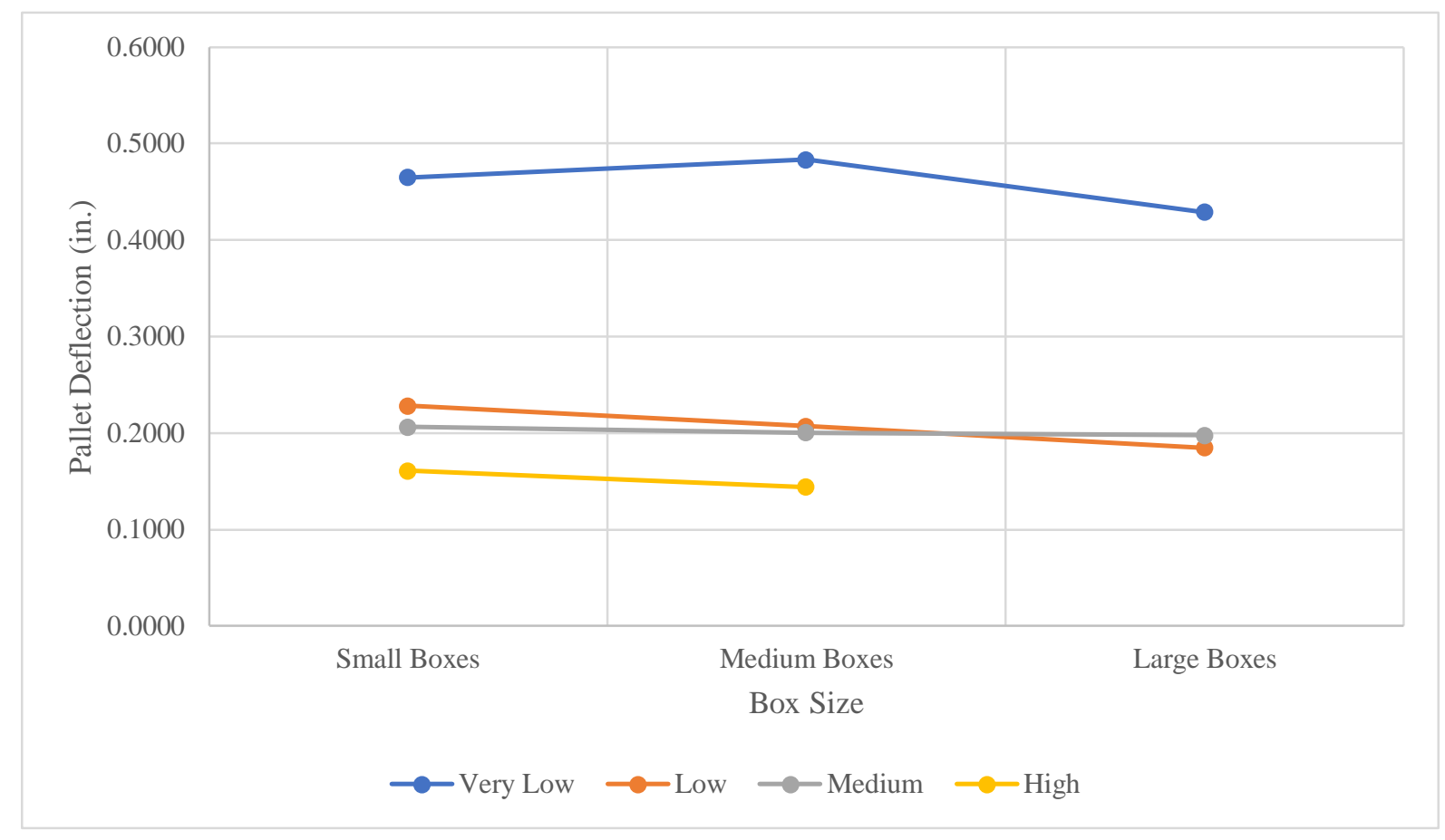

Figure 26: The effect of pallet stiffness on the pallet deflection as a function of box size for the warehouse racking across the length support condition 
Center deflection measurements for pallets in the warehouse racking across the length (RAL) support condition are shown in Table 17 and represented graphically in Figure 27. Low and medium stiffness pallets had similar deflection measurements due to the fact that both pallet designs used 0.5-inch-thick stringer boards. A change from small to large boxes was only statistically significant for the very low and low stiffness pallets. Since there are four boxes along the length of the pallet for both small and large boxes, the change in deflection observed for lower stiffness pallets indicates that the number of boxes along the width has an effect on the load bridging for pallets in the RAL support condition when pallet stiffness is low enough. The largest reduction in pallet deflection was $19 \%$, and this was achieved by changing from small to large boxes on the low stiffness pallet. Although there were statistically significant effects from box size changes on pallet deflection for the very low and low stiffness pallets, all observed changes in deflection were less than 0.05 inches and of no importance for practical purposes.

Table 17: Average pallet center deflection and the percent difference in reference to the small boxes during warehouse racking across the length support condition using boxes with headspace.

\begin{tabular}{|c|c|c|c|c|c|c|c|c|c|c|c|c|}
\hline \multirow{3}{*}{$\begin{array}{c}\text { Box } \\
\text { Size } \\
\text { Small }\end{array}$} & \multicolumn{12}{|c|}{ Pallet Deflection (in.) } \\
\hline & \multicolumn{3}{|c|}{ Very Low } & \multicolumn{3}{|c|}{ Low } & \multicolumn{3}{|c|}{ Medium } & \multicolumn{3}{|c|}{ High } \\
\hline & $\begin{array}{c}0.4648 \\
(0.0083)\end{array}$ & $\mathrm{A} / \mathrm{B}$ & & $\begin{array}{c}0.2280 \\
(0.0072)\end{array}$ & A & & $\begin{array}{c}0.2063 \\
(0.0099)\end{array}$ & A & & $\begin{array}{c}0.1610 \\
(0.0035)\end{array}$ & $\mathrm{A}$ & \\
\hline Medium & $\begin{array}{c}0.4834 \\
(0.0295)\end{array}$ & A & $4 \%$ & $\begin{array}{c}0.2072 \\
(0.0062)\end{array}$ & $\mathrm{A} / \mathrm{B}$ & $-9 \%$ & $\begin{array}{c}0.2004 \\
(0.0093)\end{array}$ & A & $-3 \%$ & $\begin{array}{c}0.1439 \\
(0.0141)\end{array}$ & $\mathrm{A}$ & $-11 \%$ \\
\hline Large & $\begin{array}{c}0.4288 \\
(0.0128)\end{array}$ & B & $-8 \%$ & $\begin{array}{c}0.1849 \\
(0.0097)\end{array}$ & B & $-19 \%$ & $\begin{array}{c}0.1975 \\
(0.0060)\end{array}$ & A & $-4 \%$ & & & \\
\hline
\end{tabular}

Note: The values in parentheses are standard deviations. The letters were determined by running a Tukey HSD with an alpha level of 0.05. Different letters for a given pallet stiffness represent statistically significant differences in expected pallet deflection 


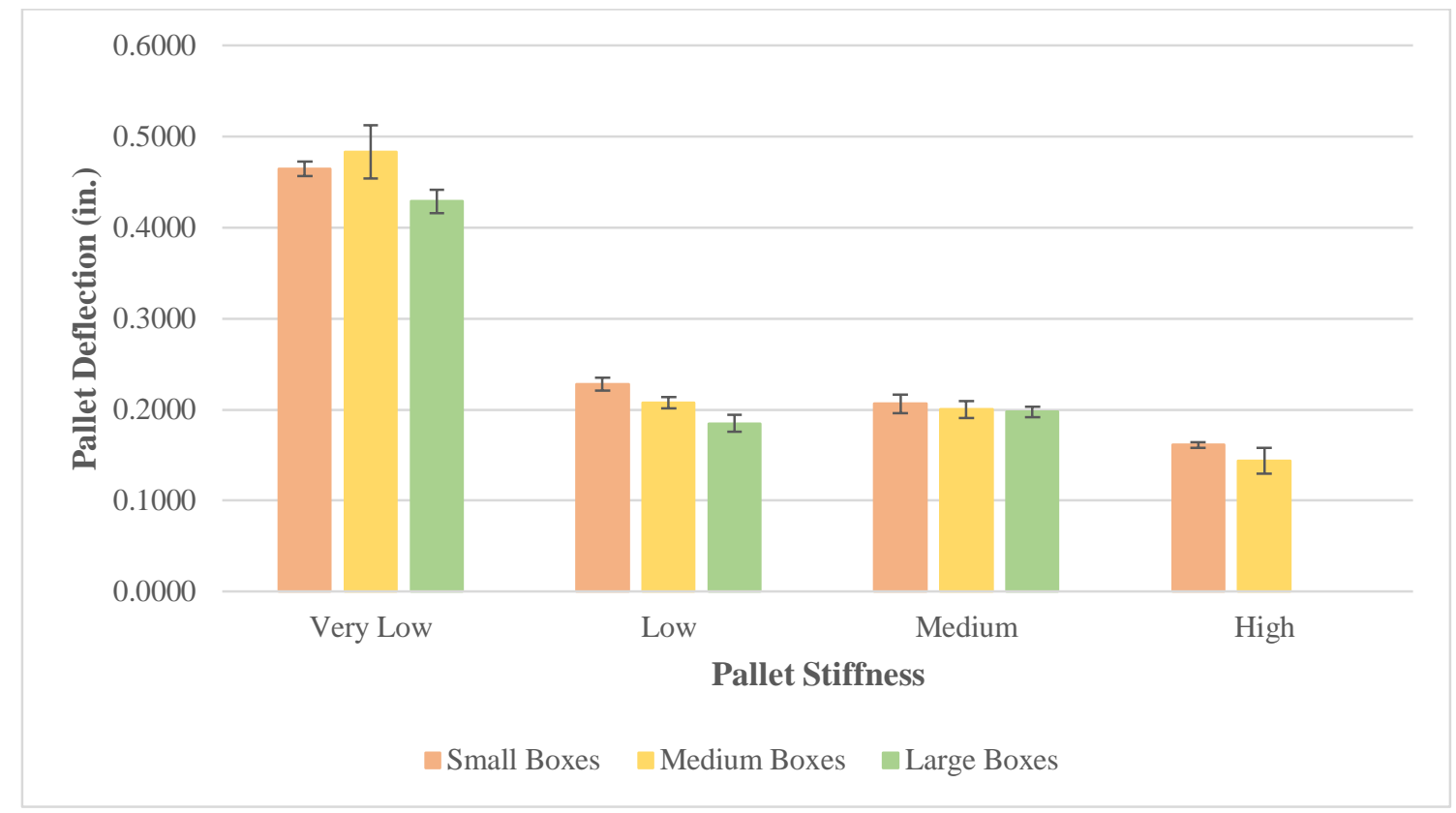

Figure 27: Average pallet center deflection during the warehouse racking across the width support condition using boxes with headspace. The whiskers represent standard deviation.

\subsubsection{Pressure Mat}

In order to understand how the pressure distribution displayed in the two-dimensional array interacted with the pallet in a warehouse racking across the length (RAL) support condition, further analysis was conducted. The steps of analyzing the pressure mat data are shown in Figure 28. A procedure similar to that which was used to analyze the warehouse racked across the width pressure mat data was employed. The pressure mat image of a half pallet was mirrored to create the whole pallet. Then, the two-dimensional array of sensels was summed across the rows parallel to the supports to create a one-dimensional array which could be graphed according to distance across the pallet (in inches). Finally, the forces across a given top deckboard were summed together to create a concentrated point load for each top deckboard. The concentrated top load was positioned to the center of the pallet's top deckboard. This same procedure was used for all box sizes tested. 


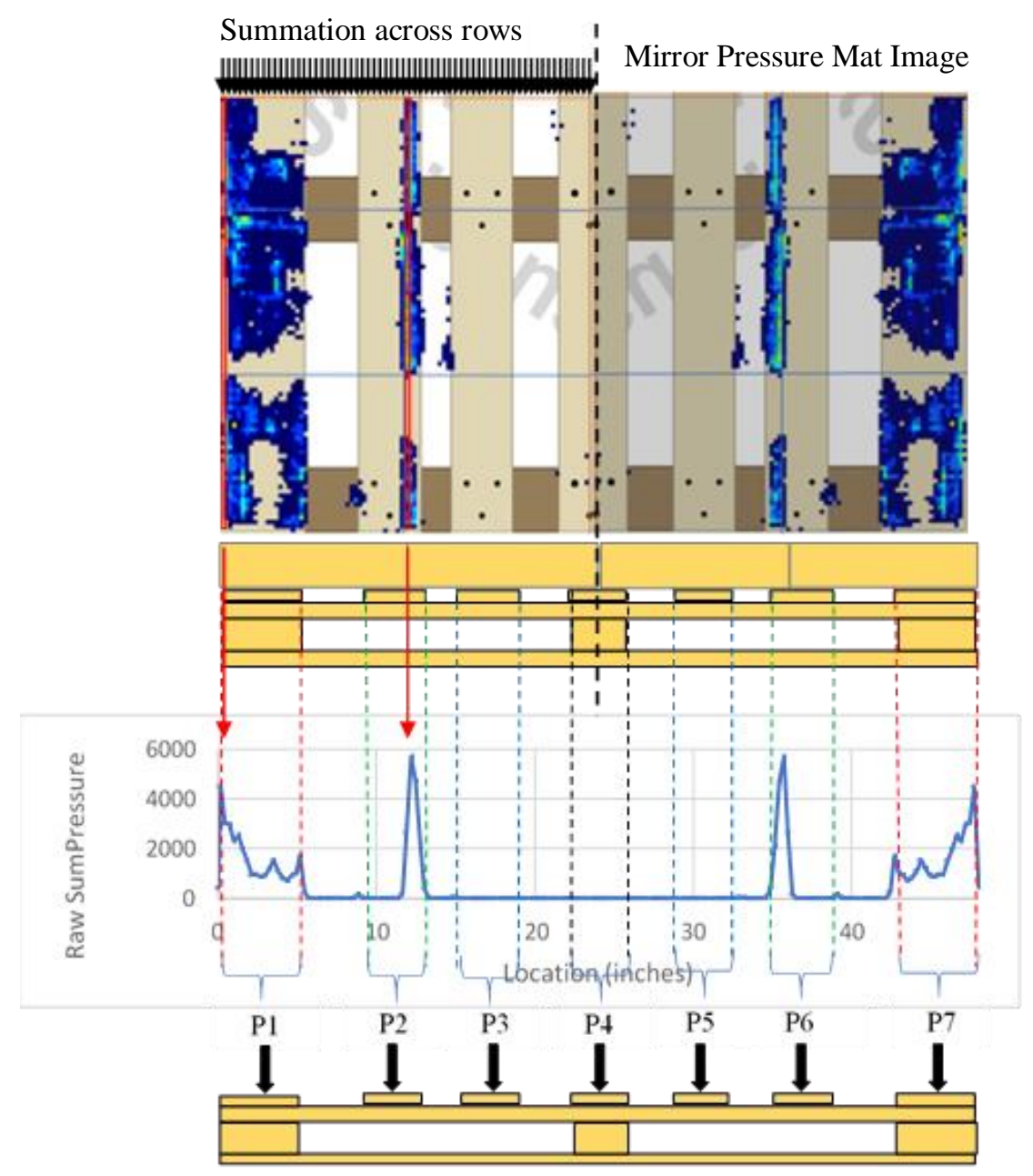

Figure 28: Visual representation of steps used for warehouse racking across the length (RAL) pressure mat analysis

The results of pressure distribution based on the point loads assigned to each top deckboard are shown in Table 18. The percentage of pressure directly over the supports is represented graphically in Figure 29. A change from small to medium boxes caused an increase in the amount of pressure distributed to the supports, while a change from medium to large boxes resulted in a reduction of the pressure distributed to the supports. These trends are true regardless of the pallet stiffness, and are caused by the number of boxes along the length (small-4, medium-3, large-4). The largest change was observed by switching from small to medium boxes on the medium stiffness pallet. The pressure over the supports went from $58.30 \%$ to $70.44 \%$. Pressure directly over the supports does not affect the deflection of the pallet. The redistribution of more pressure towards the supports due to increased box size (from small to medium), supports the reduction in pallet deflection as a function of increasing box size measured during the experiment. It is also 
evident that increased pallet stiffness given a specific box size causes a reduction in the amount of force transferred to the supports.

Table 18: Pressure distribution based on point loads assigned to individual top deckboards for small, medium, and large boxes across all levels of pallet stiffness

\begin{tabular}{|c|c|c|c|c|c|c|c|c|}
\hline \multicolumn{9}{|c|}{$\begin{array}{l}\text { Pressure distribution of each top deckboard in a warehouse racked across the length } \\
\text { support condition represented in percentages }\end{array}$} \\
\hline $\begin{array}{c}\text { Pallet } \\
\text { Stiffness }\end{array}$ & Box Size & P1 & P2 & P3 & P4 & P5 & P6 & P7 \\
\hline \multirow{3}{*}{$\begin{array}{l}\text { Very } \\
\text { Low }\end{array}$} & Small & $\begin{array}{l}33.35 \% \\
(1.6 \%)\end{array}$ & $\begin{array}{l}16.49 \% \\
(1.6 \%)\end{array}$ & $\begin{array}{l}0.13 \% \\
(0.1 \%)\end{array}$ & $\begin{array}{l}0.06 \% \\
(0.0 \%)\end{array}$ & $\begin{array}{l}0.13 \% \\
(0.1 \%)\end{array}$ & $\begin{array}{l}16.49 \% \\
(1.6 \%)\end{array}$ & $\begin{array}{l}33.35 \% \\
(1.6 \%)\end{array}$ \\
\hline & Medium & $\begin{array}{l}37.98 \% \\
(1.4 \%)\end{array}$ & $\begin{array}{l}0.00 \% \\
(0.0 \%)\end{array}$ & $\begin{array}{c}12.02 \% \\
(1.4 \%)\end{array}$ & $\begin{array}{l}0.00 \% \\
(0.0 \%)\end{array}$ & $\begin{array}{c}12.02 \% \\
(1.4 \%)\end{array}$ & $\begin{array}{l}0.00 \% \\
(0.0 \%)\end{array}$ & $\begin{array}{c}37.98 \% \\
(1.4 \%)\end{array}$ \\
\hline & Large & $\begin{array}{c}35.97 \% \\
(1.0 \%)\end{array}$ & $\begin{array}{c}12.29 \% \\
(1.2 \%)\end{array}$ & $\begin{array}{l}1.72 \% \\
(0.3 \%)\end{array}$ & $\begin{array}{l}0.04 \% \\
(0.0 \%)\end{array}$ & $\begin{array}{l}1.72 \% \\
(0.3 \%)\end{array}$ & $\begin{array}{l}12.29 \% \\
(1.2 \%)\end{array}$ & $\begin{array}{c}35.97 \% \\
(1.0 \%)\end{array}$ \\
\hline \multirow{3}{*}{ Low } & Small & $\begin{array}{c}30.87 \% \\
(1.7 \%)\end{array}$ & $\begin{array}{c}16.40 \% \\
(1.6 \%)\end{array}$ & $\begin{array}{l}2.09 \% \\
(0.1 \%)\end{array}$ & $\begin{array}{l}1.28 \% \\
(0.0 \%)\end{array}$ & $\begin{array}{l}2.09 \% \\
(0.1 \%)\end{array}$ & $\begin{array}{c}16.40 \% \\
(1.6 \%)\end{array}$ & $\begin{array}{c}30.87 \% \\
(1.7 \%)\end{array}$ \\
\hline & Medium & $\begin{array}{c}34.65 \% \\
(1.0 \%)\end{array}$ & $\begin{array}{l}3.19 \% \\
(0.4 \%)\end{array}$ & $\begin{array}{c}12.16 \% \\
(1.1 \%)\end{array}$ & $\begin{array}{l}0.00 \% \\
(0.0 \%)\end{array}$ & $\begin{array}{c}12.16 \% \\
(1.1 \%)\end{array}$ & $\begin{array}{l}3.19 \% \\
(0.4 \%)\end{array}$ & $\begin{array}{c}34.65 \% \\
(1.0 \%)\end{array}$ \\
\hline & Large & $\begin{array}{c}32.55 \% \\
(0.5 \%)\end{array}$ & $\begin{array}{l}9.95 \% \\
(0.2 \%)\end{array}$ & $\begin{array}{l}7.04 \% \\
(0.6 \%)\end{array}$ & $\begin{array}{l}0.92 \% \\
(0.1 \%)\end{array}$ & $\begin{array}{c}7.04 \% \\
(0.6 \%)\end{array}$ & $\begin{array}{l}9.95 \% \\
(0.2 \%)\end{array}$ & $\begin{array}{c}32.55 \% \\
(0.5 \%)\end{array}$ \\
\hline \multirow{3}{*}{ Medium } & Small & $\begin{array}{c}29.15 \% \\
(1.4 \%)\end{array}$ & $\begin{array}{c}18.42 \% \\
(1.1 \%)\end{array}$ & $\begin{array}{l}0.76 \% \\
(0.3 \%)\end{array}$ & $\begin{array}{l}3.34 \% \\
(0.7 \%)\end{array}$ & $\begin{array}{l}0.76 \% \\
(0.3 \%)\end{array}$ & $\begin{array}{l}18.42 \% \\
(1.1 \%)\end{array}$ & $\begin{array}{c}29.15 \% \\
(1.4 \%)\end{array}$ \\
\hline & Medium & $\begin{array}{c}35.22 \% \\
(1.0 \%)\end{array}$ & $\begin{array}{l}2.50 \% \\
(0.3 \%)\end{array}$ & $\begin{array}{c}12.28 \% \\
(0.7 \%)\end{array}$ & $\begin{array}{l}0.00 \% \\
(0.0 \%)\end{array}$ & $\begin{array}{c}12.28 \% \\
(0.7 \%)\end{array}$ & $\begin{array}{l}2.50 \% \\
(0.3 \%)\end{array}$ & $\begin{array}{c}35.22 \% \\
(1.0 \%)\end{array}$ \\
\hline & Large & $\begin{array}{c}33.24 \% \\
(0.7 \%)\end{array}$ & $\begin{array}{l}9.02 \% \\
(0.8 \%)\end{array}$ & $\begin{array}{l}7.23 \% \\
(0.4 \%)\end{array}$ & $\begin{array}{l}1.02 \% \\
(0.2 \%)\end{array}$ & $\begin{array}{l}7.23 \% \\
(0.4 \%)\end{array}$ & $\begin{array}{l}9.02 \% \\
(0.8 \%)\end{array}$ & $\begin{array}{c}33.24 \% \\
(0.7 \%)\end{array}$ \\
\hline \multirow{2}{*}{ High } & Small & $\begin{array}{c}28.01 \% \\
(1.5 \%)\end{array}$ & $\begin{array}{c}17.77 \% \\
(1.4 \%)\end{array}$ & $\begin{array}{l}2.19 \% \\
(0.2 \%)\end{array}$ & $\begin{array}{l}4.06 \% \\
(0.3 \%)\end{array}$ & $\begin{array}{l}2.19 \% \\
(0.2 \%)\end{array}$ & $\begin{array}{c}17.77 \% \\
(1.4 \%)\end{array}$ & $\begin{array}{c}28.01 \% \\
(1.5 \%)\end{array}$ \\
\hline & Medium & $\begin{array}{c}32.50 \% \\
(1.6 \%)\end{array}$ & $\begin{array}{l}2.51 \% \\
(0.3 \%)\end{array}$ & $\begin{array}{c}14.99 \% \\
(1.3 \%)\end{array}$ & $\begin{array}{l}0.00 \% \\
(0.0 \%)\end{array}$ & $\begin{array}{c}14.99 \% \\
(1.3 \%)\end{array}$ & $\begin{array}{l}2.51 \% \\
(0.3 \%)\end{array}$ & $\begin{array}{c}32.50 \% \\
(1.6 \%)\end{array}$ \\
\hline
\end{tabular}

Note: Values in parentheses are standard deviations 


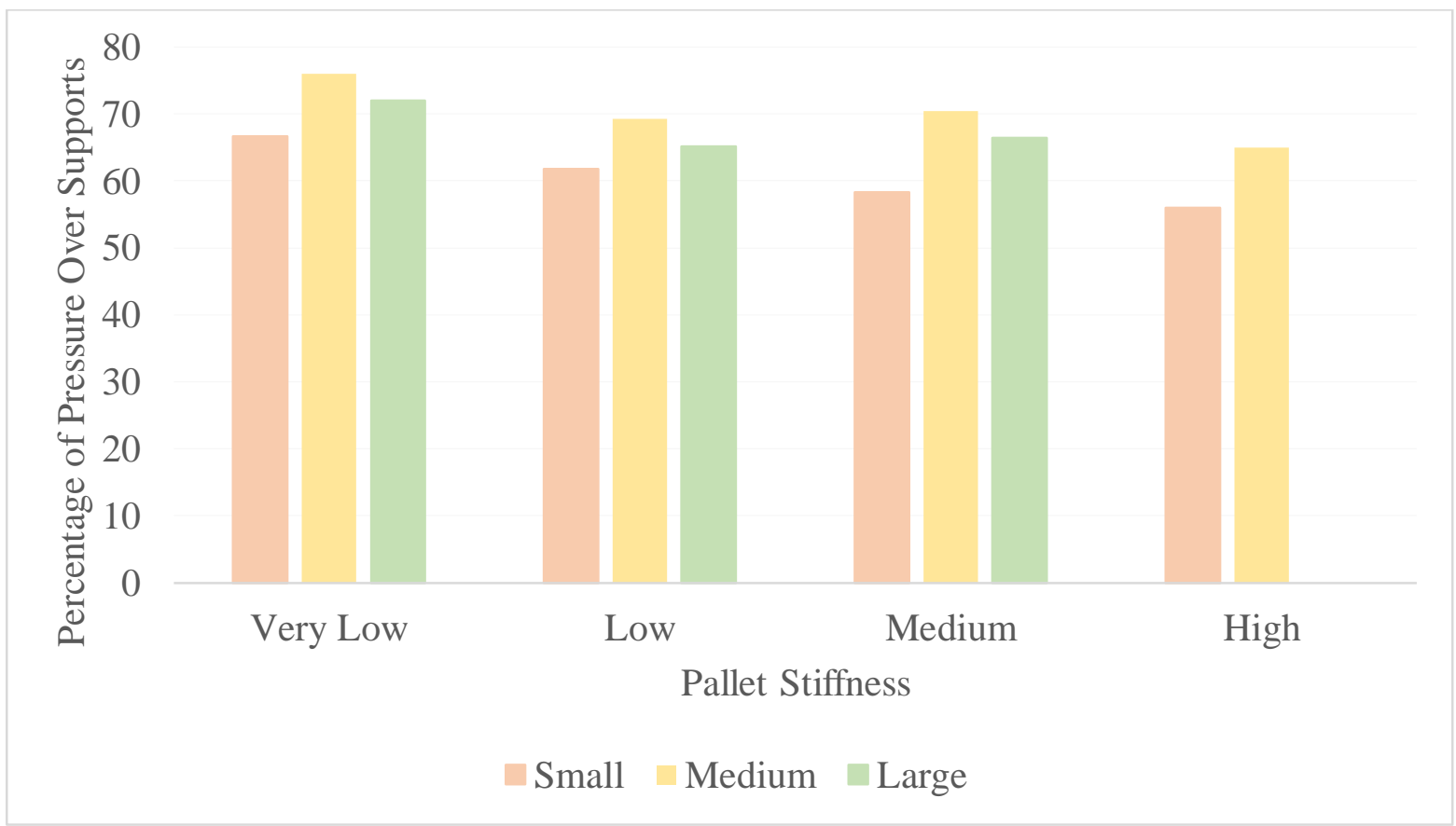

Figure 29: Percentage of pressure directly over supports for pallets supported in the warehouse racking across the length (RAL) support condition for small, medium, and large boxes across all levels of pallet stiffness

\subsection{STACKING FLOOR SUPPORT CONDITIONS}

As with the racking support conditions, all stacking support conditions were examined using analysis of variance (ANOVA) models to determine if box size and pallet stiffness had any significant effect on pallet deflection. The interactions between box size and pallet stiffness were also examined for all stacking models. Top deckboards were analyzed separately from stringer boards. For the top pallet in the double stacked condition, the analysis was split into bottom deckboards across the width and bottom deckboards across the length. Below is a detailed analysis of the various deflection measurement locations for all stacking support conditions.

\subsubsection{Top Deckboards}

Only the worst top deckboard measurements in each scenario were examined since pallet performance is governed by the worst top deckboard deflection. The worst top deckboard deflection measurements are given in Table 19 for the single stacked support condition and in Table 20 for the double stacked support condition. The analysis of variance (ANOVA) results are shown in the appendix (A.5.1). For pallets in the single stacked support condition, a statistically significant reduction in pallet deflection was experienced when switching from small to large 
boxes on the very low and low stiffness pallets. The change from small to large boxes resulted in a $50 \%$ reduction in deflection for the very low stiffness pallet and a $76 \%$ reduction for the low stiffness pallet when they were in a single stacked support condition. For pallets in the double stacked support condition, all pallet stiffnesses experienced statistically significant reductions in pallet deflection when tested with large boxes. The percent change in pallet deflection experienced by switching from small to large boxes ranged from $46 \%$ to $59 \%$ for those in the double stacked support condition. As the amount of force experienced by any pallet in a stacking support condition increases, the effect of box size becomes more relevant. While a change from small to large boxes is significant for most pallet stiffnesses in both single and double stacked support conditions, there was less than a 0.05 inch change in deflection for all combinations tested. Although small, 0.05 inches of deflection may have real world implications when handling a pallet with a floor jack.

Table 19: Average worst top deckboard deflection and the percent difference in reference to the small boxes during single stacked support condition using boxes with headspace.

\begin{tabular}{|c|c|c|c|c|c|c|c|c|}
\hline \multirow{2}{*}{ Box Size } & \multicolumn{8}{|c|}{ Pallet Deflection (in.) } \\
\hline & \multicolumn{2}{|c|}{ Very Low } & \multicolumn{2}{|c|}{ Low } & \multicolumn{2}{|c|}{ Medium } & \multicolumn{2}{|c|}{ High } \\
\hline Small & $\begin{array}{c}\text { Back } \\
0.0450 \\
(0.0044)\end{array}$ & A & $\begin{array}{c}\text { Back } \\
0.0283 \\
(0.0055)\end{array}$ & A & $\begin{array}{c}\text { Back } \\
0.0182 \\
(0.0023)\end{array}$ & A & $\begin{array}{c}\text { Back } \\
0.0130 \\
(0.0035)\end{array}$ & A \\
\hline & & A & $\begin{array}{c}\text { Back } \\
\text { Middle }\end{array}$ & A & $\begin{array}{c}\text { Back } \\
\text { Middle }\end{array}$ & A & $\begin{array}{c}\text { Back } \\
\text { Middle }\end{array}$ & A \\
\hline Medium & $\begin{array}{c}0.0460 \\
(0.0105)\end{array}$ & $2 \%$ & $\begin{array}{c}0.0307 \\
(0.0074)\end{array}$ & $8 \%$ & $\begin{array}{c}0.0183 \\
(0.0071)\end{array}$ & $1 \%$ & $\begin{array}{c}0.0295 \\
(0.0111)\end{array}$ & $127 \%$ \\
\hline Large & $\begin{array}{c}\text { Back } \\
0.0227 \\
(0.0015)\end{array}$ & $\begin{array}{c}\mathrm{B} \\
-50 \%\end{array}$ & $\begin{array}{c}\text { Back } \\
0.0067 \\
(0.0015)\end{array}$ & $\begin{array}{c}\mathrm{B} \\
-76 \%\end{array}$ & $\begin{array}{c}\text { Back } \\
0.0078 \\
(0.0038)\end{array}$ & $\begin{array}{c}\mathrm{A} \\
-57 \%\end{array}$ & & \\
\hline
\end{tabular}

Note: The values in parentheses are standard deviations. The letters were determined by running a Tukey HSD with an alpha level of 0.05. Different letters for a given pallet stiffness represent statistically significant differences in expected pallet deflection 
Table 20: Average worst top deckboard deflection and the percent difference in reference to the small boxes during double stacked support condition using boxes with headspace.

\begin{tabular}{|c|c|c|c|c|c|c|c|c|}
\hline \multirow{3}{*}{$\begin{array}{c}\text { Box Size } \\
\text { Small }\end{array}$} & \multicolumn{8}{|c|}{ Pallet Deflection (in.) } \\
\hline & \multicolumn{2}{|c|}{ Very Low } & \multicolumn{2}{|c|}{ Low } & \multicolumn{2}{|c|}{ Medium } & \multicolumn{2}{|c|}{ High } \\
\hline & $\begin{array}{c}\text { Back } \\
0.0773 \\
(0.0040 \\
)\end{array}$ & A & $\begin{array}{c}\text { Back } \\
0.0503 \\
(0.0015)\end{array}$ & A & $\begin{array}{c}\text { Back } \\
0.0368 \\
(0.0021)\end{array}$ & A & $\begin{array}{c}\text { Back } \\
0.0243 \\
(0.0025)\end{array}$ & $\mathrm{A}$ \\
\hline Medium & $\begin{array}{c}\text { Back } \\
0.0867 \\
(0.0078 \\
)\end{array}$ & $12 \%$ & $\begin{array}{c}\text { Back } \\
\text { Middle } \\
0.0420 \\
(0.0061)\end{array}$ & $-17 \%$ & $\begin{array}{c}\text { Back } \\
\text { Middle } \\
0.0310 \\
(0.0044)\end{array}$ & $-16 \%$ & $\begin{array}{c}\text { Back } \\
\text { Middle } \\
0.0348 \\
(0.0076)\end{array}$ & $43 \%$ \\
\hline Large & $\begin{array}{c}\text { Back } \\
0.0420 \\
(0.0017 \\
)\end{array}$ & $\begin{array}{c}\text { B } \\
-46 \%\end{array}$ & $\begin{array}{c}\text { Back } \\
0.0207 \\
(0.0015)\end{array}$ & $\begin{array}{c}\text { B } \\
-59 \%\end{array}$ & $\begin{array}{c}\text { Back } \\
0.0168 \\
(0.0012)\end{array}$ & $\begin{array}{c}\text { B } \\
-54 \%\end{array}$ & & \\
\hline
\end{tabular}

Note: The values in parentheses are standard deviations. The letters were determined by running a Tukey HSD with an alpha level of 0.05. Different letters for a given pallet stiffness represent statistically significant differences in expected pallet deflection

The locations where the corners of the corrugated boxes touch the pallet are shown in Figure 30. The interactions between those corners and the top deckboards of the pallet are important in understanding both the observed differences associated with the use of large boxes and the location of the worst top deckboards. The differences in pallet deflection observed for large boxes is due to the fact that the length of large boxes allow them to completely span the distance between blocks across the width causing minimal top deckboard deflection. When analyzing the locations of the worst top deckboard deflections, the locations of the box corners have been found to dictate which top deckboard will experience the greatest deflection. Since between 2/3 and 3/4 of the compressive forces have been shown to transfer through box corners (Maltenfort, 1988), the top deckboards which directly support corners experience the greatest deflection. Looking at Figure 30, it is apparent that the corners of medium boxes rest directly on the front and backmiddle top deckboards. For small and large boxes, the corners rest on the front, front-middle, and back top deckboards. For medium boxes, the worst top deckboard deflection was experienced at the back-middle measurement location for all pallet stiffnesses except the very low stiffness pallet. 
Small and large boxes consistently experienced the worst top deckboard deflection at the back measurement locations. This is due to the fact that these deckboards have two box corners resting on them; therefore, a higher tributary area associated with them. The higher tributary area results in a greater force being transferred to the deckboard and therefore greater deckboard deflection.
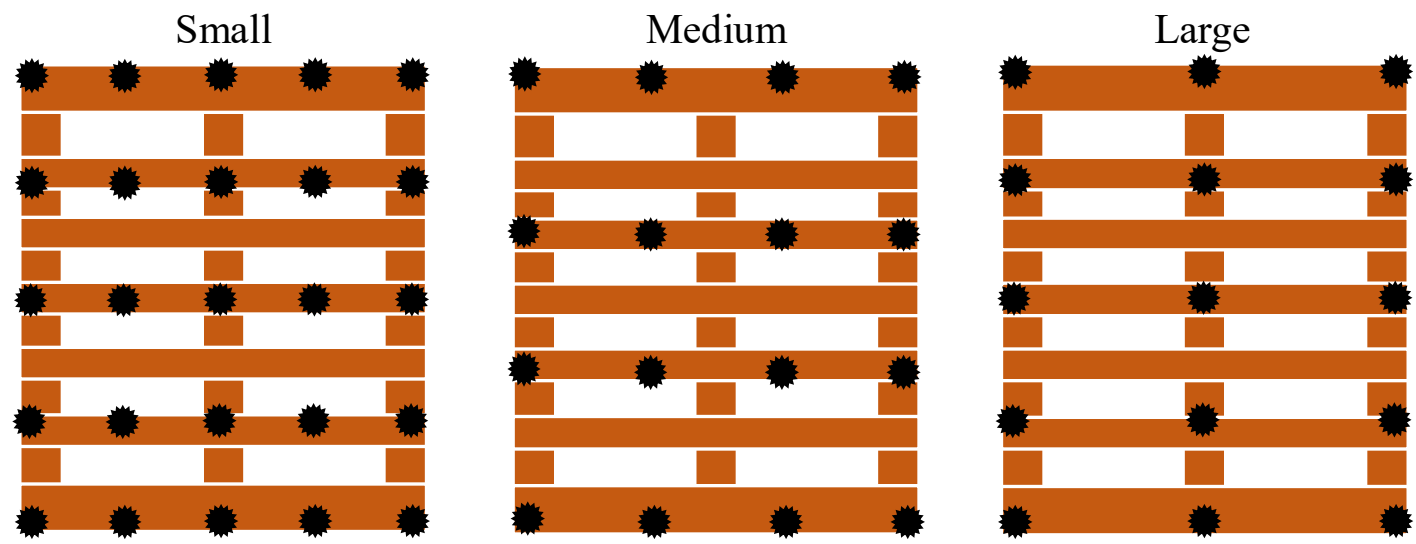

Figure 30: Graphic showing the location of the corrugated box corners for small, medium, and large boxes

\subsubsection{Stringer boards}

As with the top deckboards, only the worst stringer board deflection measurements were considered in this analysis since pallet performance is limited by the worst deflection. The worst stringer board deflection measurements are given in Table 21 for single stacked pallets and in Table 22 for pallets in the double stacked support condition. An analysis of variance (ANOVA) test was carried out for both support conditions and the results are in the appendix (A.5.2). Although an increase in deflection was observed when switching from small to medium boxes for all pallet stiffnesses in both a single stacked and double stacked support conditions, a statistically significant change can only be observed for the very low stiffness pallet. For pallets that were single stacked, there was a 54\% increase in pallet deflection when switching from small to medium boxes. For pallets in the double stacked support condition this increase was $43 \%$. While the effect of box size on stringer board deflection for pallets in single and double stacked support conditions was shown to be significant for the very low stiffness pallet, the overall change in deflection was less than 0.05 inches in both scenarios and serves no practical purpose. 
Table 21: Average worst stringer board deflection and the percent difference in reference to the small boxes during single stacked support condition using boxes with headspace.

\begin{tabular}{|c|c|c|c|c|c|c|c|c|}
\hline \multirow{2}{*}{ Box Size } & \multicolumn{8}{|c|}{ Pallet Deflection (in.) } \\
\hline & \multicolumn{2}{|c|}{ Very Low } & \multicolumn{2}{|c|}{ Low } & \multicolumn{2}{|c|}{ Medium } & \multicolumn{2}{|c|}{ High } \\
\hline \multirow{3}{*}{ Small } & Center & $\mathrm{A}$ & Center & A & Center & $\mathrm{A}$ & Center & A \\
\hline & 0.0643 & & 0.0378 & & 0.0325 & & 0.0272 & \\
\hline & $\begin{array}{c}(0.0051 \\
)\end{array}$ & & $(0.0021)$ & & $(0.0030)$ & & $(0.0025)$ & \\
\hline \multirow{2}{*}{ Medium } & $\begin{array}{l}\text { Center } \\
0.0992\end{array}$ & & $\begin{array}{l}\text { Center } \\
0.0493\end{array}$ & A & $\begin{array}{l}\text { Center } \\
0.0370\end{array}$ & A & $\begin{array}{l}\text { Center } \\
0.0413\end{array}$ & A \\
\hline & $\begin{array}{c}(0.0224 \\
)\end{array}$ & $54 \%$ & $(0.0051)$ & $30 \%$ & $(0.0069)$ & $14 \%$ & $(0.0021)$ & $52 \%$ \\
\hline \multirow{2}{*}{ Large } & $\begin{array}{c}\text { Side } \\
0.0500\end{array}$ & & $\begin{array}{l}\text { Center } \\
0.0378\end{array}$ & & $\begin{array}{l}\text { Center } \\
0.0238\end{array}$ & A & & \\
\hline & $\begin{array}{c}(0.0036 \\
)\end{array}$ & $-22 \%$ & & $0 \%$ & $(0.0050)$ & $-27 \%$ & & \\
\hline
\end{tabular}

Note: The values in parentheses are standard deviations. The letters were determined by running a Tukey HSD with an alpha level of 0.05. Different letters for a given pallet stiffness represent statistically significant differences in expected pallet deflection

Table 22: Average worst stringer board deflection and the percent difference in reference to the small boxes during double stacked support condition using boxes with headspace.

\begin{tabular}{|c|c|c|c|c|c|c|c|c|}
\hline \multirow{2}{*}{ Box Size } & \multicolumn{8}{|c|}{ Pallet Deflection (in.) } \\
\hline & \multicolumn{2}{|c|}{ Very Low } & \multicolumn{2}{|c|}{ Low } & \multicolumn{2}{|c|}{ Medium } & \multicolumn{2}{|c|}{ High } \\
\hline Small & $\begin{array}{c}\text { Center } \\
0.1023 \\
(0.0061 \\
)\end{array}$ & $\mathrm{A}$ & $\begin{array}{c}\text { Center } \\
0.0658 \\
(0.0025)\end{array}$ & $\mathrm{A}$ & $\begin{array}{c}\text { Center } \\
0.0622 \\
(0.0025)\end{array}$ & $\mathrm{A}$ & $\begin{array}{c}\text { Center } \\
0.0442 \\
(0.0015)\end{array}$ & $\mathrm{A}$ \\
\hline Medium & $\begin{array}{c}\text { Center } \\
0.1458 \\
(0.0225 \\
)\end{array}$ & $\begin{array}{c}\text { B } \\
43 \%\end{array}$ & $\begin{array}{c}\text { Center } \\
0.0763 \\
(0.0067)\end{array}$ & $\begin{array}{c}\mathrm{A} \\
16 \%\end{array}$ & $\begin{array}{c}\text { Center } \\
0.0667 \\
(0.0025)\end{array}$ & $\begin{array}{l}\mathrm{A} \\
7 \%\end{array}$ & $\begin{array}{c}\text { Center } \\
0.0597 \\
(0.0029)\end{array}$ & $\begin{array}{c}\text { A } \\
35 \%\end{array}$ \\
\hline Large & $\begin{array}{c}\text { Side } \\
0.0873 \\
(0.0035 \\
)\end{array}$ & $\begin{array}{c}\mathrm{A} \\
-15 \%\end{array}$ & $\begin{array}{c}\text { Center } \\
0.0635 \\
(0.0026)\end{array}$ & $\begin{array}{c}A \\
-3 \%\end{array}$ & $\begin{array}{c}\text { Center } \\
0.0478 \\
(0.0029)\end{array}$ & $\begin{array}{c}\mathrm{A} \\
-23 \%\end{array}$ & & \\
\hline
\end{tabular}

Note: The values in parentheses are standard deviations. The letters were determined by running a Tukey HSD with an alpha level of 0.05. Different letters for a given pallet stiffness represent statistically significant differences in expected pallet deflection 


\subsubsection{Double Stacking - Bottom Deckboards}

For the top pallet in a double stacked support condition, an analysis of variance (ANOVA) test was conducted to determine the effect of box size and pallet stiffness on the observed deflection of bottom deckboards oriented along the width and the length. The results of these ANOVA tests are in the appendix (A.5.3). The deflection measurements for the worst bottom deckboards across the width are given in Table 23, and for the worst bottom deckboards across the length are given in

Table 24. A statistically significant increase in bottom deckboard deflection across the width was observed by switching from small to medium boxes regardless of pallet stiffness. The largest increase in bottom deckboard deflection across the width was $600 \%$ and was observed when switching from small to medium boxes on the lowest stiffness pallet. Although the effect of box size on bottom deckboard deflection across the width was shown to be statistically significant for all pallet stiffnesses, the largest change in deflection was less than 0.04 inches and is of no practical importance.

For bottom deckboard deflection across the length, there is no consistent trend; the effect of box size seems to be random in nature. Only the low and high stiffness pallets showed any statistically significant effect of switching from small to medium boxes. However, for the low stiffness pallet, the change in box size resulted in a reduction of pallet deflection, while for the high stiffness pallet an increase in pallet deflection was observed due to a change in box size. Although there is no clear trend for bottom deckboard deflection across the length due to change in box size, the statistically significant differences are less than 0.02 inches and are too small to have any practical implications. 
Table 23: Average worst bottom deckboard across the width deflection and the percent difference in reference to the small boxes during double stacked support condition using boxes with headspace.

\begin{tabular}{|c|c|c|c|c|c|c|c|c|}
\hline \multirow{2}{*}{$\begin{array}{c}\text { Box } \\
\text { Size }\end{array}$} & \multicolumn{9}{|c|}{ Pallet Deflection (in.) } \\
\cline { 2 - 9 } Small & 0.0055 & & 0.0142 & & 0.0117 & & 0.0062 & \\
& $(0.0026)$ & $\mathrm{A}$ & $(0.0006)$ & $\mathrm{A}$ & $(0.0032)$ & $\mathrm{A}$ & $(0.0040)$ & $\mathrm{A}$ \\
\hline \multirow{2}{*}{ Medium } & 0.0385 & $600 \%$ & 0.0265 & $87 \%$ & 0.0330 & $183 \%$ & 0.0193 & $214 \%$ \\
& $(0.0046)$ & $\mathrm{B}$ & $(0.0060)$ & $\mathrm{B}$ & $(0.0075)$ & $\mathrm{B}$ & $(0.0023)$ & $\mathrm{B}$ \\
\hline \multirow{2}{*}{ Large } & 0.0083 & $52 \%$ & 0.0112 & $-21 \%$ & 0.0018 & $-84 \%$ & & \\
& $(0.0021)$ & $\mathrm{A}$ & $(0.0042)$ & $\mathrm{A}$ & $(0.0021)$ & $\mathrm{A}$ & & \\
\hline
\end{tabular}

Note: The values in parentheses are standard deviations. The letters were determined by running a Tukey HSD with an alpha level of 0.05. Different letters for a given pallet stiffness represent statistically significant differences in expected pallet deflection

Table 24: Average worst bottom deckboard across the length deflection and the percent difference in reference to the small boxes during double stacked support condition using boxes with headspace.

\begin{tabular}{|c|c|c|c|c|c|c|c|c|}
\hline \multirow{2}{*}{ Box Size } & \multicolumn{9}{|c|}{ Pallet Deflection (in.) } \\
\cline { 2 - 8 } Small & \multicolumn{2}{|c|}{ Very Low } & \multicolumn{2}{c|}{ Low } & \multicolumn{2}{c|}{ Medium } & \multicolumn{2}{c|}{ High } \\
\hline \multirow{4}{*}{ Medium } & Center & $\mathrm{A}$ & Center & $\mathrm{A}$ & Center & $\mathrm{A}$ & Center & $\mathrm{A}$ \\
& 0.0437 & & 0.0725 & & 0.0430 & & 0.0330 & \\
& $(0.0035)$ & & $(0.0026)$ & & $(0.0075)$ & & $(0.0010)$ & \\
\hline \multirow{5}{*}{ Large } & Center & $\mathrm{A}$ & Center & $\mathrm{B}$ & Center & $\mathrm{A}$ & Center & $\mathrm{B}$ \\
& 0.0515 & & 0.0522 & & 0.0552 & & 0.0475 & \\
& $(0.0035)$ & $18 \%$ & $(0.0025)$ & $-28 \%$ & $(0.0042)$ & $28 \%$ & $(0.0108)$ & $44 \%$ \\
& Center & $\mathrm{A}$ & Center & $\mathrm{A}$ & Center & $\mathrm{A}$ & & \\
& 0.0510 & & 0.0758 & & 0.0478 & & & \\
\hline
\end{tabular}

Note: The values in parentheses are standard deviations. The letters were determined by running a Tukey HSD with an alpha level of 0.05. Different letters for a given pallet stiffness represent statistically significant differences in expected pallet deflection

An image of the interaction between the corrugated boxes and the pallets in a double stacked support condition is shown in Figure 31. For small boxes, all of the blocks of the top pallet are directly supported by a corner of the boxes on the bottom pallet. Supporting the center block allows for minimal deflection of the top pallet as a whole and in turn minimal upward deflection of the bottom deckboards. For medium boxes, the center block is located in the center of a box and is not supported by the box corners. Since the center block is not supported by the box corners, 
there is greater deflection of the top pallet. Consequently, the bottom deckboards experience a greater upward force from the corners of the boxes on the bottom pallet and this results in a greater upward deflection. The large boxes also directly support the center block of the top pallet in a double stacked support condition and therefore minimal deflection was observed. The bending of the top pallet due to the support provided by the corrugated boxes below should hold true for both bottom deckboard deflection across the width and across the length. However, the effect box size on bottom deckboard deflection across the width displayed a clear trend while no trend was observed for bottom deckboard deflection across the length. It was concluded that bottom deckboard deflection is more effected by the location of the box corners than by box size. Box sizes where the center block of the top pallet is not directly supported will result in a greater bottom deckboard deflection. However, further research should be conducted in order to understand the effect of box size on bottom deckboard deflection along the length of the pallet. 
Small Boxes

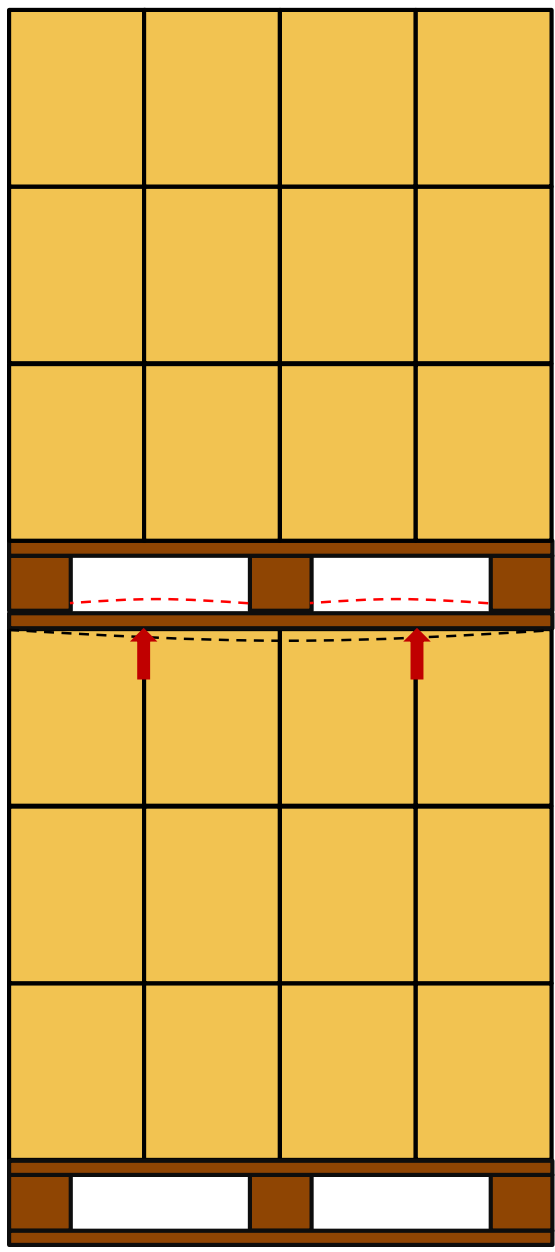

Medium Boxes

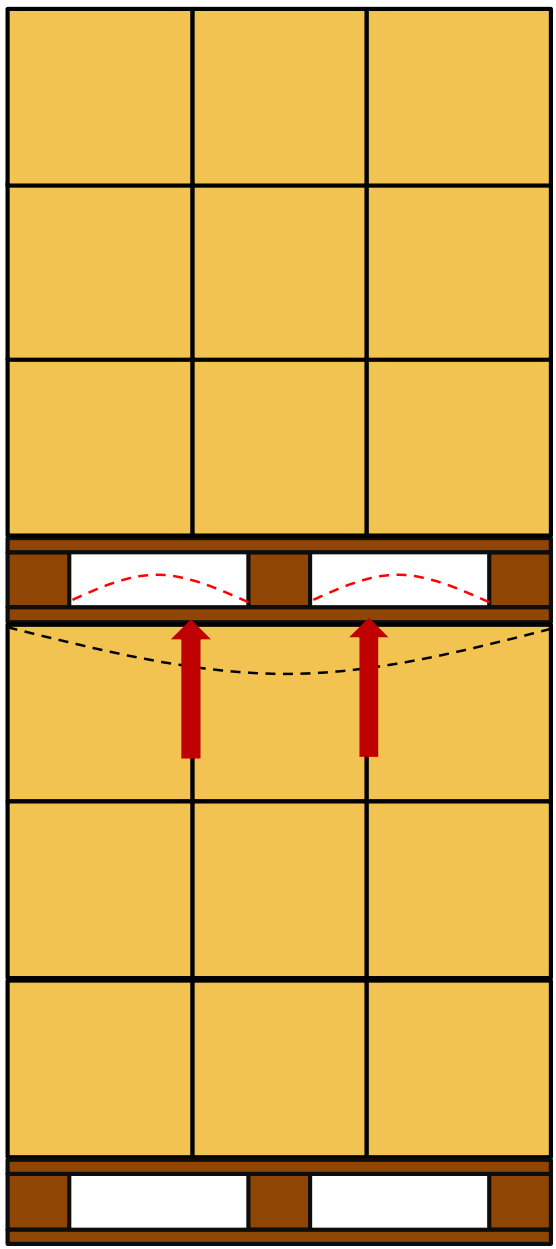

Figure 31: Graphical representation of interaction between corrugated boxes and pallets in a double stacked support condition for small and medium boxes

\subsection{UNIDIRECTIONAL BASE DESIGN VERSUS PERIMETER BASE DESIGN}

To analyze the relationship between load bridging and base design, analysis of variance (ANOVA) tests were conducted for all support conditions where deflection measurements were taken. The results of the ANOVA tests are given in Table 25 (individual ANOVA models are presented in the appendix A.5.4). The effect of pallet base design was determined to be statistically insignificant for all support conditions except double stacked floor support for top deckboards and double stacked floor support for bottom deckboards across the length. Although the ANOVA results determined that pallet base design has a statistically significant effect on pallet deflection for both the top and bottom deckboards, this difference was observed for treatments that are expected to be different (Perimeter Base/Small Boxes vs. Unidirectional Base/Medium Boxes or 
Perimeter Base/Medium Boxes vs. Unidirectional Base/Small Boxes). Box size was determined to have a statistically significant effect for pallets in all support conditions measured except for warehouse racking across the length (RAL) and single stacked floor support for top deckboards. There were no significant interaction effects for any of the support conditions examined.

Table 25: Analysis of variance (ANOVA) results of the effects tests for the main effects of base design and box size along with the interaction of base design and box size. ANOVA was performed using the deflection measurements (inches) for the various support conditions

\begin{tabular}{|c|c|c|c|c|}
\hline \multirow{2}{*}{$\begin{array}{c}\text { Support } \\
\text { Condition }\end{array}$} & Components & $\begin{array}{c}|c| \\
\text { Pase } \\
\text { Design }\end{array}$ & Box Size & $\begin{array}{c}\text { Base Design } \\
* \text { Box Size }\end{array}$ \\
\hline $\begin{array}{c}\text { Racked Across the } \\
\text { Width (RAW) }\end{array}$ & - & - & - & - \\
\hline $\begin{array}{c}\text { Racked Across the } \\
\text { Length (RAL) }\end{array}$ & - & 0.4817 & 0.4284 & 0.827 \\
\hline \multirow{2}{*}{ Single Stacked } & Top deckboards & 0.0726 & 0.4114 & 0.3466 \\
\cline { 2 - 5 } & Stringer boards & 0.1037 & $0.0437 *$ & 0.3213 \\
\hline \multirow{3}{*}{ Double Stacked } & Top deckboards & $0.0145^{*}$ & $0.0201 *$ & 0.2722 \\
\cline { 2 - 5 } & Stringer boards & 0.3369 & $0.0093^{*}$ & 0.2103 \\
\cline { 2 - 5 } & $\begin{array}{c}\text { Second Pallet - Width } \\
\text { Bottom Deckboards }\end{array}$ & - & - & - \\
\cline { 2 - 5 } & $\begin{array}{c}\text { Second Pallet - Length } \\
\text { Bottom Deckboards }\end{array}$ & $0.0230^{*}$ & $0.0004^{*}$ & 0.1985 \\
\hline
\end{tabular}

Note: p-values less than 0.05 indicate a statistically significant main or interaction effect and were marked with *.

The final analysis conducted was to determine the effect of base design on pallet deflection. A perimeter base design was compared to a unidirectional base design for medium stiffness pallets. Both small and medium boxes were tested and analyzed on both base designs. All support conditions were examined except for warehouse racking across the width (RAW) and the double stacked floor support for bottom deckboards across the width. The comparisons of the deflection results are shown in Table 26. For both small and medium boxes, no differences in deflection were observed between the perimeter base design and the unidirectional base design. This was true for all support conditions. 
Table 26: Average worst pallet deflection for medium stiffness perimeter base design and medium stiffness unidirectional base design during all support conditions using boxes with headspace.

\begin{tabular}{|c|c|c|c|c|c|c|c|c|}
\hline \multirow{3}{*}{ Support Condition } & \multicolumn{8}{|c|}{ Box Size } \\
\hline & \multicolumn{4}{|c|}{ Small } & \multicolumn{4}{|c|}{ Medium } \\
\hline & \multicolumn{2}{|c|}{ Perimeter } & \multicolumn{2}{|c|}{ Unidirectional } & \multicolumn{2}{|c|}{ Perimeter } & \multicolumn{2}{|c|}{ Unidirectional } \\
\hline RAW & & & & \\
\hline RAL & \begin{tabular}{|c|}
0.2063 \\
$(0.0099)$ \\
\end{tabular} & A & $\begin{array}{c}0.2092 \\
(0.0089) \\
\end{array}$ & A & $\begin{array}{c}0.2004 \\
(0.0093) \\
\end{array}$ & $\mathrm{a}$ & $\begin{array}{c}0.0209 \\
(0.0101) \\
\end{array}$ & $\mathrm{a}$ \\
\hline Single - TDB & $\begin{array}{c}0.0182 \\
(0.0023)\end{array}$ & $\begin{array}{c}\text { A } \\
\text { Back }\end{array}$ & $\begin{array}{c}0.0208 \\
(0.0032)\end{array}$ & $\begin{array}{c}\text { A } \\
\text { Back }\end{array}$ & $\begin{array}{c}0.0183 \\
(0.0071)\end{array}$ & $\begin{array}{c}\text { a } \\
\text { Back } \\
\text { Middle }\end{array}$ & $\begin{array}{c}0.0260 \\
(0.0030)\end{array}$ & $\begin{array}{c}\text { a } \\
\text { Back } \\
\text { Middle }\end{array}$ \\
\hline Single - SB & \begin{tabular}{|c|}
0.0325 \\
$(0.0030)$ \\
\end{tabular} & $\begin{array}{c}\text { A } \\
\text { Center }\end{array}$ & $\begin{array}{c}0.0348 \\
(0.0055)\end{array}$ & $\begin{array}{c}\text { A } \\
\text { Center }\end{array}$ & $\begin{array}{c}0.0370 \\
(0.0069)\end{array}$ & $\begin{array}{c}\mathrm{a} \\
\text { Center }\end{array}$ & $\begin{array}{c}0.0452 \\
(0.0045)\end{array}$ & $\begin{array}{c}\mathrm{a} \\
\text { Center }\end{array}$ \\
\hline Douk & \begin{tabular}{|c|}
0.0368 \\
$(0.0021)$
\end{tabular} & $\begin{array}{c}\text { A } \\
\text { Back }\end{array}$ & $\begin{array}{c}0.0398 \\
(0.0021)\end{array}$ & $\begin{array}{c}\text { A } \\
\text { Back }\end{array}$ & $\begin{array}{l}0.0310 \\
(0.0044)\end{array}$ & $\begin{array}{c}\text { a } \\
\text { Back } \\
\text { Middle }\end{array}$ & $\begin{array}{c}0.0377 \\
(0.0012)\end{array}$ & $\begin{array}{c}\text { a } \\
\text { Back } \\
\text { Middle }\end{array}$ \\
\hline Doubl & $\begin{array}{c}0.0622 \\
(0.0025) \\
\end{array}$ & $\begin{array}{c}\text { A } \\
\text { Center }\end{array}$ & $\begin{array}{c}0.0615 \\
(0.0017)\end{array}$ & $\begin{array}{c}\text { A } \\
\text { Center }\end{array}$ & $\begin{array}{c}0.0667 \\
(0.0025) \\
\end{array}$ & $\begin{array}{c}\mathrm{a} \\
\text { Center } \\
\end{array}$ & $\begin{array}{c}0.0708 \\
(0.0055) \\
\end{array}$ & $\begin{array}{c}a \\
\text { Center }\end{array}$ \\
\hline Double - BDB- F & & \multicolumn{2}{|c|}{1} & & \multicolumn{2}{|c|}{-} \\
\hline Double - BDB - L & \begin{tabular}{|c|}
0.0430 \\
$(0.0075)$ \\
\end{tabular} & $\begin{array}{c}\text { A } \\
\text { Center }\end{array}$ & $\begin{array}{c}0.0465 \\
(0.0046)\end{array}$ & $\begin{array}{c}\text { A } \\
\text { Center }\end{array}$ & $\begin{array}{c}0.0552 \\
(0.0042)\end{array}$ & $\begin{array}{c}\mathrm{a} \\
\text { Center }\end{array}$ & $\begin{array}{c}0.0677 \\
(0.0015) \\
\end{array}$ & $\begin{array}{c}\mathrm{a} \\
\text { Center }\end{array}$ \\
\hline
\end{tabular}

Note: The values in parentheses are standard deviations. The letters were determined by running a Tukey HSD with an alpha level of 0.05. Different letters for a given pallet base design represent statistically significant differences in expected pallet deflection

\section{CONCLUSION}

The following conclusions were discovered during this study.

- Headspace has no practical effect on pallet deflection for most support conditions as long as unit loads containing small boxes weigh less than 3,500 lbs, and unit loads containing large boxes weigh less than 1,750 lbs. However, the effect of headspace should be considered when stacking multiple unit loads in a floor stacking support condition.

- The effect of box size on pallet deflection was found to be significant especially when small and large boxes were compared. The effect was most prominent on low stiffness pallets and support conditions that allow more pallet bending. As much as 
a 50\% reduction in deflection was observed when large boxes were stacked on the low stiffness pallet when comparted to small boxes.

- The pressure distribution across the top surface of the pallet showed a greater redistribution of pressure towards the supports as box size increased. This pressure redistribution towards the supports explains the reduction in pallet deflection as a function of box size increasing.

- Base design was determined to have no significant effect on pallet deflection regardless of box size.

The results indicate that the load capacity of pallets could potentially be increased for certain support conditions as long as the pallet only supports larger boxes. This finding will allow designers to optimize pallet designs by reducing the required amounts of raw materials.

\section{RECOMMENDATIONS FOR FUTURE RESEARCH}

Additional research should be conducted in order to further understand load bridging on block class pallets.

- Heavier unit loads should be investigated further; it was determined that unit load weight determines the extent of load bridging.

- The effect of headspace should be further investigated by exploring various box sizes, flute sizes, and greater unit load weights.

- The effect of box size on pallet deflection for pallets in a warehouse racking across the length (RAL) support condition should be examined by using a more incremental change in box size across the length including a box size large enough to span the distance between the blocks across the length.

- Further investigate bottom deckboard deflection on the top pallet in a double stacked scenario by either increasing unit load weight or increasing the number of unit loads in a floor stacking support condition.

- Investigate various flute sizes in order to determine if the effect seen for $\mathrm{C}$-flute corrugated board applies to other flute sizes. 


\section{REFERENCES}

Adaptalift Group. (2013, September 23). Pallet Design Types. Retrieved from https://www. aalhysterforklifts.com.au/index.php/about/blog-post/pallet_design_types

Allaway, D. (2005, June 6). Busting Strength vs. Edge Crush Test. Retrieved from https://statweb.stanford.edu/ owen/courses/305-1314/bpstrengthvscrush.pdf

ASME. (2005, November 30). ASME MH1 : Pallets, Slip Sheets, and Other Bases for Unit Loads. Retrieved from https://global.ihs.com/doc_detail.cfm?\&item_s_key=00288006\&item_ key_date=940101\&input_doc_number=\&input_doc_title=\&origin $=$ HISC

ASTM International. (2015). ASTM D642-15 Standard Test Method for Determining Compressive Resistance of Shipping Containers, Components, and Unit Loads. Retrieved from https://doi.org/10.1520/D0642-15

ASTM International. (2016a). ASTM D4169-16 Standard Practice for Performance Testing of Shipping Containers and Systems. Retrieved from https://doi.org/10.1520/D4169-16

ASTM International. (2016b). ASTM D4649-03(2016) Standard Guide for Selection and Use of Stretch Wrap Films. Retrieved from https://doi.org/10.1520/D4649-03R16

ASTM International. (2017a). ASTM D1185-98a(2017) Standard Test Methods for Pallets and Related Structures Employed in Materials Handling and Shipping. Retrieved from https://doi.org/10.1520/D1185-98AR17

ASTM International. (2017b). ASTM D3043-17 Standard Test Methods for Structural Panels in Flexure. Retrieved from https://doi.org/10.1520/D3043-17

Avex Steel Products. (2018). Production of steel pallets. Retrieved from https://www.tyrestorage-pallets.com/production-of-steel-pallets

Baker, M. (2016). Effect of Pallet Deckboard Stiffness and Unit Load Factors on Corrugated Box Compression Strength (Doctoral dissertation). Virginia Polytechnic Institute and State University, Blacksburg, VA.

Bejune, J. (2001). Wood Use Trends in the Pallet and Container Industry: 1992-1999 (Master's project). Virginia Polytechnic Institute and State University, Blacksburg, VA.

Bisha, J. (2008). The Effect of Load Stabilizer Selection on Load Shift Within (Master's project). Virginia Polytechnic Institute and State University, Blacksburg, VA.

Bisha, J. (2012). Correlation of the Elastic Properties of Stretch Film on Unit Load Containment (Doctoral dissertation). Virginia Polytechnic Institute and State University, Blacksburg, VA. 
Brindley, E. (2006, December 1). Pallet Enterprise Article - Pallet Standards and Specifications - The Evolution to Today. Retrieved from http://www.palletenterprise.com/articledatabase/ view.asp? articleID=2109

Brown, R. (1999). Handbook of Polymer Testing: Physical Methods. New York, NY: Dekker.

CABKA Group. (2019). Plastic Pallets Handbook. Retrieved, from https://cabkaips.com/global/en/m/plasticpallets-service/plastic-pallets-handbook/

Change The Pallet. (2015). The Public Good Case for Governmental Leadership And Action On The Commercial Use Of Corrugated Cardboard Pallets. https://www.glpackaging.com /uploads/5/2/1/1/52114087/public_good_white_papers.pdf

Clarke, J. (2004). Pallets 101: Industry Overview and Wood, Plastic, Paper \& Metal Options. Retrieved from https://abe.psu.edu/research/bio-based-products/wood-packaging/ publications/articles-from-non-penn-state-authors/pallets-101-industry-overview-andwood-plastic-paper-metal-options

Clayton, A. (2018). Investigation of the Effect of Corrugated Boxes on the Distribution of Compression Stresses on the Top Surface of Wooden Pallets (Master's project). Virginia Polytechnic Institute and State University, Blacksburg, VA.

Cleveland Consulting Associates. (1990). Review of Progress in the Analysis of Alternative Grocery Industry Pallet System April 1990.pdf.

Collie, S. (1984). Laboratory Verification of Pallet Design Procedures (Master's project). Virginia Polytechnic Institute and State University, Blacksburg, VA.

Collins, M. (n.d.). Specifying the Ideal Stretch-Wrap Machine for the Application. Retrieved from www.orionpackaging.com

Degroot, J. A., Patel, R. M., Doughty, A. T., \& Stewart, K. B. (1994). Effect of Cast Film Fabrication Variables on Structure Development and Key Stretch Film Properties. Journal of Applied Polymer Science, 52, 365-376.

Dowler, J. (2015, March 5). The History of Packaging. Retrieved from http://www.paragonu.com/the-history-of-packaging

Fagan, B. (1982). Load-Support Conditions and Computerized Test Apparatus for Wood Pallets (Master's Project). Virginia Polytechnic Institute and State University, Blacksburg, VA.

FEFCO-ESBO. (2007). International Fibreboard Case Code. Belgium: FEFCO. http://www. fefco.org/fefco-esbo-code

Fibre Box Association. (2015). Fibre Box Handbook (75th Anniv). Itasca, IL. 
FPInnovations (2009). Pallet Trend 09. Retrieved from http://www.solutionsforwood.com /industry_info/reports.html

Frank, B., Gilgenbach, M., \& Maltenfort, M. (2010). Compression Testing to Simulate RealWorld Stresses. Packaging Technology and Science, 23(5), 275-282. https://doi.org/10. $1002 /$ pts.898

Freedonia Group. (2017). World Pallets to 2017.

Gerber, N. (2018). Investigation of New and Recovered Wood Shipping Platforms in the United States (Master's project). Virginia Polytechnic Institute and State University, Blacksburg, VA.

Hazel 4D. (2016). The Evolution of Pallet Wrap. Retrieved from https://www.hazel4d.com/en/ page/206/the-evolution-of-pallet-wrap

Highlight Industries (2018). The Portable Film Force System. Retrieved from http://www. highlightindustries.com/portable-electronic-equip

ISO. (1994). ISO 12048:1994 Packaging-Complete, Filled Transport Packages - Compression and Stacking Tests Using a Compression Tester.

ISO. (2003). ISO 6780:2003 Flat Pallets for Intercontinental Materials Handling - Principal Dimensions and Tolerances.

ISO. (2011a). ISO 8611:2011 Pallets for Materials Handling - Flat pallets.

ISO. (2011b). ISO 8611:2011-3 Pallets for Materials Handling — Flat pallets - Part 3.

ISO. (2012). ISO 3394:2012 Packaging - Complete, Filled Transport Packages and Unit Loads - Dimensions of Rigid Rectangular Packages.

ISO. (2013). ISO 13821:2002(R2013) Corrugated Fiberboard-Determination of Edgewise Crush Resistance - Waxed Edge Method.

ISO. (2014). ISO 2759:2014 Board - Determination of Bursting Strength.

ISTA. (2018). ISTA 3E-Similar Packaged-Products in Unitized Loads for Truckload Shipment

Kirwan, M. J. (2005). Paper and Paperboard Packaging Technology. Oxford, UK: Blackwell Publishing

Koning, J. W. (1995). Corrugated crossroads: A reference guide for the corrugated containers industry. Atlanta, GA: Tappi Press 
Lantech (2019). Containment Force Tool. Retrieved from https://www.lantech.com/stretchwrapping/containment-force-tool

LeBlanc, R. (2002, December 2). Pallet Enterprise Article - Pallet Evolved Along with Forklift. Retrieved from http://www.palletenterprise.com/articledatabase/view.asp?articleID=821

LeBlanc, R. (2015, May 2). Breakthroughs in Material Handling: The Emergence of the Plastic Pallet. Retrieved from https://packagingrevolution.net/breakthroughs-in-materialhandling-the-emergence-of-the-plastic-pallet/

LeBlanc, R. (2017, June 20). The Beginning of Paper Pallets - a Short History. Retrieved from https://packagingrevolution.net/the-beginning-of-paper-pallets-a-short-history/

LeBlanc, R. (2018, October 7). A History of Pallets During World War 2: A Call to Action. Retrieved from https://packagingrevolution.net/a-history-of-pallets-during-world-war-2a-call-to-action/

LeBlanc, R. (2019, January 28). Pallet Statistics: Pallet Sizes Becoming More Standardized in the U.S. Market. Retrieved from https://packagingrevolution.net/the-2-billion-pallet-man/

Li, J., Wang, B. J., \& Zhou, J. (2018). The Reliability-Based Design and Optimization Procedures for a Heavy-duty Pallet System. Advances in Mechanical Engineering, 10(1), 1-11. https://doi.org/10.1177/1687814017751752

Maltenfort, G. (1988). Corrugated Shipping Containers. New York: Jelmar Publishing Co., Inc.

McCrea, B. (2016, October 7). Pallet Usage Report: Pallets Remain Critical in the Modern-Day Warehouse - Modern Materials Handling. Retrieved from https://www.mmh.com/article/ pallets_remain_critical_in_the_modern_day_warehouse

Meng, G., Trost, T., \& Östlund, S. (2007). Stacking Misalignment of Corrugated Boxes- A Preliminary Study. Retrieved from https://pdfs.semanticscholar.org/4955/795fd02f4f9d17 bf7bd70893676bb0a16c3c.pdf

MH1 Committee. (2016). MH1-2005 Pallets, Slip Sheets, and Other Bases for Unit Loads.

Molina, E. (2017). Investigation of Pallet Stacking Pattern on Unit Load Bridging (Master's project). Virginia Polytechnic Institute and State University, Blacksburg, VA.

Monaghan, J., \& Marcondes, J. (1992). Technical Notes: Overhang and Pallet Gap Effects on the Performance of Corrugated Fiberboard Boxes. Transactions of the ASAE, 35(6), 19451947. https://doi.org/10.13031/2013.28820

Moorey, P. R. (1994). Ancient Mesopotamian Materials and Industries: The Archaeological Evidence. New York: Clarendon Press. 
NWPCA. (2014). Uniform Standard for Wood Pallets. Retrieved from https://www.palletcentral .com/page/packagingstandards

Park, J. (2015). Investigation of Fundamental Relationships to Improve the Sustainability of Unit Loads (Doctoral dissertation). Virginia Polytechnic Institute and State University, Blacksburg, VA.

Phanthanousy, S. (2017). The Effect of the Stiffness of Unit Load Components on Pallet Deflection and Box Compression Strength (Master's project). Virginia Polytechnic Institute and State University, Blacksburg, VA.

Rogers, L. K. (2011). Keeping it together. Modern Materials Handling, 66(7), 32-35

Singh, S. P., Singh, J., \& Saha, K. (2011). Effect of Palletized Box Offset on Compression Strength of Unitized and Stacked Empty Corrugated Fiberboard Boxes. Journal of Applied Packaging Research 5(3), 157-167

Singh, J., Cernokus, E., Saha, K., \& Roy, S. (2014). The Effect of Stretch Wrap Prestretch on Unitized Load Containment. Packaging Technology and Science, 27(12), 944-961.

Soroka, W. (2009). Fundamentals of Packaging Technology. Naperville, IL: Institute of Packaging Professionals.

TAPPI. (2012). T 804 Compression Test of Fiberboard Shipping Containers.

TAPPI. (2013). T 402 Standard Condition and Testing Atmospheres for Paper, Board, Pulp Handsheets, and Related Products.

TAPPI. (2017a). T 810 Bursting Strength of Corrugated and Solid Fiberboard.

TAPPI. (2017b). T 811 Edgewise Compressive Strength of Corrugated Fiberboard (Short Column Test). TAPPI Test Method T811, www.tappi.org

Twede, D. (2007). The History of Corrugated Fiberboard Shipping Containers. Retrieved from http://learn.quinnipiac.edu/charm/CHARM proceedings/CHARM article archive pdf format/Volume 13 2007/249-254-twede.pdf

Twede, D., Selke, S. E., Kamdem, D., \& Shires, D. B. (2014). Cartons, Crates and Corrugated Board: Handbook of Paper and Wood Packaging Technology. Lancaster, PA, U.S.A.: DEStech Publications.

Uline. (n.d.) Pallets. Retrieved from https://www.uline.com/Grp_147/Pallets

Wainer, M. V. (2002). Stretch Film Properties - Effects of Equipment and Process Variables. Plastic Film and Sheeting, 18, 279-286. https://doi.org/10.1177/875608702035146 
Wathen, K. (2016, November 3). Throwback Thursday - \#TBT - To The First Stretch Wrapper Invented. Retrieved January 1, 2019, from https:/www.lantech.com/blog/first-stretchwrapper-invented?region $=1$

White, M. S., Dibling, W., Rupert, R., \& Mcleod, J. (1999). Determining Pallet Maximum Working Loads from Nominal Load Measurements. Virginia Polytechnic Institute and State University, Blacksburg, VA.

White, M. S., \& Hamner, P. (2005). Pallets move the world: the case for developing system-based designs for unit loads. Forest Products Journal, 55(3), 8-16.

White, M. S. (2012). Course Materials: Pallet and Unit Load Desgin (WOOD 4224). Virginia Polytechnic Institute and State University, Blacksburg, VA.

Yoo, J. (2011). Modeling Compressive Stress Distributions at the Interface between a Pallet Deck and Distribution Packaging (Doctoral dissertation). Virginia Polytechnic Institute and State University, Blacksburg, VA. 


\section{A. APPENDIX}

\section{A.1 Component Modulus of Elasticity (MOE)}

The MOE measurement for each pallet component is attached

\section{A.2 Loading Rates}

Table 27: Loading rates for various thicknesses of plywood top deckboards, bottom deckboards, and stringer boards according to ASTM D3043-17 Standard Test Methods for Structural Panels in Flexure

\begin{tabular}{|c|c|c|}
\hline \multirow{2}{*}{$\begin{array}{c}\text { Plywood } \\
\text { Thickness }\end{array}$} & \multicolumn{2}{|c|}{ Loading Rate (in./min.) } \\
\cline { 2 - 3 } & $\begin{array}{c}\text { Top deckboard and } \\
\text { bottom deckboards }\end{array}$ & $\begin{array}{c}\text { Stringer } \\
\text { Boards }\end{array}$ \\
\hline 0.375 & 0.8640 & 1.2907 \\
\hline 0.5 & 0.6480 & 0.9680 \\
\hline 0.625 & 0.5184 & 0.7744 \\
\hline 0.75 & 0.4320 & 0.6453 \\
\hline
\end{tabular}

\section{A.3 Pallet StiffnesS}

Table 28: Stiffness values obtained from the slope of the load-deflection curve using a uniform loading method (airbag) for each pallet given various support conditions. Stiffness values were calculated both before and after testing.

\begin{tabular}{|c|c|c|c|c|c|c|c|c|}
\hline \multirow{3}{*}{\begin{tabular}{|c} 
Pallet \\
Stiffness
\end{tabular}} & \multicolumn{8}{|c|}{ Support Condition } \\
\hline & \multicolumn{2}{|c|}{$\begin{array}{l}\text { Racked Across the } \\
\text { Width (RAW) }\end{array}$} & \multicolumn{2}{|c|}{$\begin{array}{l}\text { Racked Across the } \\
\text { Length (RAL) }\end{array}$} & \multicolumn{2}{|c|}{$\begin{array}{c}\text { Stacking - Top } \\
\text { Deckboard }\end{array}$} & \multicolumn{2}{|c|}{$\begin{array}{c}\text { Stacking - Bottom } \\
\text { Deckboard }\end{array}$} \\
\hline & Before & After & Before & After & Before & After & Before & After \\
\hline Very Low & 1082 & 1186 & 791 & 827 & - & 20140 & 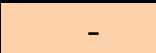 & 13226 \\
\hline Low & 2250 & 2376 & 2465 & 2479 & 30388 & 27754 & 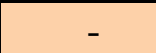 & 40966 \\
\hline Medium & 3261 & 3388 & 2606 & 2588 & 57115 & 50748 & 20307 & 34508 \\
\hline High & 4845 & 5131 & 3989 & 3951 & 64473 & 69326 & 28184 & 51862 \\
\hline
\end{tabular}




\title{
A.4 Pressure mat SPEC SheET
}

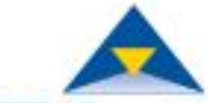

\section{Tekscan Pressure Mapping Sensor 7202}

\author{
Pressure Mapping, Force Measurement, and Tactile Sensors
}

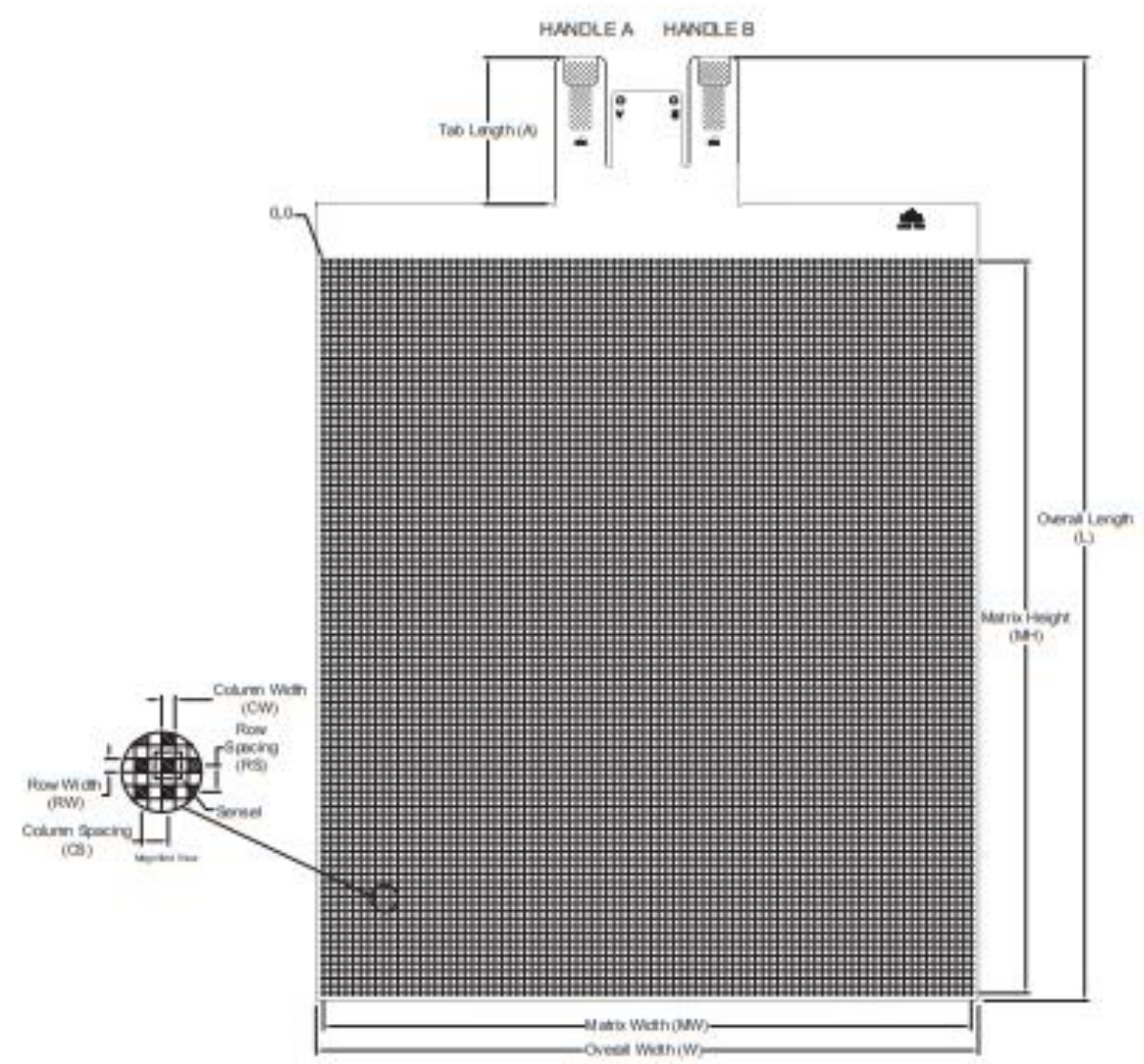

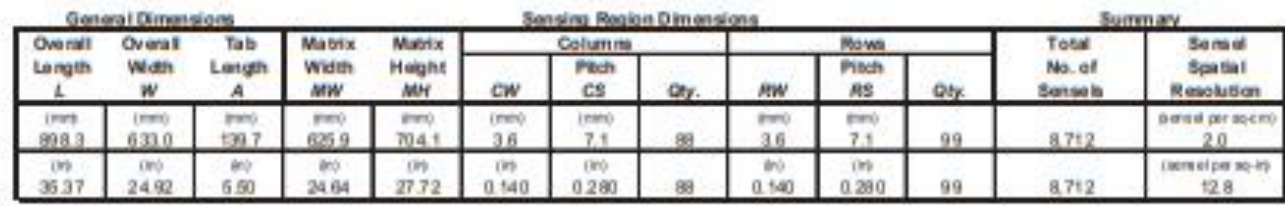

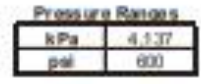

\section{$8+1.617 .464 .4262 \quad(1.800 .248 .3669$}

Binfoetekscan.com

Alwww.tekscan.com 


\section{A.5 ANOVA TABLES}

\section{A.5.1 TOP DECKBOARDS}

Single Stacked

\begin{tabular}{|c|c|c|c|c|}
\hline Source & DF & Sum of Squares & Mean Square & F Ratio \\
\hline Model & 10 & 0.00528897 & 0.000529 & 13.7214 \\
\hline Error & 22 & 0.00084800 & 0.000039 & Prob > F \\
\hline C. Total & 32 & 0.00613697 & & $<.0001^{*}$ \\
\hline
\end{tabular}

\begin{tabular}{|c|c|c|c|c|c|}
\hline Source & Nparm & DF & Sum of Squares & F Ratio & Prob > F \\
\hline Pallet & 3 & 2 & 0.00248207 & 32.1967 & $<.0001^{*}$ \\
\hline Box Size & 2 & 1 & 0.00015000 & 3.8915 & 0.0612 \\
\hline Pallet*Box Size & 6 & 5 & 0.00049615 & 2.5744 & 0.0559 \\
\hline
\end{tabular}

Double Stacked

\begin{tabular}{|c|c|c|c|c|}
\hline Source & DF & Sum of Squares & Mean Square & F Ratio \\
\hline Model & 10 & 0.01462618 & 0.001463 & 76.3709 \\
\hline Error & 22 & 0.00042133 & 0.000019 & Prob > F \\
\hline C. Total & 32 & 0.01504752 & & $<.0001^{*}$ \\
\hline
\end{tabular}

\begin{tabular}{|l|l|l|l|l|l|}
\hline Source & Nparm & DF & Sum of Squares & F Ratio & Prob > F \\
\hline Pallet & 3 & 2 & 0.00795874 & 207.7836 & $<.0001^{*}$ \\
\hline Box Size & 2 & 1 & 0.00001204 & 0.6288 & 0.4363 \\
\hline Pallet*Box Size & 6 & 5 & 0.00101250 & 10.5735 & $<.0001^{*}$ \\
\hline
\end{tabular}

\section{A.5.2 STRINGER BOARDS}

Single Stacked

\begin{tabular}{|c|c|c|c|c|}
\hline Source & DF & Sum of Squares & Mean Square & F Ratio \\
\hline Model & 10 & 0.01331273 & 0.001331 & 21.8025 \\
\hline Error & 22 & 0.00134333 & 0.000061 & Prob $>$ F \\
\hline C. Total & 32 & 0.01465606 & & $<.0001^{*}$ \\
\hline
\end{tabular}

\begin{tabular}{|c|c|c|c|c|c|}
\hline Source & Nparm & DF & Sum of Squares & F Ratio & Prob > F \\
\hline Pallet & 3 & 2 & 0.00768896 & 62.9617 & $<.0001^{*}$ \\
\hline Box Size & 2 & 1 & 0.00153600 & 25.1553 & $<.0001^{*}$ \\
\hline Pallet*Box Size & 6 & 5 & 0.00161170 & 5.2790 & $0.0025^{*}$ \\
\hline
\end{tabular}


Double Stacked

\begin{tabular}{|c|c|c|c|c|}
\hline Source & DF & Sum of Squares & Mean Square & F Ratio \\
\hline Model & 10 & 0.02482030 & 0.002482 & 42.1766 \\
\hline Error & 22 & 0.00129467 & 0.000059 & Prob > F \\
\hline C. Total & 32 & 0.02611497 & & $<.0001 *$ \\
\hline
\end{tabular}

\begin{tabular}{|c|c|c|c|c|c|}
\hline Source & Nparm & DF & Sum of Squares & F Ratio & Prob > F \\
\hline Pallet & 3 & 2 & 0.01421252 & 120.7552 & $<.0001^{*}$ \\
\hline Box Size & 2 & 1 & 0.00199838 & 33.9580 & $<.0001^{*}$ \\
\hline Pallet*Box Size & 6 & 5 & 0.00234261 & 7.9615 & $0.0002 *$ \\
\hline
\end{tabular}

\section{A.5.3 BOTTOM DECKBOARDS}

Width

\begin{tabular}{|c|c|c|c|c|}
\hline Source & DF & Sum of Squares & Mean Square & F Ratio \\
\hline Model & 10 & 0.00434018 & 0.000434 & 26.1361 \\
\hline Error & 22 & 0.00036533 & 0.000017 & Prob $>$ F \\
\hline C. Total & 32 & 0.00470552 & & $<.0001^{*}$ \\
\hline
\end{tabular}

\begin{tabular}{|c|c|c|c|c|c|}
\hline Source & Nparm & DF & Sum of Squares & F Ratio & Prob > F \\
\hline Pallet & 3 & 2 & 0.00002822 & 0.8498 & 0.4411 \\
\hline Box Size & 2 & 1 & 0.00240000 & 144.5255 & $<.0001^{*}$ \\
\hline Pallet*Box Size & 6 & 5 & 0.00052911 & 6.3725 & $0.0008^{*}$ \\
\hline
\end{tabular}

Length

\begin{tabular}{|c|c|c|c|c|}
\hline Source & DF & Sum of Squares & Mean Square & F Ratio \\
\hline Model & 10 & 0.00476073 & 0.000476 & 21.2303 \\
\hline Error & 22 & 0.00049333 & 0.000022 & Prob > F \\
\hline C. Total & 32 & 0.00525406 & & $<.0001^{*}$ \\
\hline
\end{tabular}

\begin{tabular}{|c|c|c|c|c|c|}
\hline Source & Nparm & DF & Sum of Squares & F Ratio & Prob > F \\
\hline Pallet & 3 & 2 & 0.00202896 & 45.2404 & $<.0001^{*}$ \\
\hline Box Size & 2 & 1 & 0.00009204 & 4.1046 & 0.0551 \\
\hline Pallet*Box Size & 6 & 5 & 0.00143338 & 12.7842 & $<.0001^{*}$ \\
\hline
\end{tabular}




\section{A.5.4 BASE DESIGN COMPARISON}

Warehouse racking across the length (RAL)

\begin{tabular}{|c|c|c|c|c|}
\hline Source & DF & Sum of Squares & Mean Square & F Ratio \\
\hline Model & 3 & 0.00011865 & 0.000040 & 0.4305 \\
\hline Error & 8 & 0.00073500 & 0.000092 & Prob > F \\
\hline C. Total & 11 & 0.00085365 & & 0.7369 \\
\hline
\end{tabular}

Single stacked top deckboard

\begin{tabular}{|c|c|c|c|c|}
\hline Source & DF & Sum of Squares & Mean Square & F Ratio \\
\hline Model & 3 & 0.00011292 & 0.000038 & 2.0074 \\
\hline Error & 8 & 0.00015000 & 0.000019 & Prob > F \\
\hline C. Total & 11 & 0.00026292 & & 0.1916 \\
\hline
\end{tabular}

Single stacked stringer board

\begin{tabular}{|c|c|c|c|c|}
\hline Source & DF & Sum of Squares & Mean Square & F Ratio \\
\hline Model & 3 & 0.00027492 & 0.000092 & 3.4045 \\
\hline Error & 8 & 0.00021533 & 0.000027 & Prob > F \\
\hline C. Total & 11 & 0.00049025 & & 0.0737 \\
\hline
\end{tabular}

Double stacked top deckboard

\begin{tabular}{|c|c|c|c|c|}
\hline Source & DF & Sum of Squares & Mean Square & F Ratio \\
\hline Model & 3 & 0.00014092 & 0.000047 & 6.4789 \\
\hline Error & 8 & 0.00005800 & $7.25 \mathrm{e}-6$ & Prob > F \\
\hline C. Total & 11 & 0.00019892 & & $0.0156^{*}$ \\
\hline
\end{tabular}

Double stacked stringer board

\begin{tabular}{|c|c|c|c|c|}
\hline Source & DF & Sum of Squares & Mean Square & F Ratio \\
\hline Model & 3 & 0.00016667 & 0.000056 & 4.8309 \\
\hline Error & 8 & 0.00009200 & 0.000012 & Prob > F \\
\hline C. Total & 11 & 0.00025867 & & $0.0333^{*}$ \\
\hline
\end{tabular}

Double stacked bottom deck board

\begin{tabular}{|c|c|c|c|c|}
\hline Source & DF & Sum of Squares & Mean Square & F Ratio \\
\hline Model & 3 & 0.00107333 & 0.000358 & 14.6530 \\
\hline Error & 8 & 0.00019533 & 0.000024 & Prob > F \\
\hline C. Total & 11 & 0.00126867 & & $0.0013 *$ \\
\hline
\end{tabular}

